Volume XLIV

The Journial of

Number 1, Spring 2018

Number 2, Fall 2018
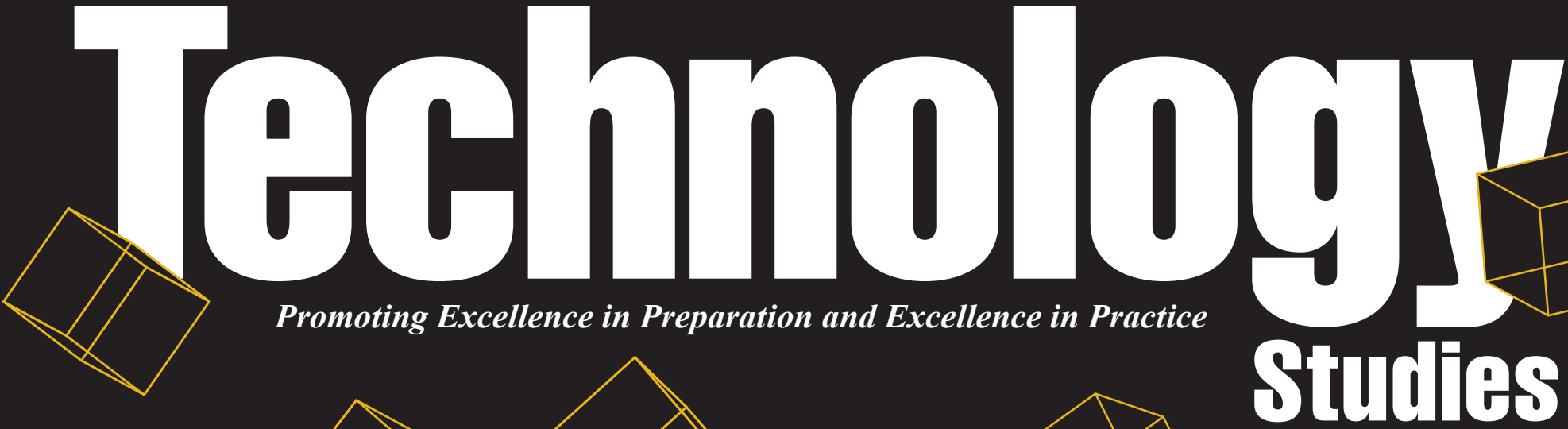

Promoting Excellence in Preparation and Excellence in Practice
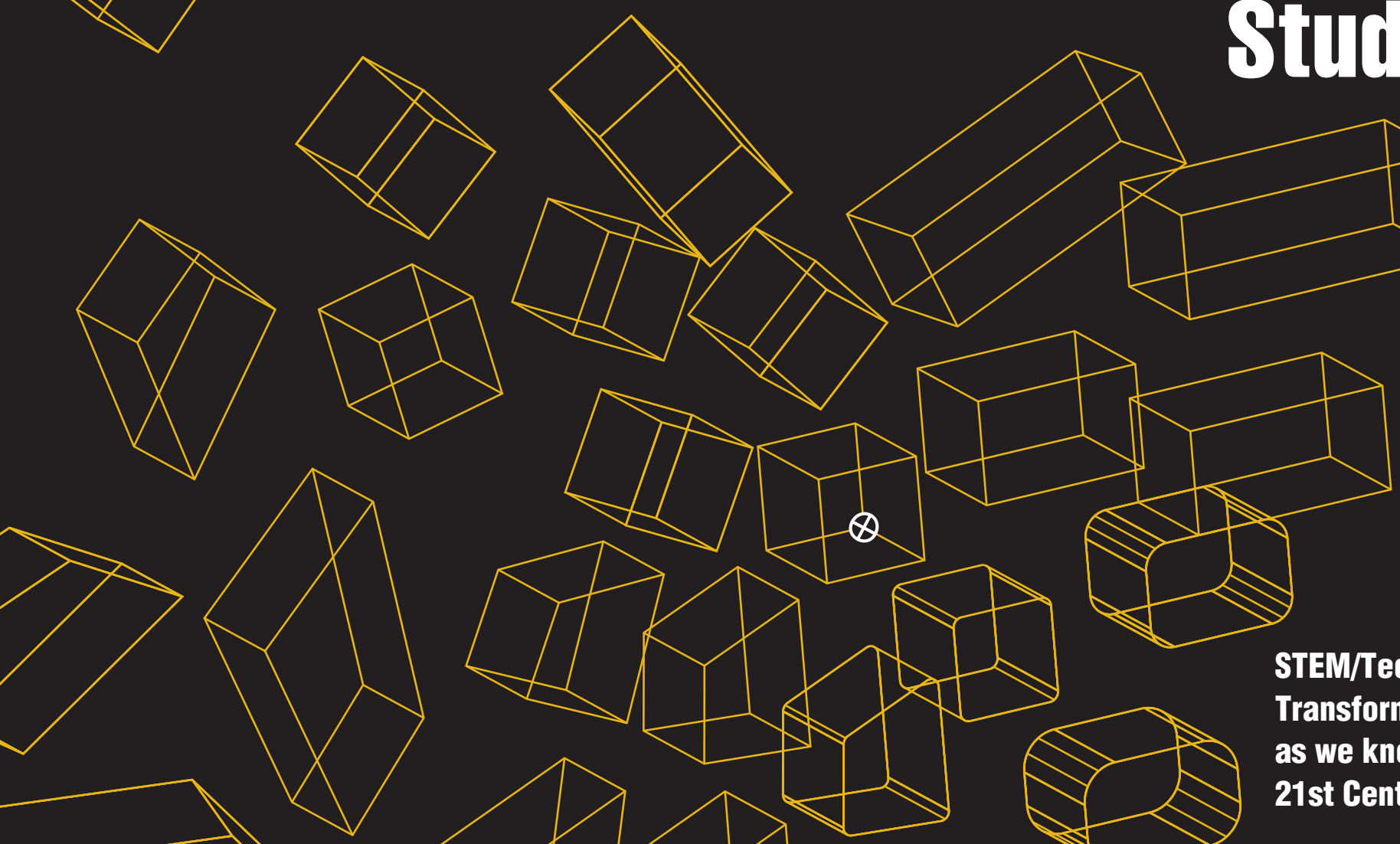

Studilias
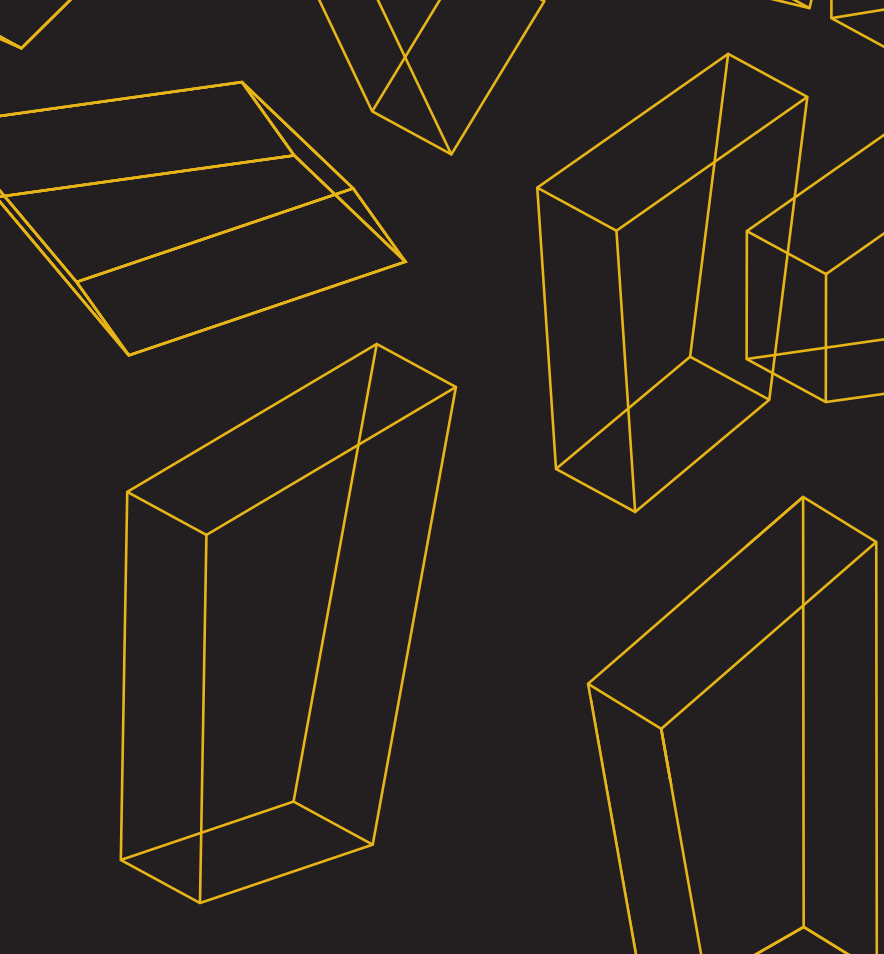

STEM/Technology

Transforming Education

as we know it in the

21st Gentury
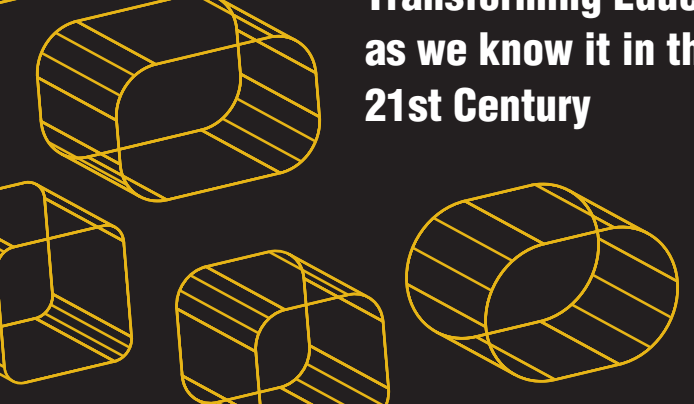

A refereed publication of $\mathcal{E}$ psilon $\mathscr{X}_{i} \mathcal{T}_{\mathfrak{a} u}$ The International Honor Society for Professions in Technology. 


\section{The Journal of Technology Studies}

A refereed publication of Epsilon $\mathscr{P}_{i} \mathcal{T}_{\mathfrak{a} u}$ The International Honor Society for Professions in Technology.

Jerry Streichler, Founding Editor and Publisher from 1977-2006

\author{
Editor \\ Charles V. Schwab \\ Agricultural and Biosystems \\ Engineering Department \\ Iowa State University
}

Note: Editorial queries should be directed to: The Editor, Journal of Technology Studies, Technology Bldg, Bowling Green State University, Bowling Green Ohio, 43403, email: jots@bgsu.edu

Editorial Board

David Batts
East Caroline University
230 Slay Building
Greenville, NC 27858
252.328 .9673
battsd@ecu.edu
Aaron C. Clark
Department of Math, Science \&
Technology Education
North Carolina State University
Box 7801, 510K Poe Hall
Raleigh, NC 27695
919.515.1771
aaron_clark@ncsu.edu
Jeremy V. Ernst
Department of Teaching and Learning
Virginia Polytechnic Institute and
State University
315 War Memorial Hall
Blacksburg, VA 24061
540.231.2040
jvernst@vt.edu
Dino Laury
Engineering Studies
Rochester Institute of Technology
52 Lomb Memorial Dr.
Rochester, NY 14623
585.475.6782
djlnet@rit.edu

Ivan Mosley, Sr.
2 Pipers Glen Ct.
Greensboro, NC 27406
336.285.6468
mosleyivant@gmail.com
David Rouch
Representing the Board of Directors
Department of Technological Studies
Ohio Northern University
Room 208 Taft Memorial
Ada, Oh 45810
419.772.2170
d-rouch@onu.edu
Luke J. Steinke
School of Technology
Eastern Illinois University
600 Lincoln Avenue
Charleston, IL 61920
217.581.6271
lsteinke@eiu.edu
Jeffery M. Ulmer
University of Central Missouri
Grinstead 014A
Warrensburg, MO 64093
600.827 .2473
julmer@ucmo.edu

The Journal of Technology Studies(JOTS) (ISSN 1071-6048) is the flagship, peer-reviewed journal of Epsilon Pi Tau, Inc., a nonprofit, academic and professional honor society. Headquarters and editorial offices are located at the Technology Building, Bowling Green State University, Bowling Green, OH 43403-0296. Use this address or jots@bgsu.edu for subscription matters or purchases.

Copyright 2018 by Epsilon Pi Tau, Inc.

The opinions expressed by the journal's authors are not necessarily those of the Board of Directors, staff, or members of Epsilon Pi Tau.

Two print issues per year are mailed to all members of the society upon request and to academic and general libraries around the globe. Issues that are published online only, the aforementioned printed issues, and past issues are available online at scholar.lib.vt.edu/ejournals/JOTS.

The journal is currently indexed in Current Index to Journals of Education (USA),International Bibliography of the Social Sciences (IBSS) (UK), and the International Vocational Education and Training and Research Database at http://www.ncver.edu.au (Australia).

Separate articles or complete issues are also available in a variety of media forms from EBSCO Publishing, 10 Estes Street, Ipswich, MA 01938-0682, USA, and ERIC, 65515th Street NW Suite 500, Washington, DC 20005, USA.

The JOTS welcomes original manuscripts from scholars worldwide focused on the depth and breadth of technology as practiced and understood past, present, and future. Epsilon Pi Tau, as perhaps the most comprehensive honor society among the technology professions, seeks to provide up-to-date and insightful information to its increasingly diverse membership as well as the broader public. Authors need not be members of the society in order to submit manuscripts for consideration. Contributions from both academics and practitioners are equally welcome.

A general guide to the breadth of topics of potential interest to our readers can be gained by consideration of the 17 subclasses within "Technology" of the classification scheme of the Library of Congress, USA < lcweb.loc.gov/catdir/cpso/lcco/lcco_t.pdf >. This includes engineering and allied disciplines, informatics in its many manifestations, industrial technology, and education in and about technology.

Authors are strongly urged to consult the journal's "Guidelines for Authors," included in this publication, or available at the society's web site (www.epsilonpitau.org) or provided upon request. It provides additional details on the breadth and nature of topics of interest, the journal's scholarly writing standards, submission guidelines, and review and publication processes.

Printed in the United States of America by Post Printing Company, Minster, Ohio.

\section{Board of Directors}

Region 1 (The nations of Europe, the Eastern Provinces of Canada, and the Northeastern United States)

Susan L. Gregg

College of Technology

Wilmington University

320 N. DuPont Hwy.

New Castle, DE 19720

302.356 .6865

susan.1.gregg@wilmu.edu

Region 2 (The nations of Africa, the Caribbean Islands, and the Southeastern United States)

Dr. Jessica L. Murphy

Department of Technology

Jackson State University

1400 JR Lynch Street Box 18480

Jackson, MS 39217

Jackson, MS 3921
601.979 .1145

jessica.1.murphy@jsums.edu
Region 3 (All members-at-large, the Canadian Province of Ontario, and the North Central United States) David Rouch

Department of Technological Studies Ohio Northern University

Room 208 Taft Memorial

Ada, Oh 45810

419.772 .2170

d-rouch@onu.edu

Region 4 (The nations of Central and South America, the Northern Territory and Central Provinces of Canada, and the Central United States)

Dominick Fazarro

Department of Technology

University of Texas at Tyler

3900 University Blvd.

Tyler, TX 75799

903.565.5911

dfazarro@uttyler.edu
Region 5 (Australia, the island nations of the Pacific and Indian Oceans, the nations of Asia, the Yukon Territory and Western Provinces of Canada, and the Western United States)

J. Brian Andrus

7404-180 Street NW

Edmonton, AB Canad

T5T 2K8

780.481 .4634

Andrus2@telusplanet.net

Two-Year Institutional Director

(Representing all Community and

Technical Colleges)

Karen Wosczyna-Birch

CT Community Colleges

College of Technology/Regional Center for Next

Generation Manufacturing

61 Woodland St.

Hartford, CT 06105

860.244 .7608

karenlee@snet.ne
Executive Director

Kevin R. Howell

Department of Technology

Appalachian State University

Boone, NC 28608

828.262.3114

howell@epsilonpitau.org 


\section{Table of Contents}

Volume XLIV, Number 1, Spring 2018

2 Infusing Computer Science in Engineering and Technology Education: An Integrated STEM Perspective

By Paul A. Asunda

14 Profile of Workforce Development Educators: A Comparative Credential, Composition, and Characteristic Analysis

By Thomas O. Williams, Jr., Jeremy V. Ernst, and Aaron C. Clark

28 Evolving Characteristics of Today's Applied Engineering College-Level Educator: 2013 to 2017 By Jeffrey M. Ulmer

41 Table of Contents, Volume XLIV, Number 2 Fall 2018 


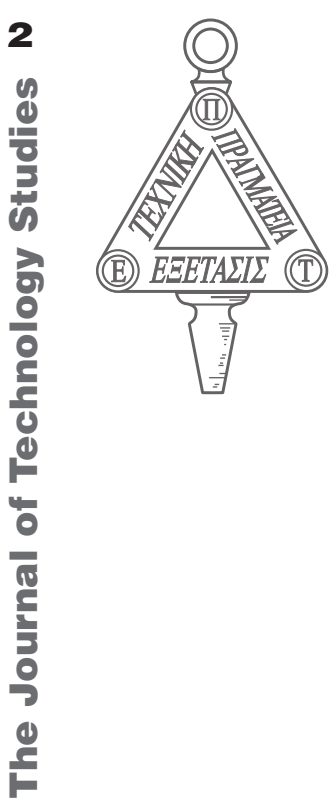

\section{Infusing Computer Science in Engineering and Technology Education: An Integrated STEM Perspective By Paul A. Asunda}

\section{ABSTRACT}

This study examined how four engineering and technology education teachers infused Computer Science Principles (CSP) and Computational Thinking (CT) practices into their classrooms from an integrated STEM perspective. Two questions guiding this inquiry were: (1) How do engineering and technology education teachers infuse CSP and $\mathrm{CT}$ into engineering and technology education?

(2) How do engineering and technology education teachers assess students' CSP and CT projects that are integrated with engineering and technology education? Data were collected through class observations and semi-structured interviews. Using an instrumental case study approach this study identified key themes; pedagogy, programming, assessment, and problem solving as strategies K-12 teachers should consider when designing instruction that seeks to infuse computer science principles, and computational thinking in engineering and technology education and integrated STEM coursework.

Keywords: computer science, computational thinking, integrated STEM, engineering and technology education, assessment, and problem solving

\section{INTRODUCTION}

Skills in the 21 st century center on the ability to analyze data, think critically, and solve problems both in teams and as individuals. Cultivating students with these types of skills requires an emphasis on STEM education paired with the breakthrough possibilities that facilitate creativity in ideas and exploration. Recent national reports emphasize the importance of Computer Science (CS) within K-12 curricula, and highlight concerns about national competitiveness and adequate workforce training in the global economy (National Science and Technology Council, 2013; The Office of Science and Technology Policy [OSTP], 2014; White House Fact Sheet, 2014). The teaching of CS at the K-12 level seeks to provide all students the opportunity to learn CSP and develop CT skills deemed necessary for success in the technological society (Yadav, Hong, \& Stephenson, 2016). This attention may be in response to the growing demand for individuals with computer science-related skills and who are prepared to address critical issues such as cyber security attacks (Koch \& Gorges, 2016). As such, there is need for a well-prepared workforce that can efficiently integrate and apply any or a combination of the CSP seven big ideas and CT skills in their work places (Mohaghegh \& McCauley, 2016). The CSP big ideas are creativity, abstraction, data, algorithms, programming, Internet, and global impact. In addition to the seven big ideas underpinning computer science, six computational thinking practices typify the kinds of activities computer scientists engage in, and by extension, must typify the learning outcomes of a computer science course. These are companions to the seven big ideas. These six ideas include the following: analyzing the effects of computation, creating computational artifacts, using abstractions and models, analyzing problems and artifacts, communicating processes and results, and working effectively in teams (Synder, Astrachabm, Briggs, \& Cuny, 2011).

The Framework for K-12 Science Education and the Next Generation Science Standards (NGSS) lists $\mathrm{CT}$ as one of the eight science and engineering practices. These standards emphasize the integration of science and engineering practices, crosscutting concepts, and core ideas in science disciplines in K-12 curricula. Such integration may refer to making meaningful connections between CSP and CT practices, and the core disciplinary practices of each STEM domain, with the goal of using this integrated knowledge to solve realworld problems. Research reveals that integrated learning also appeals to educators, because it projects real-world experiences, links subject areas, and fosters collaboration and networking among teachers (Hecht, Russo \& Flugman, 2009; Siew, Nazir, \& Chong, 2015). As such, Integrated STEM (i-STEM) education is a relatively recent phenomenon, particularly as it is still uncommon in K-12 classrooms (Chiu, Price, \& Ovrahim, 2015). Integrated STEM has been viewed as an approach to teaching and learning in a manner such that the curriculum and content of the four individual STEM disciplines seamlessly merge into real-world experiences contextually consistent with authentic problems and applications in STEM careers (Mobley, 2015; Sanders, 2009). Synthesizing lessons from schools that integrate STEM practices with computer science principles 
and computational thinking skills may begin to tell a story about how teachers plan, instruct, and assess CSP and CT in STEM programs.

Engineering and Technology education programs offer curricular flexibility that provides a variety of approaches to the infusion of computer science fundamentals into a K-12 curriculum. However, little information regarding K-12 computer science program development and integration into STEM areas is available in scholarly literature. To this end, two questions guiding this inquiry were: (1) How do engineering and technology education teachers infuse computer science principles (CSP) and CT into engineering and technology education? (2) How do engineering and technology education teachers assess students CSP and CT projects integrated with engineering and technology education?

\section{METHOD}

The interdisciplinary aspect of i-STEM provides a rich test bed to infuse computer science principles that enhance CT. Such an approach allows numerous ways students at the K-12 level exercise critical thinking as they explore the very many ways a design challenge may be solved (Curzon, Peckham, Taylor, Settle, \& Roberts, 2009). As such, this study purposefully selected and utilized snowball technique (Patton, 2002) to examine how four engineering and technology education teachers who had attended and completed Project Lead the Way (PLTW) summer CS training infused CSP and CT practices into their classrooms. The epistemology for this research was constructionism, the focus being the construction of meaning from the perspectives of these four teachers' beliefs and practices within the context of CSP, CT, and i-STEM in engineering and technology education. Crotty (1998) stated that constructionism is the view that all knowledge, and therefore all meaningful reality as such, is contingent upon human practices, being constructed in and out of interaction between human beings and their world and developed and transmitted within an essentially social context. This inquiry was designed to be a multi-site collective case study with each participant being viewed as a unit of analysis. Participants for this study were four high school teachers who were studied individually as cases and jointly examined to better understand their experiences. The study was limited to high schools within a radius of 100 miles from the researcher. In addition to driving the long distances to conduct interviews and observe teachers' natural settings, a challenge to the study was the frequency with which classroom observations were scheduled in order to observe students' working on CS-related projects. These teachers taught in the Midwest region of the United States and worked with approximately 200 students (Grades 9-12). Two of the teachers (pseudonyms Alex and John) taught at ABC high school, which enrolled approximately 600 students, with the engineering and technology courses being electives and attracting around 80 students (freshmen through seniors). Alex had three years of teaching experience, and John who had recently graduated from college was a first-year high school teacher. Teacher Cory (pseudonym) taught at EFG high school, which enrolled approximately 700 students, where approximately 70 students were pursuing engineering and technology, and other career and technical education (CTE) courses as electives. He had taught high school for a total of 20 years and was a Master PLTW teacher who had trained many teachers in PLTW curricula in the Midwest region. Teacher Brown (pseudonym) taught at MNO high school, which enrolled approximately 650 students, and had around 90 students (9-12 grade students) enrolled in the engineering and technology education courses. Teacher Brown had taught middle school for 7 years before transitioning to the high school setting, where he had taught for the last 12 years. All four teachers had graduated with a bachelor's degree in technology education / engineering and technology education. Teacher John also had a computer science minor for his undergraduate degree in his teacher preparation program.

\section{DATA COLLECTION}

A classroom observation coding instrument was developed to examine teacher's practices with students during instruction of CSP and CT in an i-STEM environment. Specifically, the practices to be observed were selected from the Secondary Science Teacher Analysis Matrix (STAM) (Gallagher \& Parker, 1995 ) to code specific behaviors and actions within the teacher's classroom. The rationale for selecting the STAM instrument items was that it addressed the research questions guiding this study: It guided the observation of CSP and CT practices related to engineering and technology education focused around the integration of STEM concepts. As such, the researcher observed and interviewed teachers based on the following items: structure of content; examples and connections; methods; labs, demonstrations and hands-on involvement; kinds of assessments; students 'questions; student-initiated activity; students' understanding of teachers expectations; resources available, and students'works. 
The observational data were collected from classroom visits, which included a total of 4-5 visits that lasted 50 minutes at all three schools. The total was 15 visits: teacher Cory was visited 6 times, Alex and John were visited 3 times each (i.e., 6 visits between the two teachers), and teacher Brown also was visited 3 times. Faceto-face interviews with each teacher lasted up to 50 minutes. As such, a total of 15 lessons were observed, and a semi-structured interview with open-ended questions was utilized to supplement classroom observation data. Berg (2001) stated that semi-structured interview guides allowed the interviewer to probe far beyond answers that might be generated by pre-prepared standardized questions. Likewise, Patton (2002) posited that open-ended interview questions enabled researchers to understand and capture participants' views. The four teachers were then invited to participate in a 50-minute interview, and all the interviews were audio recorded and transcribed verbatim.

\section{DATA ANALYSIS}

One of the researcher's challenges was to obtain and verify the true meaning of each participant's responses to the questions asked (Gall, Gall, $\&$ Borg, 2003). To begin making meaning of collected data (i.e., the interview data from the four teachers and classroom observations), the four interviews were analyzed separately as described by Miles and Huberman (1994) during data reduction, data display, conclusion drawing, and verification phases. The data analysis process helped the researcher approach the data without preconceptions about teacher's beliefs and practices. During this process the researcher reflected on the purpose of the study and the guiding research questions as they noted phrases and words that revealed each participant's CS teaching practices integrated in engineering and technology education with a focus in STEM experiences. The researcher then identified text segments that contained the same meaning and sought to derive in vivo codes from transcripts by identifying repetitive, descriptive, and interpretive phrases of participants' experiences, which were then developed into categories such as programming and pedagogy. Boeije (2009) stated that in vivo codes are not just catchy words; rather, they pinpoint the meaning of a certain experience or event. The researcher identified 14 initial in vivo codes in order (i.e., computer science, evaluation, information science, criticism, data, pedagogy, computer programming, assessment, technology, problem solving, design, teaching, coding, open ended). These codes were then compared with classroom observation data as a triangulation measure to further affirm the initial codes that had emerged from the classroom interviews into categories and subcategories. Afterward the researcher wrote memos describing identified categories to further reduce the data. Participants' explanations and ideas that had similar meanings were then collapsed into key categories informed by subcategories identified by reviewing the initial categories and participants' transcripts again. However, it should be noted that emergent categories had text descriptors in identified subcategories that overlapped. At this juncture, the researcher then embarked on establishing reliability of emerging themes by sharing these initial codes and descriptors with study participants for member- checking purposes through email correspondence for more than a month (Mays $\&$ Pope, 1995). Mays and Pope (1995) use the term "reliability" and claim that it is a significant criterion for assessing the value of a piece of qualitative research. During this process study participants crystallized their meanings and reduced the initial codes to eight, again in no order of priority to computer science, programming, teaching, coding, pedagogy, open-ended, evaluation, and assessment. The researcher then grouped these codes with accompanying text as suggested by participants into relevant categories. After member checks and reliability testing, the researcher proceeded to use Microsoft excel to display and organize data for cross-case analysis. Miles and Huberman (1994) defined cross-case analysis as searching for patterns, similarities, and differences across cases with similar variables and similar outcome measures. The researcher took note of both units to be eliminated and those that would be retained. Related terms and data with similar expressions (e.g., terms like "programming" "coding") that study participants had pointed out during member checking to express similar meanings were further grouped together into identified categories. The researcher then embarked on developing themes by grouping identified categories that had similar meaning into core themes. Table 1 provides the themes identified during this stage of analysis; they are termed as categories, along with subcategory labels, and descriptions as per the participants of this study. 
Table 1: Categories That Informed Themes Generated by Researcher

\begin{tabular}{|c|c|c|}
\hline Categories & Subcategories & Descriptors \\
\hline \multirow[t]{10}{*}{ Pedagogy } & Interactive & $\begin{array}{l}\text { Working together with, and having an influence on learning } \\
\text { process of students }\end{array}$ \\
\hline & Learning curve & Students' progress in gaining new knowledge and skills. \\
\hline & Remember & Recall an event or an experience from the past. \\
\hline & Work sheets & $\begin{array}{l}\text { Paper that teacher shares with student to help them learn similar } \\
\text { concepts and skills as they progress through a given unit. }\end{array}$ \\
\hline & Culminating projects & $\begin{array}{l}\text { Series of related projects that give students an opportunity to } \\
\text { demonstrate what they have learned at end of a given unit. }\end{array}$ \\
\hline & Tutorials & $\begin{array}{l}\text { An interactive method of learning that demonstrates concepts/ } \\
\text { skills/knowledge you want students to attain. }\end{array}$ \\
\hline & Standards & $\begin{array}{l}\text { Documented specifications that recommend what students } \\
\text { should know and be able to do at a given grade level. }\end{array}$ \\
\hline & Unit of learning & $\begin{array}{l}\text { Coherent set of concepts that teachers will instruct over a period } \\
\text { of four to five weeks. }\end{array}$ \\
\hline & Backward design & $\begin{array}{l}\text { A method of designing a unit of learning by setting an end } \\
\text { goal you want students to attain before choosing instructional } \\
\text { methods and forms of assessment. }\end{array}$ \\
\hline & Scaffolding & $\begin{array}{l}\text { Using a variety of instructional techniques to help students learn } \\
\text { progressively toward attainment of a given end goal. }\end{array}$ \\
\hline \multirow[t]{4}{*}{ Programming } & Coding / Programming & $\begin{array}{l}\text { Writing a set of instructions to execute a desired end goal in a } \\
\text { computer program. }\end{array}$ \\
\hline & Scripting languages & $\begin{array}{l}\text { A form of communication, as such instructions that computers } \\
\text { utilize to execute give task to attain a desired goal (e.g., HTML, } \\
\text { JAVA). }\end{array}$ \\
\hline & Syntax & $\begin{array}{l}\text { Relates to the spelling and grammar of a programming language } \\
\text { and hence good clean code. }\end{array}$ \\
\hline & Tool kits & $\begin{array}{l}\text { Companion wizard like program that helps students learn a } \\
\text { given programming language (e.g., Tkinter in Python). }\end{array}$ \\
\hline \multirow[t]{6}{*}{ Assessment } & Criticism & Offering value statements to make students' work better. \\
\hline & Correlation & Connecting end result of students work with process. \\
\hline & Understand & $\begin{array}{l}\text { Students being able to demonstrate the desired end goal of unit } \\
\text { of leaning set by teacher. }\end{array}$ \\
\hline & Rubrics & $\begin{array}{l}\text { Coherent set of criteria that reflect given standards and includes } \\
\text { descriptions of expected levels of student's performance. }\end{array}$ \\
\hline & Evaluation & Assigning value statements to students finished assignments. \\
\hline & Documentation & $\begin{array}{l}\text { Student's written thoughts reflecting how they arrived at their } \\
\text { final solution. }\end{array}$ \\
\hline \multirow[t]{5}{*}{$\begin{array}{l}\text { Problem } \\
\text { solving }\end{array}$} & Open ended & $\begin{array}{l}\text { No specified conditions that hinder the adoption of multiple } \\
\text { solutions to a design challenge. }\end{array}$ \\
\hline & Backward design & $\begin{array}{l}\text { No specified conditions that hinder the adoption of multiple } \\
\text { solutions to a design challenge. }\end{array}$ \\
\hline & Scaffold & $\begin{array}{l}\text { Using a variety of strategies to help provide a solution to a } \\
\text { design challenge. }\end{array}$ \\
\hline & Planning & $\begin{array}{l}\text { Process of thinking about, and organizing a strategy and key } \\
\text { activities required to solve a given design challenge. }\end{array}$ \\
\hline & Iterative & $\begin{array}{l}\text { Repeating a given procedure in an effort to optimize possible } \\
\text { solutions to a given design challenge. }\end{array}$ \\
\hline
\end{tabular}




\section{FINDINGS}

This study sought to find out how engineering and technology education teachers infuse computer science principles and computational thinking into engineering and technology education, in addition to their assessment practices. Quotes from the four teachers have been used throughout this section to emphasize core themes that emerged with no observed priority or order. Four core themes (pedagogy, problem solving, programming, assessment) were identified from the reduced meanings of participants' verbatim transcripts. Verbatim quotes from participants were used throughout this section to emphasize core themes.

\section{Core Theme Pedagogy}

Responses supporting this theme offer insights into how teachers scaffold CSP and CT into engineering and technology education. Cory shared that integration of computer science into engineering and technology education courses had been facilitated by organizations like code. org, and the Computer Science Teachers' Association (CSTA) working closely with the College Board. He shared that many forms of curricula exist that teachers could utilize. For example, author please explain abbreviation (PLTW) of which teacher Cory was certified to teach, and had facilitated professional development sessions to prepare other teachers integrate CSP and CT in their engineering and technology courses. He was of the view that these curricula offered a framework that teachers could utilize to teach CSP and CT in engineering and technology education. In contrast, Alex defined scaffolding as a teaching and learning strategy by which he helps his students learn how to write code and develop programming skills through toolkits and worksheets. Brown shared that he used a mix of hands-on activities and projects to help his students with CSP and CT concepts, whereas John viewed the process of teaching CSP and CT through design problem solving challenges to be synonymous to engineering design practices. In visiting the classrooms, the researcher was able to observe students working on various projects. For example, a data visualization project that required students to design data collection tools and utilize the tool to collect data that they could eventually analyze; design of interactive graphical user interface (GUI); and raspberry pi projects that looked into designing alarm systems controlled by a sensor and a camera. These projects required that students have some coding background. Cory used reflecting practices and recall procedures to help students relate their current projects to previous learning experiences. For example, he stated " ... other languages as one of the common widget is a canvas as I have mentioned before and we have all encountered that all the way back to our very first day in scratch right a big canvas that you use again." In contrast, teacher Alex mentioned that this being new to his school and teaching, he incorporated a survey to help him understand his students' needs and what kind of projects they would enjoy. Especially because engineering and technology courses were electives, he had to find a balance to grow the program. He also mentioned that he would give course material that looked into CSP and CT upfront so as to give his students background information. For example, he mentioned that cybersecurity was new to him and to engage his students with hands-on activities he shared that, "I went to a workshop this summer, I got a lot of materials on cybersecurity design challenges, I use these materials to guide students [to] make their own encryption device of some sort." Brown shared that there were worksheets that he accessed from the Internet to help his instruction, and John pointed out that he also used worksheets in his teaching; he was quick to mention NGSS as key factors in his teaching and planning. This was a sentiment shared by the other teachers, and they recognized the value of standards in the planning of their teaching of CS concepts in engineering and technology education. One key aspect all the teachers shared is that the projects they conducted were culminating in nature. As such, a given CS unit and designated project typically runs approximately four weeks with some buffer time built in. He pointed out that his teaching of CS including projects was modeled around the engineering design cycle.

\section{Core Theme Programming}

John noted that the good thing about computer science "is that there are a lot of different programming languages, and some of them are far easier to learn than others." John who had a minor in computer science stated that he helps his students learn how to write code by asking them to first verbalize what they want the code to do. He stated, "before you write any code or anything you have to think through the problem in your head. So I can give the students a problem and then have them explain to me or a partner how they would solve it and the write it 
down step by step." All the teachers mentioned that they infused object- oriented programming (OOP) into their engineering and technology education courses that enhance STEM learning. According to Cory this is when "someone combined data and functionality and wrapped it inside something called an object." For example, in one class observation, Cory had his students program a sphere that could be programmed to change location on the canvas, through a toolkit called Tkinter in python, one of the many toolkits he shared with his students. He began by having the students generate code to create the canvas and a sphere (i.e., the object). As they did this exercise Cory reminded his students about classes and objects. As the students worked in the OOP environment, classes and objects became the two main aspects of object-oriented programming. A class creates a new type where objects are instances of the class (Corradi \& Leonardi, 2001). Further, teachers, Brown, Cory, Alex, and John shared that that they all introduced their students to scratch software as an initial tool to generate CS and programming interest in their students. Scratch (https://scratch.mit. $\mathrm{edu} /$ ) is a free programming language developed by the Massachusetts Institute of Technology (MIT) whereby individuals can program their own interactive stories, games, and animations and share their creations with others in the online community. Cory mentioned that he started out with Scratch, and then introduced his students to app inventor, an open-source web application originally provided by Google, and now maintained by MIT, and finally Python, a high-level programming language for generalpurpose programming. In contrast, Alex and John mentioned that they looked into Python and JAVA, while Brown worked with Scratch and Python. John noted that Scratch gave students an opportunity to see drag and drop functionality from a programming perspective. He also added that Hypertext Markup Language (HTML) and other languages like Cascading Style Sheets (CSS) interested his students. According to Alex, he emphasized some key terms when teaching programming, and asked his students to take note of when learning programming included syntax, algorithms, good code, and control flow.

\section{Core Theme Problem Solving}

All the teachers attested that the essence of teaching CS to their students as an alternative way to equip them with problem solving skills. They all noted that solving a problem in CS resembled the process of solving a design challenge in engineering and technology education through the process of engineering design. Cory shared depending on the curriculum being used to introduce CS to high school students, sometimes the problems that students work on are not open ended. He also shared that he works on making the challenges his students work on as open-ended as possible. Likewise, John agreed and shared that the open-ended nature helped him explain the process of solving the problem to students using a backward design process. He stated, "I set it up in like a three step process, using backwards design a lot so I would take what objectives I want like what I want the students to learn and my goals for teaching and hopefully as I instruct, the student will be able to make the connection." Alex on the other hand, posited that it was imperative for students to learn how to write good code in order to successfully solve CS-related challenges. He mentioned that good code was clean, easy to follow, and would be easy to troubleshoot. Teacher Brown suggested that building an opened nature perspective into CS problems developed creativity in students, as such a key tenet of constructionist learning theories where students constructed mental representations of possible solutions using the engineering design process to understand the how possible solutions to a given challenge might look like. Constructionism advocates student-centered, discovery learning whereby students use information they already know to acquire more knowledge (Alesandrini \& Larson, 2002). Students learn through participation in project-based learning where they make connections between different ideas and areas of knowledge facilitated by the teacher through coaching rather than using lectures or step-by-step guidance. Cory noted that toolkits (e.g., TKinster) provided through some of the programming languages made realization of a solution to a problem become a living object through a visual medium.

\section{Core Theme Assessment}

Participants shared that assessment was seen to be a challenging aspect of infusing CS into engineering and technology education. Alex mentioned having criteria was key and aligning these to the requirements shared with students beforehand. Cory, on the other hand, shared that he used rubrics. The PLTW curricula he utilized provided rubrics that he could use in evaluating students assessments, although he also considered other informal measures and asked that students 
document all their work as they solved each presented challenge. For example, he mentioned that he considered the functionality of the final project and if students were able to adhere to the criteria shared. Cory also stated that, "I really really want them to learn. I keep on watching for the kids who are putting an effort and try to learn, the projects are cumulative in a sense and how can I give a failing grade if a kid shows me growth."

John shared that "grading" as such was a challenge, in the same vein Alex posited that he did not have paper and pencil tests in his CS classroom, rather projects. Like Cory, Brown also utilized PLTW rubrics to assess his students' completed assignments. For example, the PLTW rubric for App design, Scratch game or Story assignments had the same eight criteria elements and had a grading scale that ranged from 4 to 1 , with 4 being the highest score and 1 being the lowest. The criteria elements include: solves problem, documentation, collaboration, presentation, appropriate algorithm, explanation of algorithm, explanation of problem solution, and planning. For example, under the criterion 'solves problem' to score a 4, a student's "artifact fully addresses personal, practical, or societal intent posed by problem statement," a score of 3 depicted that "artifact addresses the personal, practical, or societal intent posed by problem statement," a score of 2 meant that "artifact mostly addresses the personal, practical, or societal intent posed by problem statement", and a score of 1 meant "artifact does not adequately address the personal, practical, or societal intent posed by problem statement." As such, the PLTW rubric elements were similar to engineering design rubrics (e.g., Asunda \& Hill 2007; Groves, Abts, \& Goldberg, 2014; Robelen, 2013; Spurlin, Rajala, \& Lavelle, 2008) that have been used to assess engineering design challenges with the exception of the criteria "appropriate algorithm" and "explanation of algorithm." These two criteria required that students show that the "code demonstrates use of appropriate algorithms" as well as provide "comments that clearly and thoroughly explain the algorithm(s)." The engineering design process asks for students to show the iteration progression they utilize to reach a viable solution and provide evidence of optimization of chosen solution, as such a similar process to the two criteria "appropriate algorithm" and "explanation of algorithm."

\section{DISCUSSION}

Computer scientists, just like engineers, play a central role in our technological infrastructure. They develop hardware, software and other applications for use by the military, businesses, and average consumers (Singh, 2016). The findings of this study revealed problem solving as a key element in infusing CSP and CT into STEM-related coursework at the K-12 level. The use of problem solving as a strategy to develop and impart in students critical thinking skills in engineering and technology education programs has been reported by several authors (e.g., Eison, 2010; Pacific Policy Research Center, 2010;

Ralston \& Bays, 2015). Participants of this study posited that the procedure their students utilized to solve computer science design challenges was similar to the engineering design problem solving process utilized by engineers and technologists to solve everyday challenges that society faces. Today, students as young as six and seven are learning the logic behind computer programs and, in some cases, how to create simple programs of their own. Working with age-appropriate programming tools like Scratch, App inventor etc. and curricula, students can be innovative in their solving of given design challenges as they explore and experiment with crosscutting interdisciplinary skills and knowledge as detailed by NGSS (Bers, 2010; Bers \& Horn, 2010; Grover \& Pea, 2013; NGSS, 2013). Programming at the K-12 consists of two bodies of theoretical work: computational thinking, which discourses problem solving with computers; and technological literacy and fluency, which addresses expressivity with new technologies (Barr, Harrison, \& Conery, 2011; Grover \& Pea, 2013; Guzdial, 2008; Lee et al., 2011; Next Generation Science Standards [NGSS], 2013; Wing 2008). Utilizing problem solving strategies to innovatively design and program computational artifacts can facilitate students' engagement in high-level cognitive processes such as divergent thinking, and reflective practice (Resnick, 2007). As such, the findings of this study report that programming as a vehicle to develop computational thinking practices may lead to the realization of viable solutions to given design challenges.

With regards to core themes pedagogy and assessment, Magana, Brophy, and Bodner, (2012) investigated aspects of teaching and learning for integrating CS modeling and simulation practices in STEM coursework. Aspects of 
teaching relate to the identification of intended learning outcomes instructors would like to accomplish when integrating computational tools into their disciplinary courses. On the other hand, learning aspects for integrating modeling and simulation practices have centered on the reasoning processes afforded by computational tools (Magana et al., 2017), as well as scaffolding strategies that can overcome possible cognitive overload (Vieira, Magana, Falk, \& Garcia, 2017; Vieira, Magana, Roy, Falk, \& Reese, 2016). Aspects of teaching and learning inform assessment practices, as well as pedagogical strategies that include hands-on, real-world projects. Such is a vehicle for the integration of CS practices and STEM coursework, as a result helping students develop useful skills and take what they learn in the classroom and apply it to everyday life. Thus, project- and problem-based challenges and learning through modeling and simulation practices engage students in rigorous and relevant learning experiences that may generate their enthusiasm as well as impart in them CSP and CT skills and knowledge. On the other hand, assessments that teachers utilize are processes used to examine students' assignments with the aspects of teaching and learning that the teacher has identified as appropriate for a given learning segment. In essence, assessment practices that these teachers utilized helped them gauge the development of CSP and CT skills by using design challenges as a vehicle to support the learning of crosscutting concepts in i-STEM environments.

\section{CONCLUSION}

In conclusion, the findings of this study suggest that i-STEM opens a range of possibilities by which teachers at the K-12 level may utilize to further develop in 21st century students skills that become future workforce requirements to be competitive at the workplace. Infusion of CSP and CT into STEM-related course work engages students in applied learning as they solve design challenges through a variety of crosscutting concepts. Such a process is similar to the engineering design process that exemplifies a process of steps that are developmental, structured, and iterative in solving design problems, building prototypes, and testing solutions. As such students are exposed to critical skills in problem solving, teamwork, time management, communication, and leadership strategies. Such an approach may ensure college and career readiness for the STEMenabled 21 st century careers.

\section{LIMITATIONS AND RECOMMENDATIONS FOR FUTURE RESEARCH}

As with all educational research, there are limitations to this study that must be addressed. The infusion of CS into STEMrelated courses through engineering and technology education is an emerging area of work. As such, there is limited literature with regards to how teachers integrated their teaching as well as assessment process. NGSS standards are a recent introduction to the K-12 arena, and teachers are still learning how to incorporate them into already existing state standards for instructional planning purposes. Besides, states are still grappling with where CS fits in the K-12 curricula, and there is a need for qualified teachers. First, a small number of participants within a radius of 100 miles were purposefully chosen for this study, limiting the ability to utilize sophisticated statistical methodologies and examine how engineering and technology education teachers infuse CSP and CT into engineering and technology education. Second, assessment strategies were varied and it was difficult to comprehend and relate how participants of this study may have integrated NGSS suggestions into assessing students' CS integrated STEM assignments and projects. It was noted that participants' utilized rubrics and that choice may not clearly highlight the role of performance assessment as highlighted in the NGSS. Although there is much that remains to be done toward integration of CS into K-12 teaching, caution must be used in generalizing findings of this study to larger populations. Future research studies would benefit from the use of a larger sample. Third, investigate assessment practices that clearly articulate and align CS to performance assessment, and lastly computer science departments and STEM educators should continue to collaborate and develop CS coursework that can be integrated into teacher education course work concepts and pedagogical knowledge practices.

Paul A. Asunda is an Assistant Professor of Engineering and Technology Teacher Education in the Department of Technology, Leadership, and Innovation at Purdue University, West Lafayette, IN. He is a member of the Gamma Rho Chapter of Epsilon Pi Tau. 
Alesandrini, K., \& Larson, L. (2002). Teachers bridge to constructivism. The Clearing House, 119-121.

Asunda, P. A., \& Hill, B. R. (2007). Critical features of engineering design in technology education. Journal of Industrial Technology Education. 44 (1), 25-48.

Barr, D., Harrison, J., \& Conery, L. (2011) Computational thinking: A digital age skill for everyone. Learning \& Leading with Technology, 38(6), 20-23.

Berg, B. L. (2001). Qualitative research methods for the social sciences (4th ed.). Needham Heights, MA: Allyn \& Bacon.

Bers, M. (2010) Beyond computer literacy: Supporting youth's positive development through technology. New Directions for Youth Development, 128, 13-23.

Bers, M. U., \& Horn, M. S. (2010). Tangible programming in early childhood: revisiting developmental assumptions through new technologies. In I. R. Berson, \& M. J. Berson (Eds.), High-tech tots: Childhood in a digital world (pp. 49-70). Greenwich, CT: Information Age Publishing.

Boeije, H. (2002). A purposeful approach to the constant comparative method in the analysis of qualitative interviews. Quality \& Quantity, 36, 391-409. doi:10.1023/A:1020909529486.

Chiu, A., Price, A. C., Ovrahim, E. (2015, April). Supporting elementary and middle school STEM education at the whole school level: A review of the literature. Paper presented at the Annual International Conference of the National Association for Research in Science Teaching [NARST], Chicago, IL. Retrieved from http://www.msichicago.org/fileadmin/Education/pdf/MSI-SLILiterature_Review_White_Paper.pdf

Corradi, A., \& Leornadi, L. (2001). Static vs. dynamic issues in object-oriented programming languages. Retrieved from https://adtmag.com/Articles/2001/07/13/Static-vs-Dynamic-Issues-inObjectOriented-Programming-Languages.aspx? $\mathrm{p}=1$

Crotty, M. (1998). The foundations of social research: Meaning and perspective in the research process. Thousand Oaks, CA: Sage.

Curzon, P., Peckham, J., Taylor, H., Settle, A., \& Roberts, E. (2009). Computational Thinking (CT): On Weaving It In. SIGCSE Bull., 41(3), 201-202. doi:10.1145/1595496.1562941.

Eison, J. (2010). Using active learning instructional strategies to create excitement and enhance learning. Retrieved from http://www.cte.cornell.edu/documents/presentations/ ActiveLearningCreatingExcitement in the Classroom-Handout.pdf

Gallagher, J., \& Parker, J. (1995). Secondary teaching analysis matrix (STAM). East Lansing, MI: Michigan State University.

Gall, M. D., Gall, J. P., \& Borg, W. R. (2003). Educational research: An introduction (7th ed.). New York: Allyn and Bacon.

Grover, S., \& Pea, R. (2013). Computational thinking in K-12: A review of the state of the field. Educational Researcher 42(1), 38-43.

Groves, F. J., Abts, R. L., \& Goldberg, L.G. (2014). Using an engineering design process portfolio scoring rubric to structure online high school engineering education. Conference presentation at 2014 ASEE. Retrieved from http://www.asee.org/public/conferences/32/papers/ 10738/view

Guzdial, M. (2008). Paving the way for computational thinking. Communications of the ACM, 51(8), $25-27$.

Hecht, D., Russo, M., \& Flugman, B. (2009). Infusing mathematics into science, technology, and engineering classes: Lessons learned from middle school teachers and students. Retrieved from http://www.hofstra.edu/pdf/Academics/Colleges/SOEAHS/ctl/mstp/mstp_STEM_Symposium.pdf. 
Koch, M., \& Gorges, T. (2016). Curricular influences on female afterschool facilitators' computer science interests and career choices. Journal of Science Education \& Technology, 25(5), 782-794. doi:10.1007/s10956-016-9636-2

Lee, I., Martin, F., Denner, J., Coulter, B., Allan, W., Erickson, J., Malyn-Smith, J. \& Werner, L. (2011). Computational Thinking for Youth in Practice. ACM Inroads, 2(1), 32-37. doi:10.1145/1929887.1929902

Magana, A. J., Brophy, S. P., \& Bodner, G. M. (2012). Instructors' intended learning outcomes for using computational simulations as learning tools. Journal of Engineering Education, 101(2), 220-243.

Mays, N., \& Pope, C. (1995). Rigor and qualitative research. British Medical Journal, 311(6997), 109-112.

Miles, M. B., \& Huberman, A. M. (1994). Qualitative data analysis: A sourcebook of new methods. Newbury Park, CA: Sage.

Mobley, C. M. (2015). Development of the SETIS instrument to measure teachers'self-efficacy to teach science in an integrated STEM framework (Unpublished doctoral dissertation). University of Tennessee, Knoxville.

Mohaghegh, M., \& McCauley, M. (2016). Computational thinking: The skill set of the 21st century. International Journal of Computer Science and Information Technologies (IJCSIT), 7(3), 1524-1530.

Next Generation Science Standards [NGSS]. (2013). The next generation science standards. Retrieved from: http://www.nextgenscience.org/next-generation-science-standards

National Science and Technology Council. (2013). A report by committee on STEM education national science and technology council. Federal science, technology, engineering, and mathematics (STEM) education 5-Year strategic Plan. Retrieved from https://www.whitehouse.gov/sites/default/files/ microsites/ostp/stem_stratplan_2013.pdf

Pacific Policy Research Center. (2010). 21st century skills for students and teachers. Honolulu: Kamehameha Schools, Research \& Evaluation Division.

Patton, M. Q. (2002). Qualitative research \& evaluation methods (3rd ed.). Thousand Oaks, CA:

Office of Science and Technology Policy [OSTP] (2014). Progress report on coordinating federal science, technology, engineering, and mathematics (STEM) education. Retrieved from https://www. whitehouse.gov/sites/default/files/microsites/ostp/stem_ed_budget_supplement_fy16-march-2015. pdf

Ralston, P., \& Bays, C. (2015). Critical thinking development in undergraduate engineering students from freshman through senior year: A 3-cohort longitudinal study. American Journal of Engineering Education, 6(2), 85-98.

Resnick, M. (2007). All I really need to know (about creative thinking) I learned (by studying how children learn) in kindergarten. ACM Creativity \& Cognition Conference, Washington DC, June 2007. Retrieved from http://web.media.mit.edu/ mres/papers.html.

Robelen, E. (2013). AP engineering may be on the horizon. Education Week, March 29, 2013. Retrieved from http://blogs.edweek.org/edweek/curriculum/2013/03/ap_engineering_may_be_on_the_ horizon.html.

Sanders, M. (2009). STEM, STEM education, STEM mania. Technology Teacher, 68(4), 20-26.

Siew, N. M., Nazir, A., \& Chong, C. L., (2015). The perceptions of pre-service and in-service teachers regarding a project-based STEM approach to teaching science. doi: 10.1186/2193-1801-4-8. eCollection 2015.

Singh, H. (2016). What is the best area of study to get into with computer coding focus, Retrieved from https://www.careervillage.org/questions/43776/ 
Spurlin, E. J. Rajala, A. S., Lavelle, P. J., Eds. (2008). Designing better engineering education through assessment: A practical resource for faculty and department chairs on using assessment and ABET criteria to improve student learning. Stylus Publishing, Sterling, Virginia

Synder L., Astrachabm, O., Briggs, A., \& Cuny, J. (2011). AP computer science principles: Six computational thinking practices - AP Computer Science Principles, Retrieved from https:// csprinciples.cs.washington.edu/sixpractices.html

Vieira, C., Magana, A. J., Falk, M. L., \& Garcia, R. E. (2017). Writing in-code comments to self-explain in computational science and engineering education. ACM Transactions on Computing Education (TOCE).

Vieira, C., Magana, A. J., Roy, A., Falk, L. M., \& Reese, J. M. (2016). Exploring undergraduate students' computational literacy in the context of problem solving. Computers in Education Journal., 7(1), $100-112$.

White House, Fact Sheet (2014). New commitments to support computer science education. Retrieved from http://www.whitehouse.gov/the-press-office/2014/12/08/fact-sheet-new-commit-ments-supportcomputer-science-education

Wing, J. (2008). Computational thinking and thinking about computing. Philosophical Transactions of The Royal Society A, 366, 3717-3725. doi:10.1098/rsta.2008.0118

Yadav, A., Hong, H., \& Stephenson, C. (2016). Computational thinking for all: Pedagogical approaches to embedding 21 st century problem solving in K-12 Classrooms. TechTrends, 60(6), 565-568. doi:10.1007/s11528-016-0087

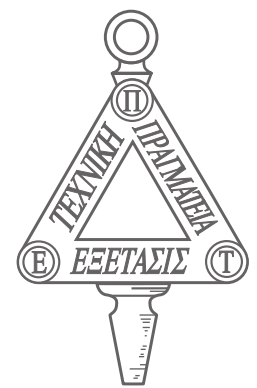




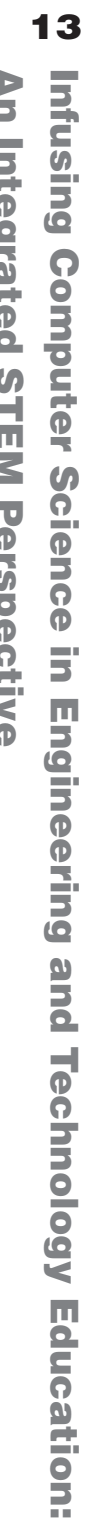




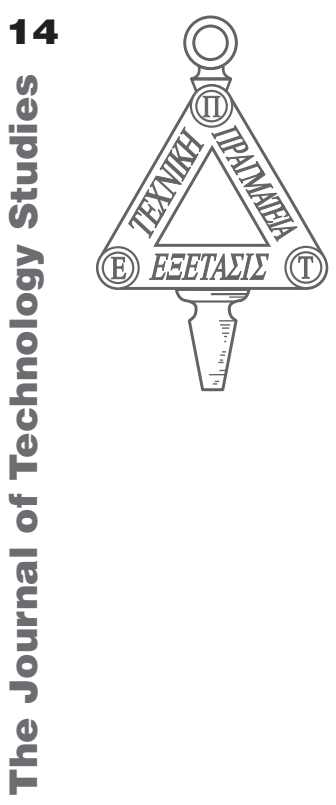

\section{Profile of Workforce Development Educators: A Comparative Credential, Composition, and Characteristic Analysis \\ By Thomas O. Williams, Jr., Jeremy V. Ernst, and Aaron C. Clark}

\begin{abstract}
The Schools and Staffing Survey (SASS) is administered by the National Center for Educational Statistics to obtain information about teachers, such as education and training, teaching assignment, certification, workload, and perceptions and attitudes about teaching. Data are weighted to approximate the population of teachers in the USA. In this study, the most recent SASS results were employed to formulate a comprehensive profile of Career and Technical Education (CTE) teacher characteristics or Workforce Development in Education. Characteristics analyzed included: gender, age, teaching experience, teaching status, race and ethnicity, educational level, certification status, caseload of students with categorical disabilities and caseload of those with limited English proficiency. These characteristics were compared within the seven identified Workforce Development teaching areas and, to make further distinction from akin fields, were also collectively compared to the STEM education fields of science, technology, engineering, and mathematics education. Analysis of the identified characteristics provided a profile of in-service Workforce Development teachers, the students that they teach, how they compare to each other within CTE, and how they compare to other STEM teachers.
\end{abstract}

Keywords: Schools and Staffing Survey, limited English proficiency, Individuals with Disabilities Act (IDEA) disabilities, teacher characteristics

\section{INTRODUCTION}

The importance of Workforce Development classes cannot be understated. Workforce Development initiatives have well-defined linkages to innovation, global competitiveness, as well as economic development (Advance CTE, 2013). Further, Workforce Development courses have been revealed to advance student competencies, problem-solving abilities and STEM-associated knowledge and skills. Students taking Workforce Development classes are more likely to perform as well or better than those not in Workforce Development programs (Castellano,
James, Stringfield, Farley, \& Wayman, 2004). Students in Workforce Development programs have lower dropout rates and are more likely to receive higher wages than those not enrolled in Workforce Development programs (Kemple \& Scott-Clayton, 2004; Plank, DeLuca, \& Estacion, 2005).

Also noted advantages of Workforce Development include completion for specific subgroups of students from select socioeconomic and academic backgrounds (Ankeny \& Lehmann, 2010; Carter, Trainor, Sun, \& Owens, 2011; Palmer \& Gaunt, 2007; Wagner, Newman, \& Javitz, 2016). Workforce Development classes and programs are important components in the education of students from these special populations. Workforce Development special populations are defined as individuals with disabilities (ADA [American with Disabilities Act], ESEA[Elementary and Secondary Education Act] IDEA [Individuals with Disabilities Act]), economically disadvantaged students, single parents, displaced homemakers, students with limited English proficiency, migrant students, and students in nontraditional programs (Dortch, 2012; U.S. Department of Education, 2012). This study focused on individuals with disabilities as defined by the Individuals with Disabilities Education Act (2004) and students with limited English proficiency. These two groups comprised 24 percent of the special population for CTE in 2006 (Dortch, 2012).

Research has shown that Workforce Development classes and programs produce positive outcomes for individuals with disabilities. Enrollment in Workforce Development classes was found to be a positive predictor of employment and post-secondary education (Benz, Lindstrom, \& Yovanoff, 2000; Harvey, 2002; Sitlington \& Frank, 1990). Test, Mazzotti, Mustian, Fowler, Kortering, and Kohler (2009) found that Workforce Development enrollment was consistently predictive of the post-secondary outcomes of students with disabilities. Similarly, Haber, Mazzotti, Mustian, Rowe, Bartholomew, Test and Fowler (2016) discovered that Workforce Development enrollment was 
predictive of employment and that the component of inclusion was also an important factor in this outcome. Mazzotti, Rowe, Sinclair, Poppen, Woods, and Shearer (2016) supported the findings of Test et al., with Workforce Development enrollment and inclusion as being predictive of educational and employment outcomes.

Plasman and Gottfried (2016) observed that students with learning disabilities who took applied STEM courses significantly increased their educational outcomes, had lower dropout rates, increased math test scores, and increased their enrollment in post-secondary education. Gottfried, Bozick, Rose, and Moore (2016) found that Workforce Development experiences consisting of applied STEM courses and schoolbased experiential programs were inadequate for supporting students with disabilities through the STEM pipeline. However, it is apparent that CTE has a positive impact on individuals with disabilities.

Workforce Development classes are especially important to special populations because in many cases the classes are concentrated on developing skills for the workplace. Students that complete two years or more of a CTE cluster are also eligible to take an industry certification exam, which further prepares them with credentials for the workplace that reflect necessary skills to be ready for the job market. Many Workforce Development programs provide job placement, vocational, and basic skills training, which are especially important to students who will not go on to higher education.

Increased teacher training has been shown to be a factor in helping teachers better understand and teach students with disabilities and limited English proficiency (LEP). Workforce Development teachers can and often carry higher caseloads of students with IDEA disabilities that have individualized education plans (IEPs) and students with LEP than core academic teachers. In some situations, Workforce Development teachers can actually have higher caseloads of IEP students than special education teachers (Ernst \& Williams, 2015; Williams, Kaui, \& Ernst, 2015).

Avramidis, Bayliss, and Burden (2000) found that teachers who had better teacher training exhibited better and positive attitudes toward inclusion of special education students in their classroom and felt more confident to meet those students' needs. Samson and Lesaux (2009) demonstrated that an improved recognition and understanding of disabilities and LEP are required to best

fit students with their educational needs.

Further, Samson and Lesaux indicated that improved recognition and understanding could be attributed to access and participation in professional learning opportunities with a focus on assisting teachers in preparation to address unique learner needs.

Kahn and Lewis (2014) surveyed 1,088 K-12 science teachers to determine their level of preparedness to work with students who had disabilities. The results showed that nearly one third of the science teachers had not received training to teach students with disabilities. The majority of those who did indicate receiving such training stated that it was on-the-job training. Similarly, Guardino (2015) surveyed 264 teachers to determine their level of preparedness to work with students who had disabilities. Fifty-four percent reported feeling that their teacher preparation program had prepared them "slightly" to "not at all" to work with these students.

Teacher credentials and teacher professional development have an important impact for teachers working with students with disabilities or LEP. Numerous studies have indicated that there is a lack of preparedness to teach students with disabilities or LEP demonstrating a need for increased training for teachers with regards to special education and LEP. More research needs to be done on how to fill these gaps to improve educational outcomes for these populations.

Workforce Development educator credentialing can vary vastly by U.S. state and local education agency considering content area, relevant work experience, preparation, and so forth (Bartlett, 2002). These characteristics have not been collectively compiled and profiled in a comprehensive way within CTE. This results in a broad range of teacher background characteristics that are quite often thought of as dissimilar or inconsistent, specifically provided that the "information is not readily available, and can be confusing [among] states" (Bartlett, 2002, p. 109). Given the influential and important role that Workforce Development teachers serve, what exactly is the characteristic profile of practicing in-service Workforce Development teachers and the number of IEP and LEP students that they teach? Additionally, how do their credentials and caseloads compare to other STEM disciplines? 


\section{RESEARCH QUESTIONS}

The individualized nature of special education services and variations in the type and intensity of disabilities makes research on interventions and methods for students with disabilities that promote success in Workforce Development challenging. Similar issues exist with the instruction of students with LEP. We believe that that both Workforce Development and the field of special education could benefit tremendously from evidence built on rigorous data and descriptive analyses as it relates to the education of individuals with disabilities. We would also like to expand this idea to the provision of Workforce Development services to students with LEP. By providing an evidencebased accounting of in-service Workforce Development teachers who are working with students with disabilities and students with LEP, their qualifications to work with these students, and their actual caseloads, information could be obtained that would help Workforce Development leaders to better accommodate these students in the classroom and facilitate training for Workforce Development teachers. Workforce Development teachers could also benefit from examining how they compare to the other STEM fields in these areas.

Considering the absence of comprehensive categorical information associated with Workforce Development teacher backgrounds and characteristics, this investigation was launched in an effort to construct a national profile of these educators, the students that they teach, and how these educators compare to educators in other STEM areas. This research addressed the characteristics and qualifications of Workforce Development teachers across seven areas traditionally considered to represent CTE (Agricultural Education, Business \& Information Technology Education, Family \& Consumer Sciences Education, Health Science Education, Marketing Education, Technology \& Engineering Education, and Trade \& Industrial Education) who are preparing students for the 21 st century workforce. It also compared Workforce Development teachers to other STEM teachers. Specifically this research addressed the following questions:

1. What are the characteristics and credentials of Workforce Development teachers?

a. What is the gender, mean age, mean teaching experience and teaching status of Workforce Development teachers? b. What is the race and ethnicity of Workforce Development teachers?

c. What is the educational level of Workforce Development teachers?

d. What is the certification status of Workforce Development teachers?

e. What certification pathway is most prevalent among Workforce Development teachers (alternative or traditional)?

f. How do these characteristics compare to other STEM teachers?

2. What student population features and characteristics are identifiable within Workforce Development classrooms?

a. What is the mean number of students with categorical disabilities served for Workforce Development teachers?

b. What is the mean number of students with limited English proficiency (LEP) served for Workforce Development teachers?

c. What is the mean service load (sum of categorical and LEP) served for Workforce Development teachers?

d. How do these caseloads compare to other STEM teachers?

e. Are there statistically significant differences between Workforce Development teachers and other STEM teachers regarding service load, categorical disabilities, and LEP caseload?

\section{METHODOLOGY Participant Selection}

In this study, the participants who gave subjectmatter codes relating to Workforce Development for the survey question, "This school year, what is your MAIN teaching assignment field at THIS school?" were selected. Participants were placed in their respective disciplines according to the subject matter codes. Table 1 shows codes and descriptors that were used to group the Workforce Development teachers into seven distinct areas. This resulted in 133,480 instances within the weighted results for all Workforce Development teachers with the following breakdown: Agriculture Education (n $=12,220)$; Business and Information Technology 
Education ( $n=19,160)$; Family and Consumer Sciences Education $(n=33,110)$; Health Science Education ( $n=7,490)$; Marketing Education $(n=$ 6,690); Technology and Engineering Education $(n=46,600)$; and Trade and Industrial Education $(n=8,210)$.

The category of STEM teachers consisted of those teachers who responded to teaching science and math. Teachers who responded with codes $211,212,213,217$, or 218 (biology or life sciences, chemistry, earth sciences, physics, and other natural sciences) were identified as science teachers. Teachers who responded with codes 191, 192, 193, 194, 195, 196, 198, 199, 200, or 201 (algebra I, algebra II, algebra III, basic and general mathematics, business and applied math, calculus and pre-calculus, geometry, pre-algebra, statistics and probability, and trigonometry) were identified as mathematics teachers. The weighted $n$ for science teachers was 226,700 and the weighted $n$ for math teachers was 281,990.

Table 1: Schools and Staffing Survey Teacher Questionnaire codes and descriptors for Workforce Development main teaching assignment.

\begin{tabular}{|c|c|c|}
\hline $\begin{array}{l}\text { Workforce } \\
\text { Development Area }\end{array}$ & Code & Description \\
\hline Agricultural Education & 241 & Agriculture and natural resources \\
\hline Business \& Information & 242 & Business management \\
\hline Technology Education & 243 & Business support \\
\hline \multirow[t]{2}{*}{$\begin{array}{l}\text { Family \& Consumer } \\
\text { Sciences Education }\end{array}$} & 253 & $\begin{array}{l}\text { Personal and public services (including culinary } \\
\text { arts, cosmetology, child care, social work, } \\
\text { protective services, custodial services, and interior } \\
\text { design) }\end{array}$ \\
\hline & 254 & Family and consumer sciences education \\
\hline Health Science Education & 245 & Healthcare occupations \\
\hline Marketing Education & 244 & Marketing and distribution \\
\hline \multirow[t]{3}{*}{$\begin{array}{l}\text { Technology \& Engineering } \\
\text { Education }\end{array}$} & 246 & $\begin{array}{l}\text { Construction trades, engineering, or science } \\
\text { technologies (including CADD and drafting) }\end{array}$ \\
\hline & 250 & Communications and related technologies \\
\hline & 255 & Industrial arts or technology education \\
\hline \multirow{2}{*}{$\begin{array}{l}\text { Trade \& Industrial } \\
\text { Education }\end{array}$} & 247 & Mechanics and repair \\
\hline & 249 & $\begin{array}{l}\text { Manufacturing or precision production } \\
\text { (electronics, metalwork, textiles, etc.) }\end{array}$ \\
\hline
\end{tabular}

\section{Instrumentation}

This study used data from the most recent Schools and Staffing Survey (SASS) conducted the National Center for Educational Statistics and administered by the Institute for Education Sciences. The SASS consists of five questionnaires: A School District Questionnaire, Principal Questionnaire, School Questionnaire, Teacher Questionnaire, and a School Library Media Center Questionnaire. According to Tourkin, Thomas, Swaim, Cox, Parmer, Jackson, Cole, and Zhang, (2010, p. 1):

The Schools and Staffing Survey (SASS) is conducted by the National Center for
Education Statistics (NCES) on behalf of the U.S. Department of Education in order to collect extensive data on American public and private elementary and secondary schools. SASS provides data on the characteristics and qualifications of teachers and principals, teacher hiring practices, professional development, class size, and other conditions in schools across the nation. The overall objective of SASS is to collect the information necessary for a comprehensive picture of elementary and secondary education in the United States. The SASS was designed 
to produce national, regional, and state estimates for public elementary and secondary schools and related components and is an excellent resource for analysis and reporting on elementary and secondary educational issues.

\section{Variables Analyzed}

Demographic variables analyzed included gender, age, race and ethnicity. Variables related to both qualifications and status were also analyzed. These included total years of teaching experience, employment status, certification route, certification status, and the highest educational level obtained. In addition, variables related to caseload were examined. This included the number of students with IDEA disabilities who required an individualized education plan, the number of students with limited English proficiency (LEP), and the service load of at-risk students with categorized disabilities and LEP.

\section{Procedure}

This study consisted of a secondary analysis of the most recent SASS TQ restricted-use license dataset. Specified Institute for Education Sciences (IES) reporting protocols were followed and data findings were submitted to the IES for approval and authorization for release.

Data were analyzed using SPSS 23.0 and AM Statistical Software. Data for the descriptive analyses were weighted using the Teacher Final Sampling Weight variable (TFNLWGT). The 88 SASS TQ supplied replicate weight variables (TREPWT1-TREPWT88) were used in the mean score comparisons to weight the data using a balanced repeating replication procedure as suggested by IES. Data for descriptive analyses were compared within the seven Workforce Development teacher areas and collectively to the population of STEM teachers. T-tests were used to determine whether there were statistically significant differences for Workforce Development teachers collectively when compared to other STEM teachers.

AM Software suggested that probability levels of $p<.016$ were deemed to be statistically significant with the weighted sample. All $n$ 's and degrees of freedom were rounded to the nearest 10 to assure anonymity per NCES and IES requirements and data in the tables may not add to the total $\mathrm{N}$ initially reported as there may be rounding adjustments. When any estimates did not meet the NCES or IES reporting protocols, they were not reported in the tables and were noted with an asterisk. (Dinkes, Cataldi \& LinKelly, 2007; Robers, Kemp, Rathbun, \& Morgan, 2014).

\section{RESULTS}

\section{Gender, Age, Teaching Experience, and Employment Status}

Demographic information concerning teacher gender, age, teaching experience and teaching status is presented in Table 2. In most cases, across the Workforce Development areas, there was a wide range of variability in all the variables investigated. The Workforce Development field of Marketing Education had the most equal representation of male $(45.5 \%)$ and female $(54.5 \%)$ teachers. Trade and Industrial Education was the most skewed toward male teachers $(96.5 \%)$ and Family and Consumer Sciences Education toward female teachers $(90.2 \%)$.

The mean age for the groups ranged from 37.54 to 48.05 years, with Trade and Industrial Education and Family and Consumer Sciences Education teachers having the highest mean age of approximately 48 years. Agricultural Education teachers had the lowest mean age of approximately 37 years. Mean years of teaching experience ranged from 10.64 years to 16.24 years, with Family and Consumer Sciences Education having the highest experience and Health Science Education the lowest. The full-time status of Workforce Development teachers ranged from $91.8 \%$ to $99.3 \%$ being reported as full-time teachers, with Technology and Engineering Education having the lowest reported percentage and Marketing Education having the highest reported percentage.

Overall, the gender makeup appears to be skewed with direction based primarily on the Workforce Development area selected, with Marketing Education being the exception as the most equally represented. The mean age and mean experience seem to suggest that the teachers are mid-career both in terms of working life expectancy and work experience. In addition, approximately $92 \%$ or more Workforce Development teachers are employed as fulltime teachers. Compared to science and math teachers, Workforce Development teachers had a higher percentage of male teachers. Workforce Development teachers tended to be older than math and science teachers and possess more teaching experience than science teachers, but they had less experience compared to math teachers. Workforce Development teachers also had the lowest percentage of full-time teachers of the three areas. 
Table 2: Workforce Development teachers' gender, mean age, mean teaching experience, and status compared to science and math teachers as reported on the Schools and Staffing Survey Teacher Questionnaire.

\begin{tabular}{|l|c|c|c|c|c|}
\hline $\begin{array}{l}\text { Agricultural } \\
\text { Education }\end{array}$ & Male & Female & Age & Experience & Full-time Status \\
\hline $\begin{array}{l}\text { Business \& } \\
\text { Information } \\
\text { Technology } \\
\text { Education }\end{array}$ & 30.8 & 69.4 & 37.54 & 12.39 & 96.9 \\
\hline $\begin{array}{l}\text { Family \& } \\
\text { Consumer } \\
\text { Sciences } \\
\text { Education }\end{array}$ & 9.8 & 90.2 & 48.02 & 16.24 & 94.5 \\
\hline $\begin{array}{l}\text { Health Science } \\
\text { Education }\end{array}$ & 19.6 & 80.4 & 46.80 & 10.64 & 93.0 \\
\hline $\begin{array}{l}\text { Marketing } \\
\text { Education }\end{array}$ & 45.5 & 54.5 & 42.38 & 13.05 & 91.9 \\
\hline $\begin{array}{l}\text { Technology \& } \\
\text { Engineering } \\
\text { Education }\end{array}$ & 73.7 & 26.3 & 46.51 & 15.40 & 99.3 \\
\hline $\begin{array}{l}\text { Trade \& Industrial } \\
\text { Education }\end{array}$ & 96.5 & 3.5 & 48.05 & 14.24 & 98.0 \\
\hline $\begin{array}{l}\text { Workforce } \\
\text { Development }\end{array}$ & 47.4 & 52.6 & 45.53 & 13.01 & 93.4 \\
\hline Science & 38.2 & 61.8 & 41.63 & 12.75 & 97.5 \\
\hline Math & 34.8 & 65.2 & 41.00 & 14.54 & 96.9 \\
\hline
\end{tabular}

Note. Male, Female and Full-time statuses are reported in percentages. Age and Experience are reported in years.

\section{Race and Ethnicity}

Teachers' own reports of their race is found in Table 3. This information was collected through the survey and was reported for the purposes of establishing a demographical make-up of Workforce Development teachers. Racial category descriptors are presented verbatim as they appeared on the SASS TQ survey. Participants were allowed to make more than one selection. As noted, data for certain descriptors did not meet IES and NCES reporting standards and were not presented in the tables.

Concerning Hispanic or Latino descent, the valid percentage ranged from a low of 0.3 percent to a high of 6.4 percent with Agricultural Education reporting the lowest percentage and Technology and Engineering Education reporting the highest percentage. With regard to the racial categories teachers self-selected, White was the most prevalent racial category chosen with percentages ranging from a low of $78.4 \%$ in Marketing Education to a high of $94.1 \%$ in Agricultural Education. Black or African-American was the next most prevalent category chosen. Percentages ranged from a low of 3.0 percent for Agriculture Education to a high of $14.1 \%$ for Marketing Education. The category of American Indian or Alaskan Native ranged from $0.3 \%$ for Business \& Information Technology Education to approximately $5 \%$ for Health Science Education and Trade \& Industrial Education. Data for Native Hawaiian or Other Pacific Islanders had sufficiently low unweighted $n$ 's that the data did not meet IES reporting standards.

Clearly the two most prevalent self-selected racial categories represented in Workforce Development are White and Black or AfricanAmerican, and, in most cases, represented over $90 \%$ of the variability in the racial categories. Asian, American Indian or Alaskan Native, and Native Hawaiian or Other Pacific Islanders were the least prevalent self-selected racial categories and the least represented in all the Workforce 
Table 3: Percentage of Workforce Development teachers' self-reported racial and ethnic categories from the Schools and Staffing Survey Teacher Questionnaire compared to science and math teachers.

\begin{tabular}{|c|c|c|c|c|c|c|}
\hline & Hispanic & White & $\begin{array}{l}\text { Black or } \\
\text { African- } \\
\text { American }\end{array}$ & Asian & $\begin{array}{c}\text { Native } \\
\text { Hawailian } \\
\text { or Other } \\
\text { Pacific } \\
\text { Islander }\end{array}$ & $\begin{array}{c}\text { American } \\
\text { Indian or } \\
\text { Alaska } \\
\text { Native }\end{array}$ \\
\hline Agricultural Education & 0.3 & 94.1 & 3.0 & 0.5 & * & 1.9 \\
\hline $\begin{array}{l}\text { Business \& Information } \\
\text { Technology Education }\end{array}$ & 4.9 & 85.3 & 7.8 & 0.6 & * & 0.3 \\
\hline $\begin{array}{l}\text { Family \& Consumer } \\
\text { Sciences Education }\end{array}$ & 2.4 & 84.1 & 9.3 & 0.4 & * & 1.1 \\
\hline $\begin{array}{l}\text { Health Science } \\
\text { Education }\end{array}$ & 0.9 & 88.5 & 5.1 & * & * & 4.6 \\
\hline Marketing Education & * & 78.4 & 14.1 & * & * & 1.2 \\
\hline $\begin{array}{l}\text { Technology \& } \\
\text { Engineering Education }\end{array}$ & 6.4 & 85.1 & 4.0 & 1.7 & * & * \\
\hline $\begin{array}{l}\text { Trade \& Industrial } \\
\text { Education }\end{array}$ & 5.3 & 83.2 & 5.2 & * & * & 4.9 \\
\hline Workforce Development & 3.9 & 84.7 & 6.7 & 1.2 & 0.1 & 1.3 \\
\hline Science & 5.6 & 82.6 & 6.1 & 3.3 & 0.2 & 0.5 \\
\hline Math & 6.5 & 80.7 & 7.7 & 3.8 & 0.1 & 0.4 \\
\hline
\end{tabular}

Note. Descriptors were taken directly from the SASS TQ. Percentages may not add to 100 percent because respondents were allowed to choose multiple categories. * Did not meet IES reporting requirements.

Development categories. Collectively speaking, Workforce Development had the highest level of White teachers and the lowest level of Hispanic teachers when these were compared to science and math teachers.

\section{Level of Education}

Table 4 shows the highest level of education that was reported for each Workforce Development area. It should be noted that only the highest degree obtained is reported. It does not include the reporting of multiple or similar degrees. The highest percentage group reporting a Bachelor's degrees or less was Trade and Industrial Education (79.6\%). It was followed closely by Health Science Education (62.4\%) and Agricultural Education (62.0\%). The highest percentage reporting a Master's degree or higher was Business and Information Technology Education (55.6\%). The highest level of education obtained appeared to be largely determined by the Workforce Development area chosen and the licensure requirements for that area. Collectively, Workforce Development had the least amount of educators with a master's degree or higher when compared to math and science.

\section{Certification Status, Route, and Qualification Status}

In Table 5 the certification status, certification route, and qualification status of Workforce Development teachers is shown. The percentage of Workforce Development teachers with regular or standard state certification ranges from a low of $72 \%$ for Health Science Education to a high of $94.3 \%$ for Marketing Education. The number of Workforce Development teachers being certified through alternative licensure programs ranged from a low of seven percent for Agriculture Education to a high $72.6 \%$ for Health Science Education. However, there was a large degree of variability in the certification routes for Workforce Development teachers depending upon the content area. Collectively, Workforce Development teachers had the lowest level of regular or standard state certification and the highest level of alternative certification when compared to science and math teachers. 
Table 4: Percentage of Workforce Development teachers' highest degree obtained

compared to science and math teachers on the Schools and Staffing Survey Teacher

Questionnaire.

\begin{tabular}{|c|c|c|c|c|}
\hline & $\begin{array}{l}\text { Bachelors } \\
\text { or less }\end{array}$ & Masters & $\begin{array}{l}\text { Educational } \\
\text { Specialist }\end{array}$ & Doctorate \\
\hline $\begin{array}{l}\text { Agricultural Education } \\
\text { Business \& Information }\end{array}$ & 62.0 & 28.1 & 7.3 & * \\
\hline Technology Education & 36.1 & 55.6 & 7.4 & * \\
\hline $\begin{array}{l}\text { Family \& Consumer } \\
\text { Sciences Education }\end{array}$ & 53.8 & 41.2 & 4.3 & * \\
\hline Health Science Education & 62.4 & 28.7 & 3.1 & * \\
\hline $\begin{array}{l}\text { Marketing Education } \\
\text { Technology \& } \\
\text { Enqineering Education }\end{array}$ & $\begin{array}{l}37.3 \\
52.6\end{array}$ & $\begin{array}{l}43.9 \\
41.5\end{array}$ & $\begin{array}{l}9.5 \\
4.9\end{array}$ & $\begin{array}{l}9.3 \\
*\end{array}$ \\
\hline $\begin{array}{l}\text { Trade \& Industrial } \\
\text { Education }\end{array}$ & 79.6 & 18.4 & * & * \\
\hline Workforce Development & 51.7 & 41.3 & 5.5 & 1.3 \\
\hline Science & 41.3 & 49.4 & 6.5 & 2.8 \\
\hline Math & 43.2 & 50.1 & 5.5 & 1.6 \\
\hline
\end{tabular}

Note. * Did not meet IES reporting requirements.

Table 5: Percentage of Workforce Development teachers' certification, career path entry, and qualification status compared to science and math teachers as reported on the Schools and Staffing Survey Teacher Questionnaire.

\begin{tabular}{|l|c|c|c|}
\hline & $\begin{array}{c}\text { Regular or } \\
\text { standard state } \\
\text { certificate }\end{array}$ & $\begin{array}{c}\text { Alternative } \\
\text { certification } \\
\text { program }\end{array}$ & $\begin{array}{c}\text { Traditional } \\
\text { certification } \\
\text { program }\end{array}$ \\
\hline Agricultural Education & 92.6 & 7.0 & 93.0 \\
\hline $\begin{array}{l}\text { Business \& Information } \\
\text { Technology Education }\end{array}$ & 88.5 & 24.8 & 75.2 \\
$\begin{array}{l}\text { Family \& Consumer } \\
\text { Sciences Education }\end{array}$ & 88.4 & 19.6 & 80.4 \\
Health Science Education & 72.0 & 72.6 & 27.4 \\
Marketing Education & 94.3 & 43.1 & 56.9 \\
Technology \& Engineering & 86.1 & 21.6 & 78.4 \\
Education & 81.9 & 38.6 & 61.4 \\
Trade \& Industrial & 86.5 & 26.0 & 74.0 \\
Education & 91.2 & 25.3 & 74.7 \\
Workforce Development & 89.8 & 17.8 & 82.2 \\
\hline Science & & & \\
Math & &
\end{tabular}




\section{Caseload}

Regarding students with categorized disabilities, Technology and Engineering Education reported the highest mean number of students with categorized disabilities with approximately 19 students on their caseload. Health and Science Education reported the lowest number of students with categorized disabilities with a mean caseload of approximately seven students. The mean number of student with LEP served by Workforce Development teachers ranged from a low of two for Marketing Education to a high of nine for Trade and Industrial Education. The mean service load of Workforce Development teachers, which was the combination of students with categorical disabilities and LEP, ranged from a low of nine for Health and Science Education to a high of 27 for Technology and Engineering Education. Table 6 shows the caseloads for all areas.
With regard to student caseload, there is a large amount of variability within Workforce Development across the total number of students taught, the number of students with disabilities taught, and number of LEP students taught and the combined service load. Some areas have a much higher overall caseload of students, while others have considerably more students with categorized disabilities and LEP. Collectively, Workforce Development had a higher overall special population load than science or math teachers.

\section{Statistically Significant Differences in Caseloads}

With regard to differences across measures of caseload, there was a wide range of variability within the seven areas of Workforce Development and when they were collectively compared to science and math teachers. Within

Table 6: Workforce Development teachers' mean caseloads compared to science and math teachers on the as reported on the Schools and Staffing Survey Teacher Questionnaire.

\begin{tabular}{|l|c|c|c|} 
& Categorical & LEP & $\begin{array}{c}\text { Service } \\
\text { Load }\end{array}$ \\
\hline Agricultural Education & $\begin{array}{c}13.74 \\
(0.88)\end{array}$ & $\begin{array}{c}2.84 \\
(0.90)\end{array}$ & $\begin{array}{c}16.58 \\
(1.26)\end{array}$ \\
\hline Business \& Information Technology Education & $\begin{array}{c}14.05 \\
(1.23)\end{array}$ & $\begin{array}{c}14.05 \\
(1.23)\end{array}$ & $\begin{array}{c}14.05 \\
(1.23)\end{array}$ \\
\hline Family \& Consumer Sciences Education & $\begin{array}{c}16.03 \\
(1.09)\end{array}$ & $\begin{array}{c}4.77 \\
(0.59)\end{array}$ & $\begin{array}{c}20.80 \\
(1.45)\end{array}$ \\
\hline Health Science Education & 7.24 & 2.25 & 9.49 \\
& $(1.34)$ & $(0.56)$ & $(1.68)$ \\
\hline Marketing Education & $\begin{array}{c}10.86 \\
(1.94)\end{array}$ & $\begin{array}{c}2.31 \\
(0.85)\end{array}$ & $\begin{array}{c}13.17 \\
(2.25)\end{array}$ \\
\hline Technology \& Engineering Education & $\begin{array}{c}19.39 \\
(1.80)\end{array}$ & $\begin{array}{c}7.16 \\
(1.14)\end{array}$ & $\begin{array}{l}26.54 \\
(2.14)\end{array}$ \\
\hline Trade \& Industrial Education & $\begin{array}{c}15.01 \\
(3.12)\end{array}$ & $\begin{array}{c}8.99 \\
(3.49)\end{array}$ & $\begin{array}{l}24.00 \\
(5.95)\end{array}$ \\
\hline Workforce Development & 15.78 & 5.28 & 20.93 \\
& $(0.72)$ & $(0.46)$ & $(0.93)$ \\
\hline Science & 13.35 & 7.10 & 20.50 \\
& $(0.52)$ & $(0.52)$ & $(0.82)$ \\
\hline Math & $\begin{array}{c}9.84 \\
(0.32)\end{array}$ & $\begin{array}{c}5.58 \\
(0.38)\end{array}$ & $\begin{array}{l}15.81 \\
(0.57)\end{array}$ \\
\hline
\end{tabular}

Note. Categorical are students with disabilities with individualized education programs. LEP is limited English proficiency. Service Load is the sum of Categorical and LEP. Standard error is in parentheses. 
Workforce Development, there was a large degree of variability within each group. Some areas of Workforce Development teachers had more students with categorical, LEP, and at-risk than others. Collectively, Workforce Development had a statically significant higher load of students with categorical disabilities than math and science, a statically significantly lower load of students with LEP than Science, and a statistically significantly higher number of students at-risk than math.

\section{Categorical Service Load}

The categorical service load is the number of students taught with IEPs. In terms of absolute numbers, Workforce Development teachers had the highest mean number of students with categorical disabilities and math teachers had the lowest. When compared, Workforce Development teachers $(M=21.06, S D=18.53)$ had a statistically significantly higher number of students with categorized disabilities than did math teachers $(M=9.84, S D=10.57)$; $t(90)=$ $7.52, p=0$ and a statically significantly higher number than did science teachers $(M=13.41, S D$ $=14.26) ; t(90)=2.81, p<.01$. Science teachers $(M=13.41, S D=14.26)$ also had a statistically significantly higher number of students with categorized disabilities than did math teachers $(M=9.84, S D=10.57) ; t(90)=5.41, p=0$.

\section{LEP Service Load}

LEP service load is the number of students with limited English proficiency taught. Science teachers had the highest number of students while LEP and Workforce Development teachers had the lowest. Science teachers $(M=7.10, S D$

$=15.89$ ) had statically significantly more students with LEP than did Workforce Development teachers $(M=5.28, S D=14.17) ; t(90)=-2.70$, $p<.01$ but with no statistically significant differences with math teachers $(M=5.98, S D$ $=12.90) ; t(90)=1.77, p<.08$. There was also no statistically significant difference found on the number of students with LEP between Workforce Development teachers $(M=5.28, S D=14.17)$ and math teachers $(M=5.98, S D=12.90) ; t(90)$ $=-1.23, p=.22$.

\section{At-risk Service Load}

At-risk service load was the sum of students with categorized disabilities and students with LEP. Workforce Development teachers had the highest number of students labeled at-risk and math teachers had the lowest. Collectively, Workforce Development teachers had a statically significantly higher service load of students labeled at-risk than did math teachers. There was a statistically significant difference in the scores for Workforce Development teachers $(M=21.6, S D=23.9)$ and math teachers $(M=$ $15.81, S D=17.83) ; t(90)=4.91, p=0$. There was also a statistically significant difference for science teachers $(M=20.50, S D=23.94)$ and math teachers $(M=15.81, S D=17.83) ; t(90)=$ $4.34, p=0$. There were no statistically significant differences in service load between Workforce Development teachers $(M=21.6, S D=23.9)$ and science teachers $(M=20.50, S D=23.94)$; $t(90)=0.45, p=0.66$. It appears that of the three areas, Workforce Development teachers and science teachers have a comparable caseload of students labeled at-risk and that both have a statistically significantly higher caseload of atrisk students than did math teachers.

\section{CONCLUSION}

Because Workforce Development teachers represent such a wide range of content areas, the researchers suspected that there might be a high degree of variability within the seven Workforce Development areas examined. This was confirmed. The characteristics of Workforce Development teachers varied across the fields represented and the variables analyzed. Some areas tended to have more teacher diversity related to race and gender. Others had more teaching experience and percentages of Master's degrees. Within Workforce Development, the caseloads of students varied greatly and Workforce Development was shown to be a diverse field regarding teachers' characteristics and credentials.

Collectively speaking, Workforce Development was similar to the STEM fields of math and science pertaining to teachers' race. However, Workforce Development had a higher ratio of females to males than did teachers of math and science. Workforce Development teachers were older and more experienced than math and science teachers. They did, however, have a lower percentage of teachers with Master's degrees or higher and were slightly less likely to be fully certified than their math and science peers. A higher percentage of Workforce Development teachers also entered the teaching field through alternative certification programs than did either math or science teachers. Both Workforce Development and science teachers had statically significantly higher IEP and LEP caseloads than did math teachers.

Maintaining the ability to access and compile teacher characteristic and student population 
information is important as future credentialing and service initiatives are contingent upon such facts. In structuring future programming for teacher learning, Workforce Development curricula, student transition opportunities, and other student and/or teacher initiatives, actual needs of the population of interest can be factored. For example, if a professional development workshop is offered to a group of Technology and Engineering Educators, the prevalent student subgroups of LEP and students with categorical disabilities may warrant focus.

Characteristic data not only enhances teacher development and professional continuation programming, but it also builds capacity for informed and purposeful evidence-based decision making. The possibilities are quite abundant: enrollment patterns and trajectories can be forecasted to allocate adequate resource and space, population characteristics can be tracked to promote further equity in access to courses, and so forth. Aside from the possibilities of projecting and structuring timely support mechanisms, characteristic information enables the identification of current deficiencies, surplus, and need. These considerations span far beyond the local and regional levels, as Workforce Development teachers now prepare individuals for a global economy and workforce where the implications of successes and failures of student preparation are prospectively global. The future workforce plays an immensely important part in driving innovation and economic growth (Committee on Prospering in the Global Economy of the 21 st Century, 2007). "As economies have developed in wealth and complexity since the industrial revolution, [skilled] workers have grown in relative importance as a share of the labor market, and [associated] skills are widely needed across a ... variety of blue-collar, craft, and profes $\neg$ sional occupations (Rothwell, 2014, p. 2)." Accessible Workforce Development programming, supported by high-caliber professional educators, can contribute not only to a healthy and sustainable economy (Gabe, 2009) but also to high satisfaction, reward, and quality of life, especially for students with categorical disabilities and LEP.
Declaration of conflicting interests. The authors have no conflicting interests.

Dr. Thomas O. Williams, Jr. is an Associate Professor in Special Education in the School of Education at Virginia Polytechnic Institute and State University, Blacksburg.

\section{Dr. Jeremy V. Ernst is Associate Dean for Research and Professor in the College of Arts and Sciences at Embry-Riddle Aeronautical University's Worldwide Campus. He is a member of the Gamma Tau Chapter of Epsilon Pi Tau.}

Dr. Aaron C. Clark is a Professor and Director of Graduate Programs for the Department of STEM Education within the College of Education at North Carolina State University, Raleigh. He is a member of the Alpha Pi Chapter of Epsilon Pi Tau. 
Advance CTE. (2013). CTE is your STEM strategy. Silver Spring, MD: Career Tech. Retrieved November 16, 2016 from https://careertech.org/sites/default/files/CTEYourSTEMStrategyFINAL.pdf

Ankeny, E. M., \& Lehmann, J. P. (2010). Journey toward self-determination: Voices of students with disabilities who participated in a secondary transition program on a community college campus. Remedial and Special Education, 32(1), 279-289.

Avaramidis, E., Bayliss, P., \& Burden, R. (2000). A survey into mainstream teachers' attitudes towards the inclusion of children with special educational needs in the ordinary school in one local education authority. Educational Psychology, 20(2), 191-211. doi:10.1080/713663717

Bartlett, J. E. (2002). Preparing, licensing, and certifying post-secondary Career and Technical Educators. Journal of Vocational Education Research, 27(1), 109-130.

Benz, M. R., Lindstrom, L., \& Yovanoff, P. (2000). Improving graduation and employment outcomes of students with disabilities: Predictive factors and student perspectives. Exceptional Children, 66(4), 509-529.

Carter, E. W., Trainor, A. A., Sun, Y., \& Owens, L. (2011). Assessing the transition-related strengths and needs of adolescents with high-incidence disabilities. Exceptional Children, 76(1), 74-94.

Castellano, M., James III, R., Stringfield, S., Farley, E. N., \& Wayman, J. C. (2004). The Effect of CTE-Enhanced Whole-School Reform on Student Course taking and Performance in English and Science. National Research Center for Career and Technical Education.

Dinkes, R., Cataldi, E. F., \& Lin-Kelly, W. (2007). Indicators of School Crime and Safety: 2007 (NCES 2008-021/NCJ 219553). National Center for Education Statistics, Institute of Education Sciences, U.S. Department of Education, and Bureau of Justice Statistics, Office of Justice Programs, U.S. Department of Justice. Washington, DC.

Dortch, C. (2012). Carl D. Perkins Career and Technical Education Act of 2006: Background and Performance. Congressional Research Service 7-5700. Retrieved from https://fas.org/sgp/crs/misc/ R42863.pdf

Ernst, J.V., \& Williams, T.O. (2015). The "who, what, and how conversation": Characteristics and responsibilities of current in-service technology and engineering educators. Journal of Technology Studies (41)1, 48-56.

Gabe, T. (2009). Knowledge and earnings. Journal of Regional Science, 49(3), 439-457.

Gottfried, M. A., Bozick, R., Rose, E., \& Moore, R. (2016). Does career and technical education strengthen the STEM pipeline? Comparing students with and without disabilities. Journal of Disability Policy Studies, 26(4), 232-244.

Guardino, C. (2015). Evaluating teachers' preparedness to work with students who are deaf and hard of hearing with disabilities. American Annals of the Deaf, 160(4), 415-426. doi:10.1353/ aad.2015.0030

Haber, M. G., Mazzotti, V. L., Mustian, A. L., Rowe, D. A., Bartholomew, A. L., Test, D. W. \& Fowler, C. H. (2016). What works, when, for whom, and with whom: A meta-analytic review of predictors of post-secondary success for students with disabilities. Review of Educational Research, 86(1), pp.123-162. 
Harvey, M. W. (2002). Comparison of post-secondary transitional outcomes between students with and without disabilities by secondary vocational education participation: Findings from the national education longitudinal study. Career Development for Exceptional Individuals, 25(2), 99-122.

Individuals With Disabilities Education Act, 20 U.S.C. § 1400 (2004).

Kahn, S., \& Lewis, A. (2014). Survey on teaching science to K-12 students with disabilities: Teacher preparedness and attitudes. Journal of Science Teacher Education, 25(8), 885-910. doi: 10.1007/ s10972-014-9406-z

Kemple, J. J., \& Scott-Clayton, J. (2004). Career academies: Impacts on labor market outcomes and educational attainment. New York, NY: MDRC.

Mazzotti, V. L., Rowe, D. R., Sinclair, J., Poppen, M., Woods, W. E., \& Shearer, M. L. (2016, November). Predictors of post-school success: A systematic review of NLTS2 secondary analyses. Career Development and Transition for Exceptional Individuals, 39(4), 196-215.

Palmer, L. B., \& Gaunt, D. (2007). Current profile of CTE and non-CTE students: Who are we serving. Journal of Career and Technical Education, 23(1), 35-43.

Plank, S., DeLuca, S., \& Estacion, A. (2005). Dropping out of high school and the place of career and technical education: A survival analysis of surviving high school. St. Paul, MN: National Research Center for Career and Technical Education.

Plasman, J. S., \& Gottfried, M. A. (2016). Applied STEM coursework, high school dropout rates, and students with learning disabilities. Educational Policy. doi: 0895904816673738.

Robers, S., Kemp, J., Rathbun, A., \& Morgan, R. E. (2014). Indicators of School Crime and Safety: 2013 (NCES 2014-042/NCJ 243299). National Center for Education Statistics, U.S. Department of Education, and Bureau of Justice Statistics, Office of Justice Programs, U.S. Department of Justice. Washington, DC.

Rothwell, J. (2014). Still searching: Job vacancies and STEM skills. Brookings Institute: Washington, DC.

Samson, J. F., \& Lesaux, N. K. (2009). Language minority learners in special education: Rates and predictors of identification for services, Journal of Learning Disabilities, 42, 148-162. doi: $10.1177 / 0022219408326221$.

Sitlington, P. L., \& Frank, A. R. (1990). Are adolescents with learning disabilities successfully crossing the bridge into adult life? Learning Disability Quarterly, 13(2), 97-111.

Test, D. W., Mazzotti, V. L., Mustian, A. L., Fowler, C. H., Kortering, L., \& Kohler, P. (2009). Evidence based secondary transition predictors for improving post school outcomes for students with disabilities. Career Development for Exceptional Individuals, 32(3), 160-181.

Tourkin, S., Thomas, T., Swaim, N., Cox, S., Parmer, R., Jackson, B., Cole, C., \& Zhang, B. (2010). Documentation for the 2007-08 Schools and Staffing Survey (NCES 2010-332). U.S. Department of Education. Washington, DC: National Center for Education Statistics. Retrieved June 17, 2014 from http://nces.ed.gov/pubsearch

U.S. Department of Education (2012), Office of Vocational and Adult Education, Carl D. Perkins Career and Technical Education Act of 2006, Report to Congress on State Performance, Program Year 2008-09, Washington, D.C., 2012. 
Wagner, M. M., Newman, L. A., \& Javitz, H. S. (2016). The benefits of high school career and technical education (CTE) for youth with learning disabilities. Journal of Learning Disabilities, 49(6), 658-670.

Williams, T. O., Kaui, T., \& Ernst, J. V. (2015). Special populations at risk of dropping out of school: A discipline-based analysis of STEM educators. Journal of STEM Education: Innovations and Research, 16(1), 38-42.

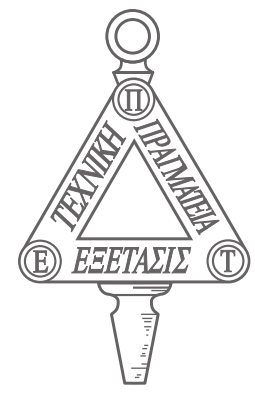




\title{
Evolving Characteristics of Today's Applied Engineering College-Level Educator: 2013 to 2017
}

\author{
By Jeffrey M. Ulmer
}

\section{ABSTRACT}

This manuscript was created to document faculty, and academic support, issues from 2013 to 2017. The 2013 manuscript was published by the Journal of Technology Studies. This four-years-later study provided greater insight for academics that asked the research question: "What is the latest in our teaching career field?" Issues of concern to faculty included positional status (adjunct, contract, tenure-track, tenure), faculty rank, length of time in current rank, length of time in nonacademic professional work (before or after academic work), primary academic program, total number of students taught per semester, average academic salary, contract length, administrative duties and salary benefits. Other issues included academic professional accreditation, degree levels offered, market pay (competitive) presence, academic freedom, benefits cost of coverage (health insurance, life insurance, etc.), the use of faculty talent, the management of teaching assignments, and the number of credit hours taught per semester. Finally, questions about the percentage of teaching load (face-to-face, hybrid, and online), the ease of resource and support acquisition, expectations for research (scholarship), unique ways that an academic institution compensates beyond the base salary, expectations for promotion and tenure, and additional comments pertinent to an academic's role in academia. In the 2013 study, 244 people (from 39 states) participated (only 212 responses were valid). This number dropped to 103 people from 27 states in 2017 (only 90 responses were valid). Although the survey population was smaller for 2017, the number of respondents was determined to be sufficient for reporting to other academics in a publication. Significant results in the study from 2013 to 2017 included an increase from 63.86 to 74.45 students taught per semester and a faculty salary mean change from $\$ 73,567$ to $\$ 77,306$ per year. Other survey indicators presented minimal change from 2013 to 2017.

Keywords: Higher Education, Professional Development

\section{INTRODUCTION}

Education is undergoing substantial transformation in order to meet the current (and urgent) low-cost mandate of today's public, postsecondary education institutions, and politicians. The purpose of this article is to compare survey results from the Winter of 2013 study, to the Winter of 2017 study. Results from the Winter of 2013 survey (the article was titled: "Characteristics of Today's Applied Engineering College-Level Educator") were published in Volume XL, Number 1, Spring 2014 of The Journal of Technology Studies. In this study, effort was put forth to share a baseline four year later of educator facts in the following areas: salaries, technological advancement, professional experience, course loads, class sizes, globalization, and lack of advancement opportunities. This survey (Winter of 2017) is a duplication of the Winter 2013 survey in order to collect updated information of educators from the postsecondary applied engineering/ technology programs and institutions across the United States of America. The purpose, and justification, for the repeat of this study was to help educators understand how their career choice of teaching has evolved in only four years. It was also hopeful that meaningful trends could be drawn on issues of most concern to faculty.

Little has changed in the literature review from the Winter of 2013 to the Winter of 2017 relating to the demands placed upon educators. Shortages of well-trained and well-prepared faculty are still a concern as well as are low salaries and salary compression. Although while the Bureau of Labor Statistics (BLS) projected a postsecondary teacher growth at $17 \%$ from 2010 to 2020 (in the 2010 citation), the renewed BLS (2016) projection has decreased to $13 \%$ growth from 2014 to 2024. In 2010, the BLS reported that a postsecondary teacher earned a median salary of $\$ 62,050$. The median annual wage increased to $\$ 72,470$ in May of 2015 (BLS, 2016, December). Considering the 12-month unadjusted Consumer Price Indices (2016), the consumer price index (CPI) rose 1.6\% (January of 2011), increased $2.9 \%$ (January of 2012), increased 1.6\% (January 
of 2013), increased $1.6 \%$ (January of 2014), declined $-0.1 \%$ (January of 2015), and increased $0.0 \%$ in May of 2015, the unadjusted wage in May of 2015 should have been roughly $\$ 66,896$ $(+7.8 \% ;+\$ 4,846)$. Nevertheless, the 2010 median salary of $\$ 62,050$ (in the Winter of 2013 report from a listed 2010 BLS website) increased to $\$ 72,470(+16.8 \%,+\$ 10,420)$ in the May of 2015. Therefore, some salary escalation has been realized by faculty.

There also has been no change in the applied engineering college-level educator requirements to deliver remedial, introductory, intermediate, and advanced technical content to students in traditional-classroom, hybrid/blended, and $100 \%$ online delivery settings. As reported in the 2013 report, many faculty members are not only teaching typical lecture courses but also being tasked with managing student laboratories, advising students, participating in professional association events, continued service in faculty governance committees, financial responsibilities, and continued personal professional development at high competency levels (Chikasanda, OtrelCass, \& Jones, 2010). Many faculty members have forsaken education as a profession due to these factors. The words of Steinke and Putnam (2011) still hold true that applied engineering educators leave the teaching profession due to "low salaries, lack of career advancement, or administrative support, student and peer issues, and other school and environmentrelated concerns" (p. 41). Again, this renewed study was conducted to collect updated information from educators in postsecondary applied engineering/technology programs, and institutions across the United States of America, and hopefully draw meaningful trends on issues that faculty care about.

\section{ONGOING CHALLENGES FACING EDUCATORS}

Readers of this updated study are encouraged to read the Winter of 2013 article for a more detailed literature review. Key faculty challenges in the previous study included Wheeler's (2004) seven fundamental reasons for the decline of the traditional university system (and the faculty wrapped up in the system): "technological innovation, adverse economic climate, mounting commercial competition, demands for greater flexibility, subject proliferation, erosion of academic staff base and globalization" (p. 12). Mention was also made of an educator's passion for teaching (McClellan, 2012), educational reality adaptation (Osborn, 2012) - aka "do more for less," and Privateer's (1999) observation "factoring in the growing tendency of federal officials, governors, legislators, governing boards, and college and university administrators to envision instructional technologies as a panacea able to maintain the status quo while dramatically cutting delivery costs" (p. 66).

\section{Financial Challenges}

Kelderman (2012) reported in the previous study that state appropriations for colleges had declined 7.6 percent from 2011-2012. Mitchell, Leachman, and Masterson (2016, August 15) reported the following anecdotal information on ending state financial support (p. 1):

- $\quad$ Forty-six states - all except Montana, North Dakota, Wisconsin, and Wyoming - are spending less per student during the 201516 school year than they did before the previous recession (2007-2008).

- Tuition increases have compensated for only part of the revenue loss resulting from state funding cuts. Over the past several years, public colleges and universities have cut faculty positions, eliminated course offerings, closed campuses, and reduced student services, among other cuts.

- A sampling of state funding cuts and increases from 2008-2016 (see the article for a listing of all states) from the worst to the best: Arizona (-55.6\%), South Carolina (-37.0\%), Kentucky (-32.0\%), Delaware (-28.8\%), New Jersey $(-23.2 \%)$, Missouri (-22.2\%), Georgia (-19.8\%), Utah $(-13.7 \%)$, Colorado (-8.4\%), Nebraska $(-5.3 \%)$, California (-3.2\%), Montana $(+1.8 \%)$, Wyoming $(+21.0 \%)$, and North Dakota $(+46.0 \%)$. Note: only four of the fifty states had increases in state appropriations.

Even though these financial adjustments are disheartening, a few academics and higher education technology-proficient support personal, believe that increasing enrollments and class sizes, through higher use of technology and institution image-upgrading, may be a temporary solution to revenue loss (Baggetta, 2016; Donoghue, 2011; Doggett \& Lightner, 2010; Sevier, 1996) and retaining of faculty (Field, 2011; Miller, 2011). 


\section{Salaries}

Salaries may help to retain and attract qualified faculty. Postsecondary teachers earned a 2010 median salary of $\$ 62,050$ per year with no requirement of related occupational experience, which increased to $\$ 72,470$ in May of 2015 (BLS, 2016, December). In the Winter of 2013 study, it was reported that faculty in the more specialized area of career and technical education (technology and applied engineering) teachers earned a median salary of $\$ 53,920$ per year with 1 to 5 years of related occupational experience (Bureau of Labor Statistics, 2010; Occupational Outlook Handbook, 2012). The 2015 Median Pay had now decreased to $\$ 52,800$ per year (Bureau of Labor Statistics, 2016; Occupational Handbook, 2016).

\section{Technological Advancement}

Although technologies used for education continue to be more advanced, and somewhat more taxing in terms of student topic competency attainment (Jones, 2013), technology and innovation are still viewed as a necessity for the applied engineering college-level educator (Baggetta, 2016; Devine, 2006; Kenney, McGee, \& Bhatnagar, 2012; Donlevy, 2005; Grumwald, 2010; Wheeler, 2004 ).

\section{Professional Experience}

Colleges and universities still strive to hire experienced industrial professionals who can serve as faculty (Garrison, 2005; Levine, 2015). Furthermore, Garrison (2005) mentioned that industrial professionals switch to teaching because they have a "desire to teach," which benefits students because of their varied experiences from industrial settings. These industrial-to-academia professionals typically switch professions through adjunct work, teaching part-time at community colleges, and often become night-class mentors for community colleges and universities (Zackal, 2014). While these faculty members may lack a terminal degree required at a major university, "[they] do possess the needed skills to help students reach their educational goals through a greater connection to what happens in the real world" (Nickolich, Feldhaus, Cotton, Barrett, \& Smallwood, 2010).

\section{Course Loads, Class Sizes, and Faculty Hours Worked}

Increasing faculty course loads and class sizes appears to be one way in which academia is seeking to offset downturns in financial support (Donoghue, 2011) - while at the same time community college and university administrators ignore the additional loads of faculty governance committees, higher levels of scholarship, more professional development, increased recruitment, and accreditation duties they have placed upon these faculty, not to mention, the need for these same faculty to teach assigned courses (which often seems to be an afterthought by many administrators). Furthermore, release time and reduced teaching time, to handle the extra duties and increased class sizes, have become a thing of the past (Barwick, 2007; Wilson, 2011). As one example of defined faculty work hours, under the new Texas State Technical College "Faculty Expectations and Workload" statewide operating standard, and Texas Education Code - Section 51.402, "full-time salaried employees may not be authorized to work less than 40 hours per week (TSTC, 2016, October 3, p. 2).” This same document also provides detailed faculty duties and definitions regarding the following: administrative assignments, direct instructional activities, faculty workload, full-time faculty members, instructional activities, instructional development, professional development, and service.

\section{Globalization}

No changes were made to this section in the Winter of 2017 report. The following information was detailed in the Winter of 2013 study and is still pertinent today. Wheeler (2004) also mentions globalization as a cause for decline. Globalization is affecting how students should be educated (Ayokanmbi, 2011). Therefore technology educators should align course content with the needs of industry (Hogan, 2009; Jones, Smith, \& Callahan, 2010). Demographic changes, technology advances and globalization are claimed to be the game-changers in the $21 \mathrm{st}$ century (Donlevy, 2005; Karoly \& Panis, 2004). In fact, many educators are being encouraged to insist that their applied engineering students acquire global perspectives through exposure to cultures in other countries and be prepared for mobile careers (Ayokanmbi, 2011). 
Lack of Advancement Opportunities

As was mentioned in the 2013 study, the lack of opportunities for advancement or clearly outlined paths for advancement also seem to be a concern for faculty. Today's educator may or may not be tenured or in a tenure-track position as a lecturer, instructor, assistant professor, or associate professor. Naturally this all varies greatly with the type of institution and the mission of the institution. Once into academia as an associate professor, the industrial-turned-academic professional is faced with many issues: nonclear definitions to attain full professor status; aligning institutional with personal professional goals; creating (and following through) a clearly defined research agenda; balancing teaching with research (scholarship) and service and while, at the same time, providing leadership to junior faculty (Fox, n.d.).

\section{PURPOSE OF THE STUDY}

The purpose of this renewed study was fourfold for applied engineering college-level educators: (a) conduct a broad literature review on employment conditions affecting faculty, (b) administer a career-status-update survey to faculty in the United States, (c) report summarized survey results on the current and evolving characteristics in order to identify future, more in-depth research needs, and (d) compare the results from the Winter of 2013 study to the results of this Winter of 2017 study.

\section{METHODOLOGY}

A 23-question online survey was developed for distribution to faculty through the Association of Technology, Management and Applied Engineering (ATMAE) and Texas A\&M Engineering Technology (tamu.edu) Listservs at United States' community colleges and universities who possess Engineering Technology, Industrial Technology, or Technology programs. Information was obtained from faculty through an introductory listserv email and enclosed web link to the survey. The survey was posted in late December of 2016 and continued through the middle of January, 2017. Survey responses were kept confidential for this study.

Summarized survey data using Microsoft Visio, Microsoft Excel, and IBM SPSS Statistics (2017) were used to categorize:

- State of employment

- Positional status
- Faculty rank

- Length of time in current rank

- Length of time in a non-academic position (before or after academia)

- Primary academic program for employment

- Number of students taught

- Academic salary

- Non-academic salary

- Accreditation agencies supporting the program

- Degree levels obtainable for students

- Institutional offering of market pay

- Level of academic freedom

- Benefits cost of coverage

- Effective use of faculty talents

- Manageability of teaching requirements Credit hours taught per semester

- Percent of share for class type (face-to-face, hybrid, online)

- Ease in getting resources for teaching and labs

- Level of expectations for research (scholarship)

- Unique ways in which the institution supports faculty beyond base contract salary

- Expectations for promotion and tenure and general comments related to the college/university

- Satisfaction level at your institution

Study limitations could exist due to information provided by survey respondents in 2013 and 2017. For instance, as in the 2013 survey, and in this 2017 study, faculty may not possess a comprehensive understanding of the actual reasons for the way in which their institution is managing academic affairs. Furthermore, low salaries or benefits could be due to poor faculty performance or discord present between the faculty member and his/her immediate chair or supervisor. Another potential limitation was the use of a researcher-developed instrument with limited validity and reliability.

\section{SURVEY RESULTS State Representation for Study}

2013 Study: Two hundred and forty-four people from 39 states provided survey data, although this number was reduced to 212 survey respondents after removing individuals who did not provide one of the following responses: 1 . The primary 
applied engineering-related program, 2. State worked in, 3. Faculty rank, 4. Positional status, or 5. Average academic salary. This action was taken since these five questions were the baseline for extraction of information for summarization for faculty.

2017 Study: One hundred and three people from 27 states (see Figure 1) provided survey data, although this number was reduced to 90 survey respondents after removing individuals who did not provide one of the five responses reported in the 2017 study.

\section{Positional Status}

Table 1 provides information on the primary positional status for survey faculty in 2013 and 2017.

\section{Faculty Rank}

Table 2 provides information on faculty rank of survey respondents for 2013 and 2017.

\section{Length of Time in Current Rank}

2013 Study: The mean years of service for the respondents were ten years. The range was from one year to 40 years with a surprising number of respondents with less than ten years of service.

2017 Study: The mean years of service for the respondents were 9.23 years. The range was from one year to 38 years.

\section{Length of Time in a Non-academic Position}

2013 Study. The respondents had varying lengths of service in non-academic positions with a range of 0-50 years and a mean of 12.34 years.

2017 Study. The respondents had varying lengths of service in non-academic positions with a range of 0-35 years and a mean of 14.1 years.

\section{Primary Programs and Degree Levels}

Figure 2 illustrates the number of 2013 and 2017 faculty who teach in academic programs (with greater than 5 responses for each item).

Figure 3 depicts degree levels taught as reported by greater than 10 survey respondents for 2013 and 2017.

\section{Faculty Credit Load by Semester and Students per Semester}

The mean credit hours faculty taught by semester is 12.27 for 2013 . This value decreased to 11.45 credit hours taught by semester in 2017 .

The number of students typically taught by a faculty member in 2013 versus 2017 resulted in a mean of 63.86 students taught per semester for 2013. This value increased to 74.45 students in 2017.

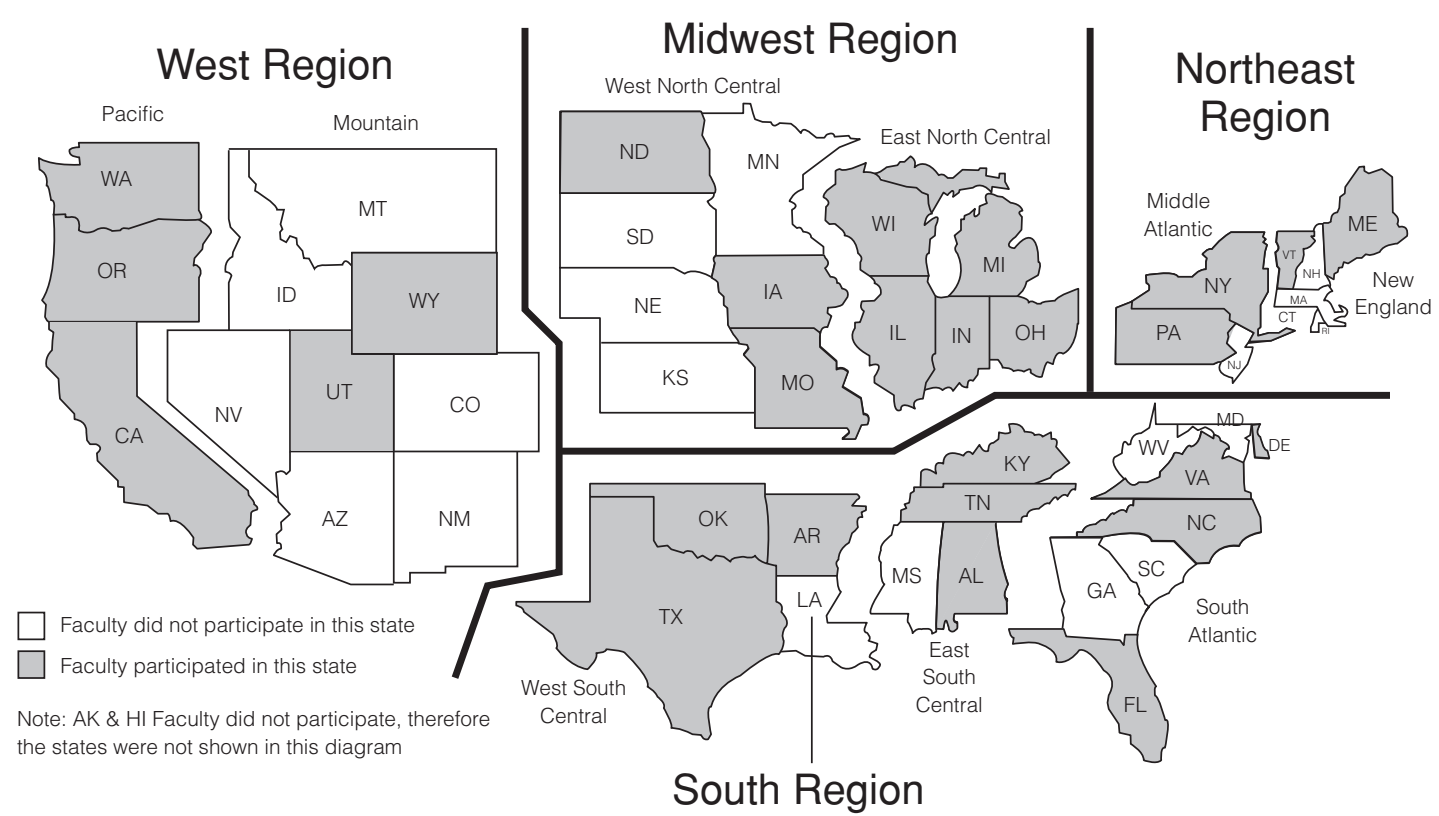

Figure 1. Survey participation by region, sub-region and state in 2016/2017 
Table 1. Positional Status of Survey Respondents for 2013 and 2017

\begin{tabular}{|l|cc|cc|}
\hline \multicolumn{2}{|c}{$\mathbf{2 0 1 3}$} & $\%$ & $n$ & $\%$ \\
\hline Positional Status & $n$ & 21 & 25 & 28 \\
\hline Contract-only & 44 & 19 & 10 & 11 \\
Tenure-track & 41 & 60 & 47 & 52 \\
Emeritus & 127 & NA & 1 & 1 \\
Adjunct & NA & NA & 7 & 8 \\
\hline
\end{tabular}

Table 2. Faculty Rank of Survey Respondents for 2013 and 2017

\begin{tabular}{|l|cc|cc|}
\hline \multicolumn{2}{|c|}{$\mathbf{2 0 1 3}$} & $\%$ & $n$ & $\%$ \\
\hline Cositional Status & $n$ & 1 & 0 & 0 \\
Director & 2 & 1 & 0 & 0 \\
Adjunct & 2 & 2 & 7 & 8 \\
Lecturer & 4 & 2 & 6 & 7 \\
Instructor & 4 & 13 & 11 & 12 \\
Assistant Professor & 28 & 16 & 16 & 18 \\
Associate Professor & 35 & 36 & 22 & 24 \\
Full Professor & 76 & 29 & 28 & 31 \\
\hline
\end{tabular}

\section{Academic Program Number by Study Year}

Construction Technology or Management

Design \& Drafting Technology (or CADD)

Electronics Technology
Engineering Technology
Industrial Technology

Manufacturing Technology

Technology Management

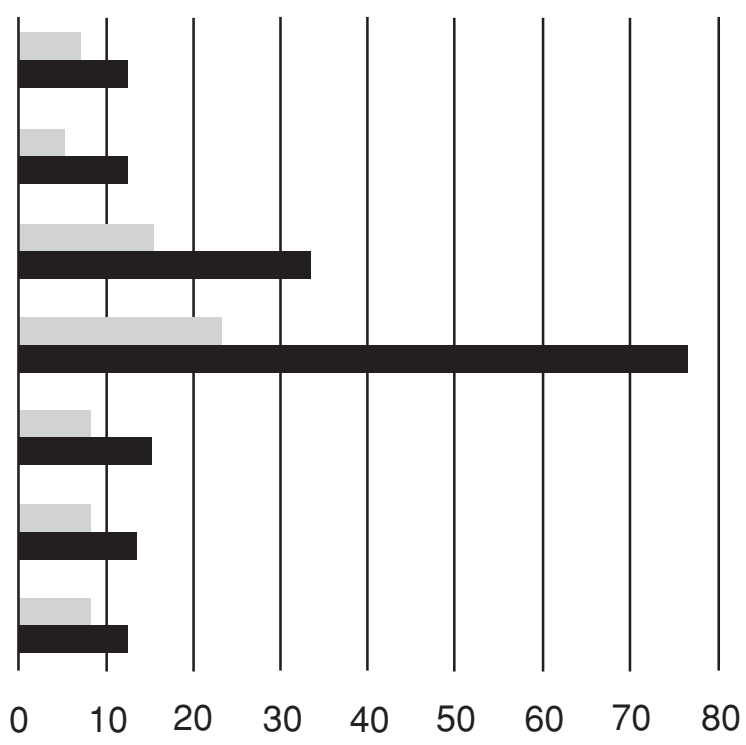

$2017 \square 2013$

Figure 2. 2013 and 2017 Study. Number of academic programs by study year $(n>5)$ 


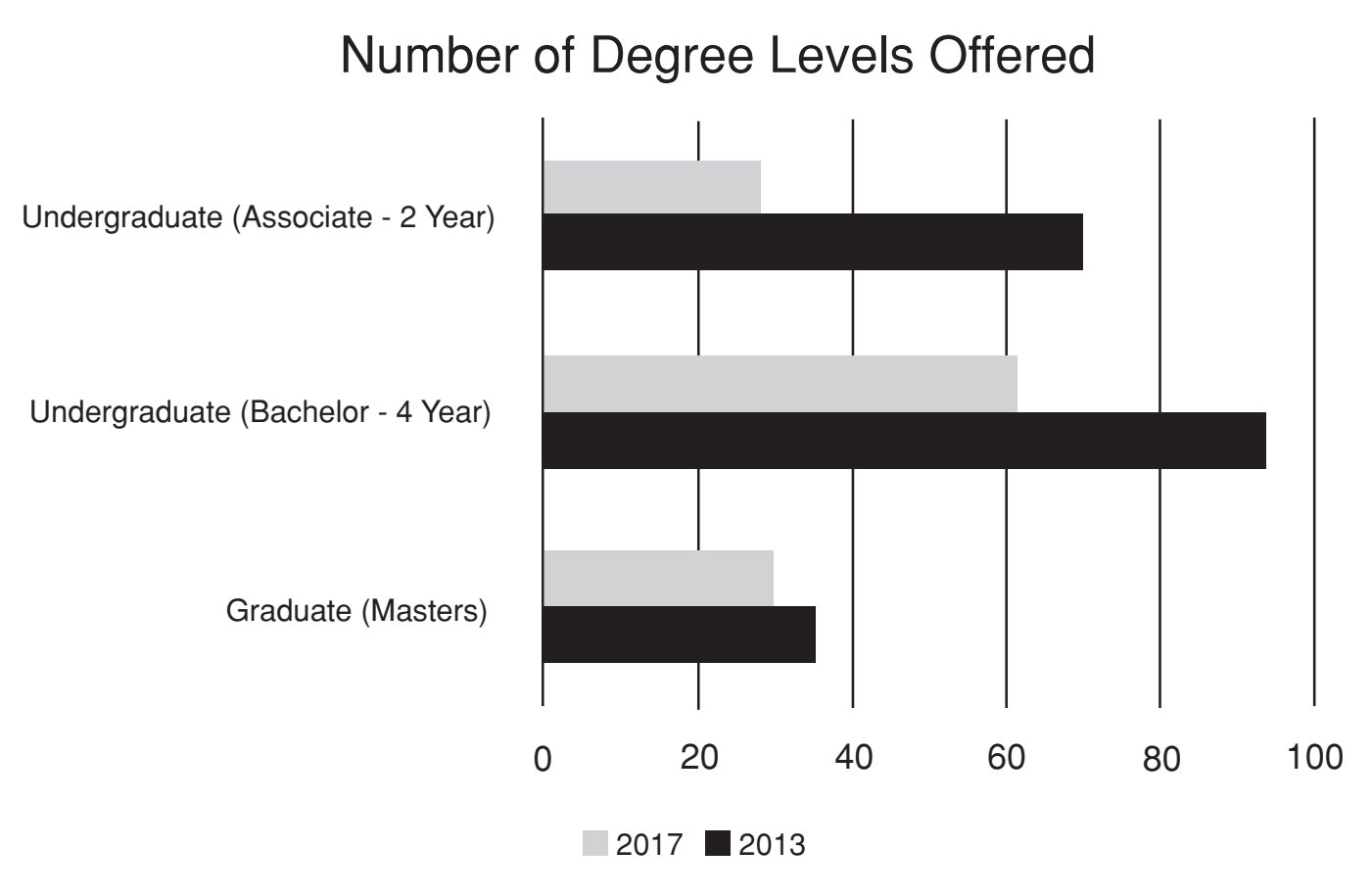

Figure 3. 2013 and 2017 Study. Degree levels instructed $(n>10)$

\section{Faculty Salary and Contract Length}

Faculty salary mean was $\$ 73,567$ with a standard deviation of $\$ 24,890$ in 2013. 2017 modestly raised the faculty salary mean to $\$ 77,306$ with a standard deviation of $\$ 29,002$ (see Figure 4). The mean yearly contract length for faculty was 9.38 months for 2013 and 9.39 months for 2017.

\section{Administration Position and Pay}

Various faculty members reported add-on positions of chair, coordinator, department head, and program director for both the 2013 and 2017 surveys. Very few individuals answered this question in the 2017 survey. Consistent additional means of support for reporting faculty were in online course development, release time, grant work, and teaching summer classes for both surveys.

\section{Market Pay}

In the 2013 study, survey respondents reported that $50 \%$ of their institutions did not provide market pay. In this 2017 study, the number of institutions has risen to $57 \%$. Professional organizations utilized for market pay comparison included the following for both 2013 and 2017: AAUP, ABET, ACCE, ASEE, ATMAE, CUPAHR, and IEEE.

\section{Accreditation Body}

Primary accreditation bodies utilized by academic institutions were as follows (several faculty chose not to answer this question for both the 2013 and 2017 surveys):

- Accrediting Board for Engineering \& Technology (ABET-EAC) (2013: 9), (2017: 6)

- Accrediting Board for Engineering \& Technology (ABET-ETAC) (2013: 94), (2017: 35)

- American Council for Construction Education (ACCE) (2013: 10), (2017: 5)

- Association of Technology, Management, and Applied Engineering (ATMAE) (2013: 45), (2017: 36)

\section{Academic Freedom, Benefits Cost of Coverage, Talent Usage and Teaching Manageability}

Figure 5 provides 2013 -to-2017 changes in faculty Academic Freedom (scale of 1-to-5; 5 being the highest), Benefits Cost of Coverage ([how well an institution covers insurance and other benefits], scale of 1-to-5; 5 being the highest), Faculty Talent Usage (scale of 1-to-5; 5 being the highest), and Teaching Assignment Manageability (scale of 1-to-10; 10 being the highest). 


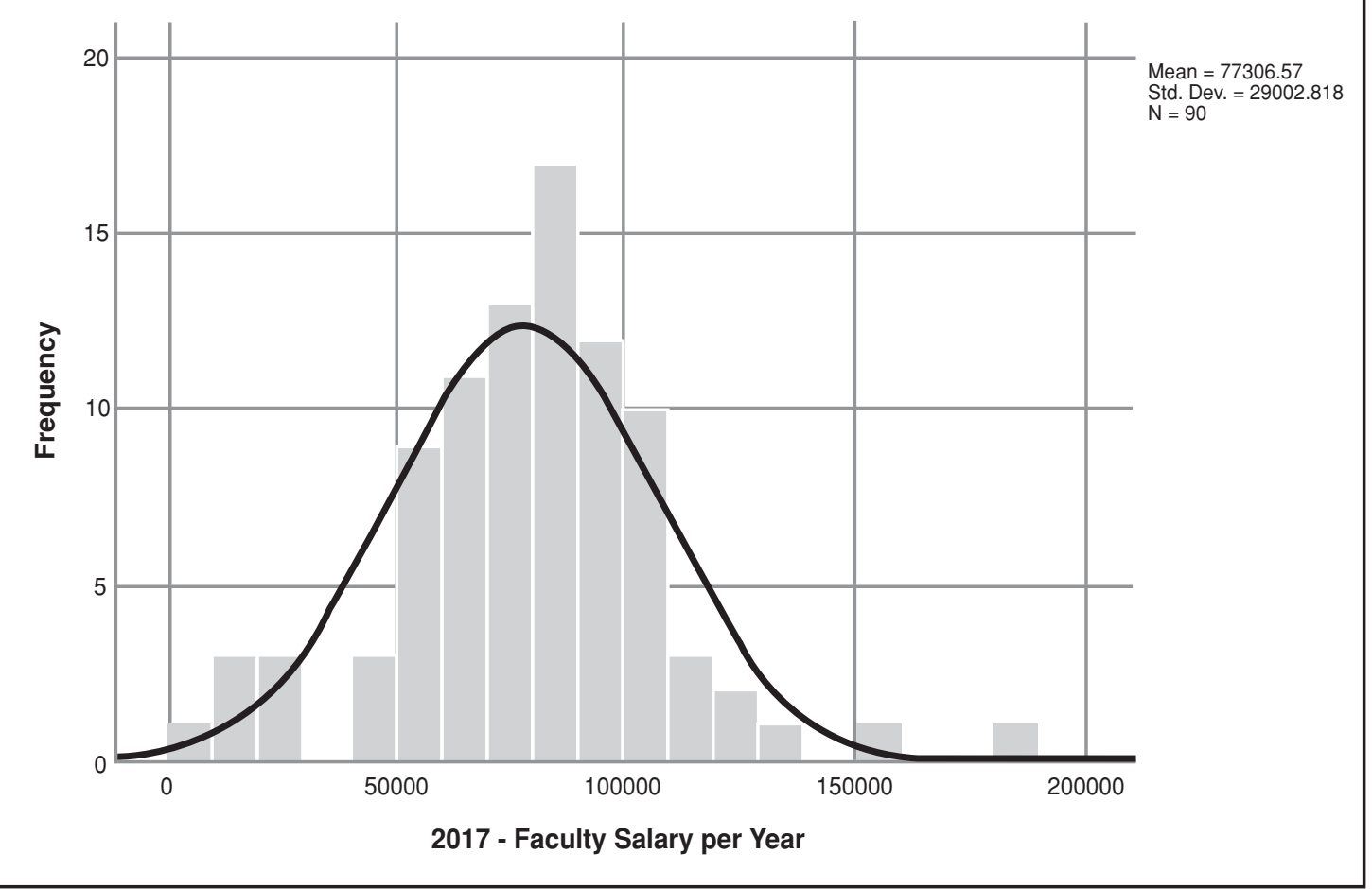

Figure 4. 2017 Study. Faculty salary per year

\section{Teaching Method}

Teaching online and hybrid classes went up from 2013 to 2017. Teaching face-to-face classes decreased during the same time period (see Figure 6).

\section{Resources and Support, and Research (Scholarship) Expectations}

Changes in faculty Resources and Support (scale of 1-to-10; 10 being the highest) was 6.33 in 2013 and at 6.07 in 2017. Research (scholarship) expectations by academic institutions (scale of 1-to-5; 5 being the highest) was 2.87 in 2013; and at 2.87 in 2017.

\section{Promotion and Tenure Expectations}

The summarized anecdotal information of the faculty for 2013 and 2017 is provided next in relation to a respondent's university tenure and promotion procedures or expectations.

\section{3}

- Two publications required per year

- Five years teaching and 15 hours of Master's credit to apply for assistant professor
- A joke. No new faculty mentoring. No feedback from administration on how well we are doing

- Absolutely ridiculous and highly arbitrary - even though there are written requirements

- Based strictly on education and years of service

- Does not hire full time but depends on adjuncts

- Expect too much scholarly activity given the teaching loads

- I will get tenure this year - the target is moving

- It is a fair system

- One is completely at the mercy of the academic politics

2017

- Teaching, research, and service are expected to be excellent

- Expectations for research have become excessive to the detriment of teaching

- Fair, but haven't changed since 1980 when state mandates were employed 


\section{Various Faculty Indicators}

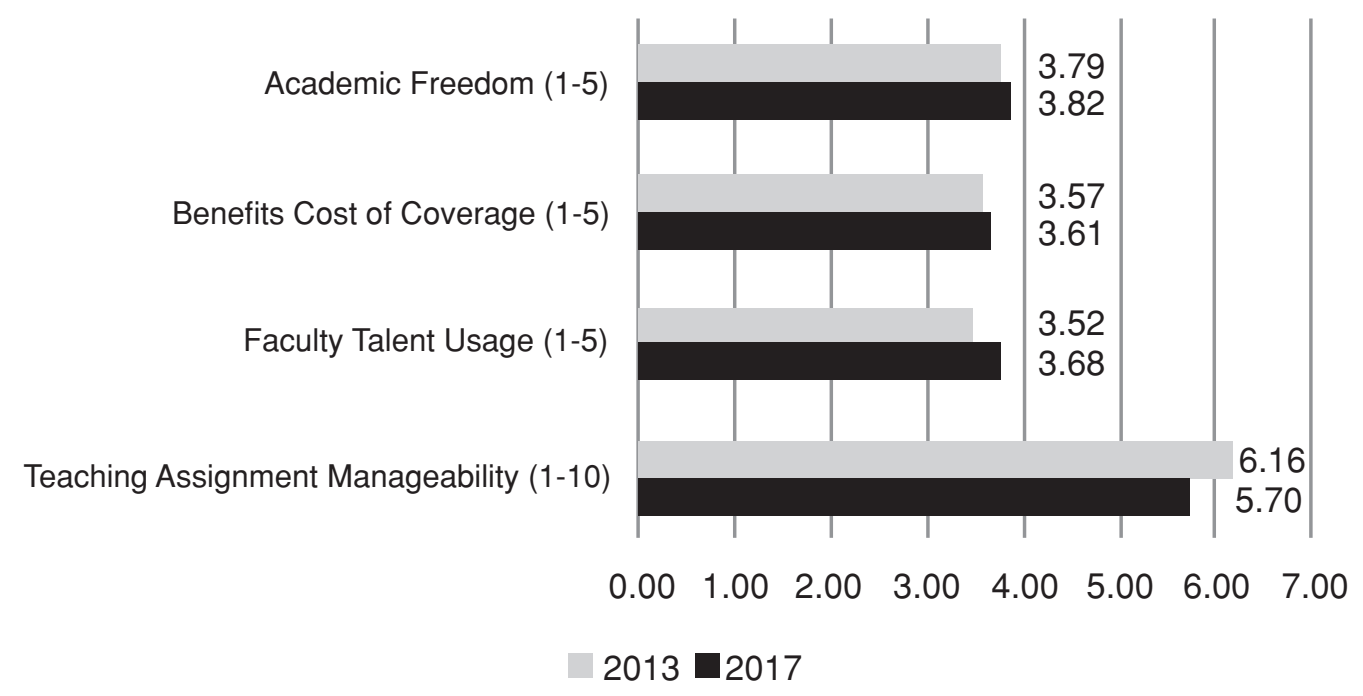

Figure 5. 2013 and 2017 Study. Various faculty indicators

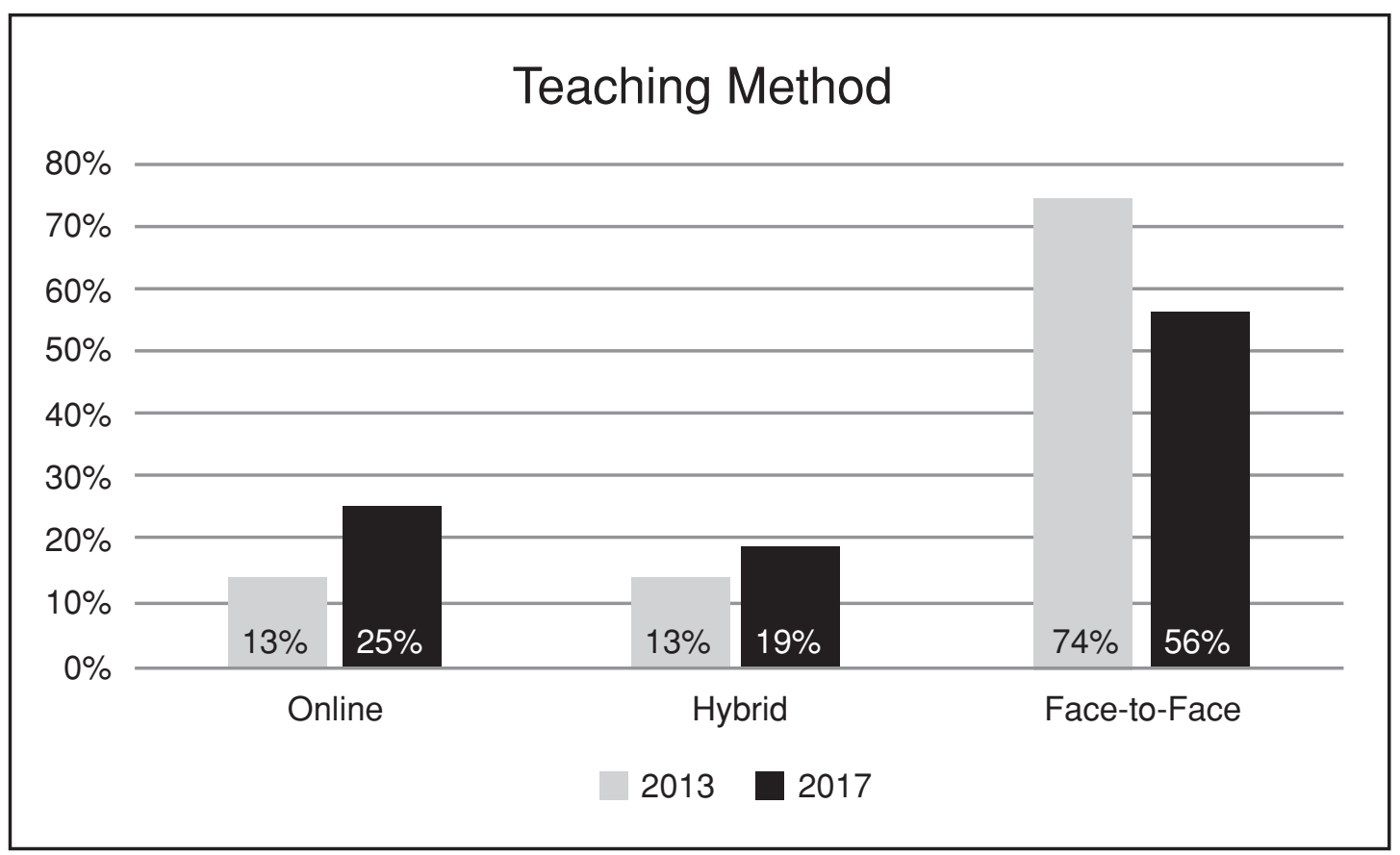

Figure 6. 2013 and 2017 Study. Teaching method 
- My department has fairly low standards

- Generally reasonable, although I think tenure is an outdated concept

- The expectations are very fair and doable

- $\quad$ Getting harder. Skewed heavily toward Ph.D.s

- $\quad$ Moving target

- $\quad$ Fair for tenure. Lofty for full professor

- $\quad$ Faculty members are not treated fairly, even if you meet the requirements for tenure. Top leaders, and the provost, make their own decisions

\section{CONCLUSION AND DISCUSSION} Both the 2013 and 2017 surveys attempted to get at the heart of issues of most concern to academics in the United States of America. These issues included positional status (adjunct, contract, tenure-track, tenure), faculty rank, length of time in current rank, length of time in non-academic professional work (before or after academic work), primary academic program, total number of students taught per semester, average academic salary, contract length, administrative duties and salary benefits, academic professional accreditation, degree levels offered, market pay (competitive) presence, academic freedom, benefits cost of coverage (health insurance, life insurance, etc.), using faculty talent, managing of teaching assignments, number of credit hours taught per semester, percentage of teaching load (face to face, hybrid, online), resource and ease of support acquisition, expectations for research (scholarship), unique ways that an academic institution compensates educators beyond the base salary, expectations for promotion and tenure, and other comments pertinent to an academic's role in academia. In the 2013 study, 244 people (from 39 states) participated (only 212 responses were valid). This number dropped to 103 people from 27 states in 2017 (only 90 responses were valid). Even though the survey population was smaller for 2017, the number of respondents was determined to be sufficient for reporting to other academics in a publication.

Key stable or trending changes from 2013 to 2017 were identified and provided below:

- $\quad$ There was very little change in the mean years of service for faculty (2013: 10 years; 2017: 9.23 years)
- Length of time in non-academic positions before or after academic employment increased from 12.34 years (2013) to 14.1 years (2017)

- $\quad$ Engineering Technology remains to be the highest recorded program by respondents from either 2013 or 2017

- $\quad$ Faculty credit load went down from 12.27 credit hours (2013) to 11.45 credit hours (2017)

- The number of students taught, per semester, by faculty increased from 63.86 (2013) to 74.45 (2017)

- $\quad$ Faculty salary mean went up from $\$ 73,567$ (2013) to $\$ 77,306$ (2017), a modest 5\% increase

- Academic institutional use of competitive (market) pay increased from 50\% (2013) to $57 \%$ (2017) by survey respondents. Note: this is not conclusive because some of the faculty members reporting could have been from the same institution as another faculty member who participated in the survey

- $\quad$ Very little change for faculty in 2013 to 2017 was noted in terms of academic freedom, benefits cost of coverage, use of faculty talent, or the managing of teaching assignments.

- Teaching methods increased for online education ( $13 \%$ to $25 \%$ ) and hybrid education ( $13 \%$ to $19 \%$ ), but decreased for face-to-face education (74\% to $56 \%$ ) from 2013to 2017. Little change for research expectations (scholarship) were noted

- Anecdotal information on university tenure and promotion procedures or expectations seemed to be same from 2013 to 2017. Some faculty stated that the expectations are fair while other faculty believed that upper administrators have their own agenda regarding promotions or tenure

Note that many of the factors listed previously are intertwined in terms of cause and effect.

When one factor changes, another factor is affected. Therefore, it is difficult to draw extensive conclusions about why faculty teaching methods have increased for online and hybrid courses, but decreased for face-to-face type courses. This could be due to administrative changes at some institutions but not at others. It could also be due to the student culture in one 
part of the United States is different from the culture in another area of the United States. That is why this study provides the basic facts of what survey respondents have provided.

\section{FUTURE RESEARCH}

The one glaring requirement for a future is more passage of time. Four years may seem like a long time, but academia moves slowly in terms of change. The author recommends a new survey after another 4 years has passed beyond 2017, using the same criteria in this survey in order to collect trending data. It is hopeful that after 4 years, faculty will be able to report more information on salary changes, rank upheavals (use of more adjuncts), loss of tenure (states appear to be questioning the need for it), and general cost-cutting methods employed by state academic institutions to remain fiscally solvent during state cutbacks in financial support.
The academic's life is not an easy one. The indicators utilized in this survey attempted to obtain a "pulse" on the state of the faculty in the United States of America. The two elements missing, which also appear to be missing in many surveys, is of "hope" and "overall satisfaction" of the academic in nurturing minds. When, and if, this survey is repeated, it is the author's sincere hope that the next researcher will determine a unique way to capture these two vital areas for a satisfied faculty member.

Jeffrey M. Ulmer, PhD is a Professor of Technology Management, Engineering Technology and Industrial Management at the University of Central Missouri, Warrensburg. 
Ayokanmbi, F. M. (2011). Competencies for global engineers and technologists. Journal of Industrial Technology, 27(1).

Baggetta, M. (2016, February 9). How professors can best use technology in their classrooms. Retrieved from https://blog.tophat.com/how-professors-can-best-use-technology/

Barwick, D. W. (2007). Does class size matter? Inside Higher Ed. Retrieved from http://www. insidehighered.com/views/2007/12/06/barwick

Bureau of Labor Statistics. (2016, December 23). Consumer Price Index Archived New Releases. Retrieved from https://www.bls.gov/bls/news-release/cpi.htm\#2013

Bureau of Labor Statistics. (2012, April 10). Postsecondary teachers. Retrieved from http://www.bls. gov/ooh/education-training-and-library/postsecondary-teachers.htm

Bureau of Labor Statistics. (2016, December 23). Postsecondary teachers. Retrieved from http://www. bls.gov/ooh/education-training-and-library/postsecondary-teachers.htm

Chikasanda, K. C., Otrel-Cass, K., \& Jones, A. (2010). Teachers' views about technical education: implications for reforms towards a broad based technology curriculum in Malawi. International Journal of Technology, Design and Education, 21, 363-379.

Devine, K. L. (2006). Improving the knowledge transfer skills of industrial technology students. Journal of Industrial Technology, 22(2).

Doggett, A. M., \& Lightner, S. (2010). Online graduate degree recruiting: is it different? Journal of Industrial Technology, 26(4).

Donlevy, J. (2005). The future of work: Technology beckons. International Journal of Instructional Media, 32(3).

Donoghue, F. (2011). The implications of teaching-load increases. The Chronicle of Higher Education. Retrieved from http://chronicle.com/blogs/innovations/the-implications-of-teaching-loadincreases/30636. In The implications of teaching-load increases. Retrieved from http://chronicle. $\mathrm{com} /$ blogs/innovations/the-implications-of-teaching-load-increases/30636

Field, K. (2011). Faculty at for-profits allege constant pressure to keep students enrolled. The Chronicle of Higher Education. Retrieved from http://chronicle.com/article/Pawns-in-the-ForProfit/127424/

Fox, R. B. (n.d.). Mentoring Mid-Career Faculty. American Speech-Language-Hearing Association. Retrieved from http://www.asha.org/Academic/questions/Mentoring-Mid-Career-Faculty/

Garrison, C. P. (2005). Who moves from industry to academia and why: An exploratory survey and analysis. Education, 125(3), 414-421

Grumwald, P. (2010). Educators, technology and 21st century skills: Dispelling five myths. Grumwald Associates LLC. Retrieved from http://www.grunwald.com/pdfs/Educators_Technology_21st Century-Skills_GRUNWALD-WALDEN_Report.pdf. In Educators, technology and 21st century skills: Dispelling five myths. Retrieved from http://www.grunwald.com/pdfs/Educators Technology_21stCentury-Skills_GRUNWALD-WALDEN_Report.pdf

Hogan, R. L. (2009). Assessment of technology graduate students' learning preference styles utilizing the Myers-Briggs type indicator. Journal of Industrial Technology, 25(1).

Jones, M. P., Smith, R. R., \& Callahan, R. N. (2010). Perspectives of how academia is keeping pace with the changing needs of manufacturing professionals. Journal of Industrial Technology, 26(1).

Jones, R. T. (2013). The new American workforce: Challenges and opportunities for higher education. Education Workforce Policy, LLP. Retrieved from http://www.educationworkforcepolicy.com/ papers.html 
Karoly, L. A., \& Panis, C. W. A. (2004). The 21st century at work: Forces shaping the future workforce and workplace in the United States. Retrieved from http://www.rand.org/content/dam/rand/pubs/ monographs/2004/RAND_MG164.pdf

Kelderman, E. (2012). State support for colleges falls 7.6\% in 2012 fiscal year. The Chronicle of Higher Education. Retrieved from http://chronicle.com/article/State-Support-For-Higher/130414/

Kenney, L., McGee, P., \& Bhatnagar, K. (2012). Different, not deficient: the challenges women face in STEM fields. The Journal of Technology, Management, and Applied Engineering, 28(2).

Levine, A.G. (2015, October 9). Industry Experience as a Platform for Academic Careers. Retrieved from http://www.sciencemag.org/careers/features/2015/10/industry-experience-platform-academiccareers

McClellan, G. S. (2012, July 18). Maintaining your passion for the job. Retrieved from http:// chronicle.com/article/Maintaining-Your-Passion-for/132905/

Miller, M. (2011). Manufacturing education: evolving to challenge adversity and public sentiment. The Journal of Industrial Technology, 27(2).

Mitchell, M., Leachman, M., \& Masterdon, K. (August 15, 2016). State cuts to higher education threaten quality and affordability at public colleges. Retrieved from: http://www.cbpp.org/research/ state-budget-and-tax/funding-down-tuition-up

Nickolich, D., Feldhaus, C., Cotton, S., Barrett, A., \& Smallwood, J. (2010). Perceived life satisfaction of workplace specialist 1 faculty and mentors participating in a first-year STEM teacher training project. The Journal of Technology Studies, 36(2).

Occupational Outlook Handbook. (2012). Career and technical education teachers. Retrieved from http://www.bls.gov/ooh/education-training-and-library/career-and-technical-education-teachers.htm

Occupational Outlook Handbook. (2016). Career and technical education teachers. Retrieved from https://www.bls.gov/ooh/education-training-and-library/career-and-technical-education-teachers.htm

Osborn, E. (2012). New realities. The Chronicle of Higher Education. Retrieved from http://chronicle. com/blogs/onhiring/new-realities/32979

Privateer, P. M. (1999, Jan/Feb). Academic technology and the future of higher education. The Journal of Higher Education, 70(1), 1.

Sevier, R. A. (1996). Those important things: what every college president needs to know about marketing and student recruitment. College and University, 71(4).

Texas State Technical College (2016, October 3). Statewide Operating Standard - Faculty Expectations and Workload. Retrieved from http://www.tstc.edu/governance/es

Wheeler, S. (2004). Five smooth stones: fighting for the survival of higher education. Distance Learning, 1(3).

Zackal, J. (2014). Becoming a community college professor. Retrieved from https://www.higheredjobs. com/articles/articleDisplay.cfm? ID $=525$

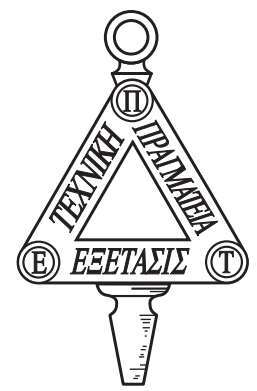




\section{Table of Contents}

Volume XLIV, Number 2, Fall 2018

42 A Century of Perspectives that Influenced the Consideration of Technology as a Critical Component of STEM Education in the United States By Mark Snyder

58 Examining the Potential of Adaptive Comparative Judgment for Elementary STEM Design Assessment By Scott R. Bartholomew, Greg J. Strimel, Liwei Zhang, and Jessica Homan

76 The 2017 Paul T. Hiser Exemplary Publication Award Recipients

77 Guidelines for the Journal of Technology Studies 


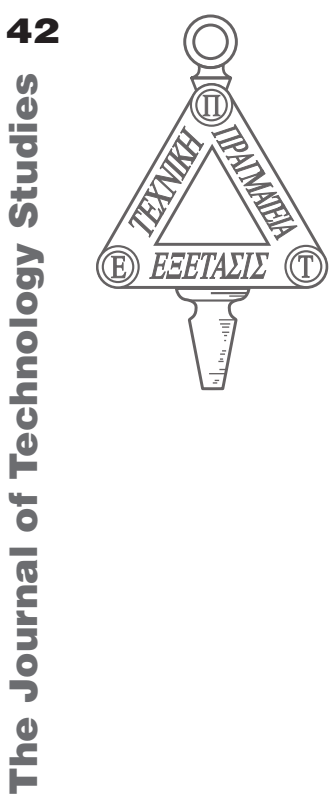

\section{A Century of Perspectives that Influenced the Consideration of Technology as a Critical Component of STEM Education in the United States \\ By Mark Snyder}

\section{ABSTRACT}

Technology and engineering education is recognized as a way to integrate disciplines, such as math and science, using hands-on learning activities to solve problems. Doing so helps students become technologically literate and work productively in society. Historically, many different views evolved regarding the need for instruction related to technology and technical processes. Numerous systems and methods were devised to achieve this goal in the United States. During the early part of the 20th century, a number of education professionals theorized about the implications of technology as it related to the study of industry.

These leaders eventually declared technology as integral to their field. Especially during the period of economic growth that followed World War II, many considered the study of technology, and the man-made world, a vital concern in the curriculum of industrial education. Increased foreign competition, characterized by events such as the launching of the first Soviet "Sputnik," resulted in private support and government initiatives for improvement in education, particularly math and science, but eventually in other content areas, including industrial education.

In the 21 st century, the study and integration of technology is accepted as a key component in the Science, Technology, Engineering and Mathematics (STEM) movement. Familiarity with the evolution of general education related to technology in the United States helps us understand the rationale behind the inclusion of technology in the STEM acronym. This historical review identifies key perspectives and practices that led to the inception of technology education at the end of the 20th century - which, in turn, contributed to the integrated STEM movement. But what is the impetus for including "technology" in STEM education? What is the role of technology and engineering in STEM education?

Keywords: STEM, education, technology, engineering, history

\section{The Influence of Technology Identified within Industrial Education}

As early as 1917, Charles Bennett referred to the effects of technology on people in his book Manual Arts, containing this excerpt:

... industrial development has been so rapid and so varied in our country-it has affected every man's life to such an extent that if he is to retain sufficient mastery of his environment to make it serve his needs, he is forced to acquire considerable practical knowledge of the materials, principles, and processes of industry. (1917, pp. 14-15)

This rationale for the study of industry was based upon the need for people to adapt to changes caused by society's industrial growth. Bennett's reference to mankind's "mastery of his environment to make it serve his needs" could be considered plausible as an explanation for technology.

John Dewey authored strong opinions about the growth of industrial education throughout his lifetime, during which the United States entered the Machine Age. The industrialization of the late 19th century and acceleration of technology Dewey witnessed had a decided impact on his educational philosophy. In Democracy and Education, Dewey stated:

Industry has ceased to be essentially an empirical, rule-of-thumb procedure, handed down by custom. Its technique is now technological: that is to say based upon machinery resulting from discoveries in mathematics, physics, chemistry, bacteriology, etc. ... As a consequence, industrial occupations have infinitely greater intellectual content and infinitely larger cultural possibilities than they used to possess. The demand for such education as will acquaint workers with the scientific and social bases and bearings of their pursuits becomes imperative, since those who are without it inevitably sink to the role of appendages to the machines they operate. (1916, p. 314) 
In the book, John Dewey's Pragmatic Technology, Hickman said of Dewey: “... he sought to demonstrate that the methods and means by which technological inquiry take place are the methods and means by which all knowing, in its 'honorific' sense, is generated" (1990, p. 4).

The "industrial-social theory," influenced by Dewey and posited by James Russell and Gordon Bonser, was intended to provide intellectual investigation of a wide range of endeavors typifying the industrial processes that provided for basic human needs and were thus technological in nature. Consider this passage from the 1923 Bonser-Mossman definition of industrial arts: "... a study of the changes made by man in the forms of materials to increase their values, and of the problems of life related to those changes" (Bonser \& Mossman, 1923, p. 5). C. Lemons wrote, "this definition may be the first documented reference to the technological society as a purpose for teaching industrial arts" (1988, p. 59).

In 1934, Maris Proffitt described what he considered essential "functions of industrial arts." Among the functions suggested by Proffitt was the following study of material cultures:

A study of material cultures of American society in a perspective of great world civilizations will reveal a fundamental origin of industrial arts. This origin refers to elements of utility, efficiency, and beauty in things that have been developed and used by man throughout history. This origin more than any other distinguishes industrial arts as a broad subject of study. (Cited in Anderson, 1940, p. 234)

Proffitt's reference to a "fundamental origin of industrial arts" seems to be a search for a professional motive and the second sentence of this passage is comparable to modern definitions of technology as physical elements.

In 1935, A. Swope viewed industry as incidental to the principles of science. He reasoned that "it is conceivable that we may as a nation depart on some other avenue of adventure than the application of scientific principles which were formulated two or three generations ago to industrial life primarily." Swope also believed that we would progress beyond industrialization and he felt that "our training in school might be the means of adapting the child to see beyond these horizons" (cited in Lemons, 1988, p. 56). Swope was confident that technological advancement would occur, and he suggested that educators could address the needs of students related to such change.

In January 1940, The Phi Delta Kappan, printed a special issue dedicated entirely to the topic "Industrial Arts in General Education." In this issue, Albert Siepert, William Warner, and other leaders of industrial arts education attempted to clarify the mission of industrial arts. Siepert, the Dean of Education for the Bradley Polytechnic Institute in Peoria, Illinois, authored the initial article titled "Philosophy," in which he stated:

If industrial arts teaching is to acquaint the school pupil with the products of industry, if the purpose is to orient the individual whose life is to be spent in a world so much dependent upon technology, then first-hand experience appears to be essential. (1940, p. 235)

Here again, Siepert identified the substantial influence that technology can have on society and the individual. His predominant point was that by providing "hands-on" experiences, industrial arts readily facilitated learning that would prepare students for life in a technological society.

\section{The Curriculum to Reflect Technology}

The aftermath of World War II, including the rapid economic growth and advancement of technology caused by that event, contributed to a new perspective on the instruction of industrial arts. For several years following the war, various leaders in the profession encouraged teachers to modify their programs by, as Meyer put it, "grasp[ing] the technological bull by his educational horns" (1951, p. 16). Discourse of this nature was motivated by a momentous effort that not only focused on the concept of technology, but also provided a means to develop programs with an emphasis on technology within the context of industry.

In April, 1947, a new interpretation of industrial arts, initially referred to as "The New Industrial Arts Curriculum," was imparted by William Warner, Joseph Gary, Carlton Gerbracht, Harold Gilbert, John Lisack, Paul Kleintjes, \& Kenneth Phillips. Warner, who had served in the war, 
introduced this new plan at the eighth annual American Industrial Arts Association (AIAA) convention held in Columbus, Ohio. For Warner, it was the next logical step in the advancement of his philosophy and practices. In A Curriculum to Reflect Technology, Warner and his protégés defined industrial arts as follows:

Functionally, industrial arts as a general and fundamental school subject in a free society is concerned with providing experiences that will help persons of all ages and both sexes to profit by the technology, because all are involved as consumers, many as producers, and there are countless recreational opportunities for all. (Warner, Gary, Gerbracht, Gilbert, Lisack, Kleintjes, \& Phillips, 1965, p. 41)

Dwight Curtis wrote a review of Warner's conference presentation that was printed in the June 1947 issue of The Industrial Arts Teacher. He commented, "the presentation by Dr. Warner, and the interpretations that followed, completely redefined the position of industrial arts in general education in the public school, and solicited both re-evaluation of the present program and consideration of the implementation of the new" (p. 1).

Delmar Olson said of this effort, "it was too far ahead of the times to gain general acceptance, but like all advance thinking it has had its impact on the profession" (1963, p. 15). Warner, himself, had a different feeling about the acceptance of the project as evidenced by the following, which he wrote retrospectively:

The result, as herein reported, was featured at the AIAA Convention of 1947 which I revived in Columbus, Ohio, following World War II, and where we were fearful of the outcome until the discussions which followed, when our findings were not only accepted, but praised on all sides. (Warner et al., 1965, p. 5).

Eventually, "The New Industrial Arts Curriculum" became known as A Curriculum to Reflect Technology, with content "derived via a socioeconomic analysis of the technology and not by job or trade analysis as of old...." (Warner et al., 1965, p. 41). It included six subject matter classifications: Power, Transportation, Manufacturing, Construction, Communication, and Management.
Thomas Latimer summarized:

For the most part, it remained a proposal, probably because Warner did not have the funds to promote and enhance it nationally. The plan was probably too far ahead of its time....

Even though the curriculum was never totally implemented, today there are many elements of The Curriculum to Reflect Technology present in educational systems throughout the United States. (1981, p. 48)

Indeed, there is evidence of the influence of Warner's Curriculum in the content of programs nationwide. However, there were many other efforts to identify technology as integral to industrial arts during the late 1940s and through the 1950s.

\section{Appeals for a New Approach to Industrial Arts}

In 1948, at the ninth annual AIAA conference held in Washington DC, a resolution on "The Impact of Technology" was authorized by the Association. From that resolution comes the following excerpt:engineering education.

Whereas, certain of the school subjects such as industrial arts have not kept pace through adequately orienting all Americans to cope with the problems involved, now therefore, be it RESOLVED, that the industrial arts profession as represented by the AMERICAN INDUSTRIAL ARTS ASSOCIATION and its affiliates, as well as all the federal, state, and local agencies concerned, be stimulated to interpret and implement the issues, the subject matter, and the means involved, in order that all Americans may more readily adjust to and enjoy the potentialities of a good life made possible through an ever-expanding technology. (AIAA, 1948, p. 2)

Also in 1948, Walter Williams, Jr., Professor at the University of Florida and Vice President of the AIAA, declared "Industrial Arts Faces a New Era." In an article for The Industrial Arts Teacher, Williams observed:

For a time the true educational concept of industrial arts was lost, and its position was relegated to a secondary place in the scheme of general education. Now, under 
the pressure of a complex technological society the narrow view of the manual arts concept is fast giving way to a more comprehensive and flexible interpretation of industrial arts or technology. That a crucial need exists for technological literacy is apparent.... (p. 1)

Gordon Wilber, the ninth President of the AIAA, was another educator with timely insight. He referred to the influence of technology in his book Industrial Arts in General Education, when he defined industrial arts as "...those phases of general education which deal with industry-its organization, materials, occupations, processes, and products-and with the problems resulting from the industrial and technological nature of society" (Wilber, 1948, p. 2). Wilber also expressed the conviction that education was critical to the development of technology by stating: "if society did nothing more than transmit its culture there would be no progress or improvement. Education has the further objective, therefore, to provide for extending and improving the way of life" (p. 6). This could be accomplished, he believed, through instruction that challenged the critical thinking skills of students.

In 1951, Harvey Meyer, Associate Professor at the University of Florida-Gainesville, asked of his peers, "Industrial Arts - What Next?" Meyer knew that "every boy and girl, regardless of present interest or future occupation, is forced to an acquaintanceship with the products of technology." As a result he felt that, "work with materials and toward a grasp of technology needs to be a part of the experience of every boy and girl" (p. 15).

Meyer recognized that "as teachers of industrial arts, a field yet young in education, we have groped for truth and sought our role in leading youth toward a real and functioning technological literacy." Meyer continued, stating:

Our problem is not that of substituting something new for something old. It is not to discard the classics in the interest of the technics-or this will destroy both. Our task is to provide the cultural matrix of the arts, the sciences, and the humanities so that the equally cultural technologies can find their rightful place and make their vast and vital contribution. (Meyer, 1951, p. 16)
Through the 1950's, Meyer maintained an interest in the role of technology in industrial arts and had begun to consider technology as fundamental to the profession. The following passage from his article, titled "Creed, Deed, and Need," is an example of how his thought had progressed:

As has been pointed out in these pages before, basic science can do a great deal in the initial stages of any development; but in the final analysis, it is technology that puts the findings of basic science to work. Unless the children in our schools and the young people entering college have a real and vibrant grasp of what is involved in technology, it is indeed doubtful if they can take full advantage of the technological progress now so imminent and so necessary. (Meyer, 1959, p. 17)

In 1954, John Whitesel, a former president of the AIAA, was elected president of the American Council on Industrial Arts Teacher Education (ACIATE). As the newly elected president, he expressed hope that industrial arts professionals could redefine "the contributions of industrial arts in a modern program of education, and redesigning the program of industrial arts in an effort to make the fullest contributions possible in the light of present day technological needs" (1954, p. 9). The following year, Burl Osburn, the twelfth President of the AIAA and Department Head of Industrial Arts at the State Teachers College in Millersville, Pennsylvania, addressed the National Education Association Assembly held in Chicago on July 4, 1955. His speech, "Industrial Arts in Modern Education," clarified the status of Industrial Arts for members of other NEA organizations.
We can begin to see, therefore, that as method industrial arts education is the directing of experiences in the transmission and improvement of man's control of forces and materials for the enhancement of personal-social living. As a subject it is concerned with the processes of producing goods and their personal and technological effects. (p. 8)

Here, the method of industrial arts was identified as an effort to guide learners toward bettering their lives and their environment. 
In 1958, at the annual meeting of the National Society of College Teachers of Education and the American Association of Colleges for Teacher Education, the ACIATE sponsored a symposium titled "Industrial Arts Teacher Education for a Technological Era.” Many well-respected individuals participated in a major session on the topic of "Curricular Innovations for an Age of Technology." This session dealt with such concepts as quality control, mass production, group experiments, and the idea of providing service to science and other subject areas. This symposium occurred shortly after the Soviet Union launched its "Sputnik" satellite in 1957. President Dwight Eisenhower established the National Aeronautics and Space Administration (NASA) in 1958 and challenged Americans to respond to the "space race" by becoming leaders in science, technology, engineering, and math.

\section{Early Curriculum Efforts Organized Around Technology}

In the late 1950s, Donald Maley organized what became well known as The Maryland Plan. This plan initially concerned itself with instructional methods developed through an analysis of human needs. By the 1960's this plan grew into a major curriculum project based on three assumptions:

1. Industrial arts is a cultural experience dealing with a comprehensive and indepth study of one of the most dominant forces (technology) in the contemporary society.

2. Many of the content items for industrial arts have persisted throughout the history of mankind as matters of vital importance and primary cultural focus in the evolving societies.

3. There is an increasing void in education with respect to the understanding of industry and technology as dominant cultural factors. (Cited in Cochran, 1970, pp. 80-81)

The critical focus on the development of the learner was the primary instructional emphasis of The Maryland Plan; however, the content base was drawn from both industry and technology. According to this plan, the study of the organization, materials, occupations, processes, and products of industry remained constant in the subject matter. Yet, technology was considered the core around which industry had grown. Regarding The Maryland Plan, Cochran stated:

The rationale for such a program was based upon the fact that the secondary school curriculum was dominated by mathematics and science, and the significant role of technology in the society was being overlooked. As a result, a concerted effort was made to develop a program based upon the integration and application of mathematical, scientific, creative, and manipulative abilities of youth. (1970, p. 80)

The appreciation of past technologies was to be enhanced through activities utilizing an anthropological approach. Students would also identify and confront the problems of living in an industrial and technological society. Essentially, The Maryland Plan blended the positive aspects of both the industry-based and the technologybased positions. That this was intended is apparent in Maley's later definition of industrial arts published in 1973:

Those phases of general education which deal with technology, its evolution, utilization, and significance; with industry, its organization, materials, occupations, processes, and products; and with the problems and benefits resulting from the technological nature of society. (Maley, 1973, pp. 2-3)

\section{Also, The Minnesota Plan for Industrial Arts} Teacher Education was published in 1958. This proposal, developed at the University of Minnesota, contained recommendations for improving the preparation of industrial arts teachers. Suggested changes involved a revision of the industrial arts subject matter to include individualized instruction in three "cores of experience:" science-mathematics, technology, and design. Meyer expressed a highly favorable opinion of The Minnesota Plan as follows:

They develop in this curriculum such items as industrial orientation, materials, a great deal of design, studies of power, studies of wave motion, chemistry and metallurgy, and in general depart rather radically yet apparently quite soundly from the normal and traditional industrial arts program. This is something we need to explore. $(1959$, p. 17) 
Also, Olson said this plan "should be considered as one of the significant contributions to teachereducation curriculum development in the second half of the century" (1963, p. 16). The Minnesota Plan contributed dramatically to the revision of industrial arts teacher education programs across the nation.

\section{Original Technology-based Programs}

During the 1960s, primarily two people guided the focus on technology as a theme for curriculum development in industrial arts. Delmar Olson and Paul DeVore each based his identification of content for industrial arts, to some degree, on separate analyses of technology. In 1957, Olson completed his graduate studies at The Ohio State University. His dissertation, Technology and Industrial Arts: Derivation of Subject Matter from Technology with Implications for Industrial Arts, included a proposal for an industrial arts curriculum "derived from an analysis of contemporary industry and reflective of technology. ..." Published through the backing of the honor society Epsilon Pi Tau, this proposal was considered as a plan, for the first time, by participants in the 1959 Virginia Industrial Arts Association conference (Olson, 1957, pp. 15-16).

In 1963, Olson, a professor of industrial arts at Kent State University, authored the book Industrial Arts and Technology, which improved upon his dissertation and focused on the need for a major change in the curriculum. In his book, Olson specified six functions of industrial arts derived from the technological culture and man as the creator and user of technology. Olson identified the sources that influenced the selection of his functions, likening them "to the outcomes of industrial arts as seen by Bonser and Mossman" and "the purposes of industrial arts as expressed in the Ohio Prospectus" (p. 165). In his article "Curriculum Movements in the 1960's," Daniel Householder (1979) said of Olson's plan: "his six functions for industrial arts: technical competence, occupational orientation, consumer competence, recreational liberation, cultural appreciation, and social competence, required a thorough understanding of technology" (p. 120).

Ronald Todd has stated: "Olson was the first to grapple with the difficult problem of identifying the new content structure of industrial arts if it were, indeed, to reflect technology" (1991, p. 20). Olson's analysis of technology, in Industrial Arts and Technology, was particularly noteworthy for the following explanation of the relationship between industry and technology:

Now study is defined as careful examination, investigation, inquiry, and research in order to determine the facts. And a science is defined as systematized knowledge derived from study, observation, experiment, and test. A broad interpretation of industry considers it as the system of enterprises for the development, production, and utilization of material goods and services by which a people gain control over their physical environment. Through rather logical deduction, then, technology becomes the science of industry. (1963, p. 55)

Olson's consideration of technology was rational and quite thorough. Yet, as unique as this approach was, Olson maintained the model of industrial arts as a study of industry. "Consequently," stated Olson, "we study industry to learn about technology, its techniques, skills, processes, products, services, and occupations" (1963, p. 55). Olson's early reasoning was revolutionary, but it did not break the mold that was the basis for traditional industrial arts programs.

Later in his career, Olson made it clear that he considered technology a body of knowledge equal to other content areas in general education. In 1971, he authored an article titled, "Technology, Environment, and Industrial Arts" in which he stated:
Industrial Arts education now takes responsibility for a basic, fundamental education, which every American needs because he lives in a technological environment. To interpret means to bring out the meaning of, and to do this technology becomes the discipline and the curriculum for industrial arts education.... We call it a new industrial arts. (p. 15)

In 1973, Olson, then Coordinator for Graduate Study in Industrial Arts at North Carolina State University, authored a publication titled Technol-o-gee. In it, he stated, "industrial arts, 
a discipline in general education, is the study of the technology" (1973, p. i). He also wrote: "industrial arts being a discipline serves a multi-faceted role among the academics as it functions within the context of general education with its body of knowledge representing the technology. It has its own identity, integrity, and responsibility" (1973, p. 6).

Though Olson originated the concept of analyzing technology to determine the functions of industrial arts, it is evident that his early analysis of technology was to be utilized primarily within the context of a study of industry. However, Paul W. DeVore, a former student of Olson's, contemplated the role of technology in industrial arts on a much broader scale.

DeVore taught industrial arts at the secondary level, later joined the faculty of Grove City College, and in 1956 was hired by the State University College, Oswego, New York. By 1960, he had become the director of the reputable industrial arts division at Oswego.

While at Oswego, DeVore's thinking about technology intensified. In 1964, the first annual report on the national convention of the AIAA, titled New Directions for Industrial Arts, was published. At that conference, DeVore made a presentation titled Technology: A Structure for Industrial Arts Content. In this address, he stated, "the efforts of the profession have failed to establish this area of education as an intellectual discipline" (DeVore, 1964b, p. 78). This statement was backed by his earlier effort to determine exactly what comprised an intellectual discipline. In Technology: An Intellectual Discipline, DeVore posited the following definition of a discipline:

An intellectual discipline:

1. has a recognizable and significant tradition, an identifiable history.

2. has an organized body of knowledge which has a structure with unity among the parts...

3 . is related to man's activities and aspirations and becomes essential to man by addressing itself to the solution of problems of paramount significance to man and his society,

4. identifies as a part of its tradition and history a considerable achievement in both eminent men and their ideas, and...
5. relates to the future of man by providing the stimulation and inspiration for man to further his ideals and to reach his goals. (DeVore, 1964a, p. 10)

DeVore found that technology fit the criteria to be considered an intellectual discipline in all but one aspect. The exception was that, to that point, no structure had been established for the organization of the content, or body of knowledge, for the study of technology. Thus, he proposed that technology be organized into seven areas: construction, communication, manufacturing, transportation, research and development, organization and management, and craft and service industries (DeVore, 1964a, p. 15). These organizers were similar to the classification scheme by Olson in the industry analysis from Industrial Arts and Technology.

On the final page of Technology: An Intellectual Discipline, DeVore issued a challenge to his colleagues in the profession. He wrote:

Those engaged in industrial arts education face a challenge. The challenge is simply stated. Educate the youth of today for a culture dominated by technology.

This is the challenge and the opportunity. To accept the challenge and to take advantage of the opportunity industrial arts educators need only address themselves to the study of the organized body of technological knowledge. (1964a, p. 15)

DeVore's perception of technology as a discipline was not without its critics. Anderson and Olstadt commented:

Those in industrial arts who feel that technology is the more appropriate body of knowledge have not analyzed all of the knowledge associated with technology. They have not structured the understanding necessary to understand technology. They have, rather, categorized different types of technology. This is not an unnecessary step or an unimportant activity. It is, in fact, one of the first steps necessary in the development of a body of knowledge. What has been developed is a vertical approach to the study of technology. (1971, p. 248)

Amidst the nationwide development of curriculum, DeVore's proposal also came under fire for not supplying a clear means to implement 
his new schema. In response, he prepared taxonometric principles to determine areas of technology that could apply to the structure of industrial arts. DeVore also explored methods for implementing the study of technology in public schools. Much of that work was accomplished during the 1965-66 academic year, when he took a sabbatical-which he spent at the University of Maryland.

The following year, DeVore moved on to West Virginia University, where he was allowed a great deal of freedom to study technology. In 1968, he authored a monograph, titled Structure and Content: Foundations for Curriculum Development, based on his work while at the University of Maryland. In his taxonomy, DeVore broke the study of technology into two broad elements - technical and cultural-social that each led further into a series of hierarchical elements. The second level of the hierarchy for technical elements consisted of production, communication, and transportation.

In Structure and Content: Foundations for Curriculum Development, DeVore voiced his support of the study of "man and technology" as an alternative foundation for the industrial arts curriculum. The study of man and technology was to be primarily "concerned with man as the creator of technology regardless of national origin" (1968, p. 2).

DeVore pointed out that technology studies would be suitable to the goals of general education and would be an area of knowledge readily addressed as a discipline. This new approach was also expected to provide a meaningful relation between technology and the historical, anthropological, social, and economic aspects of our culture. DeVore further asserted that a discipline is essentially a body of knowledge that meets the following criteria: it must be dynamic, cumulative, theoretical, structural, and integrative (1968, pp. 4-5). DeVore later declared:

The study of the creation and utilization of adaptive means, including tools, machines, materials, techniques, and technical systems, and the relation of the behavior of these elements and systems to human beings, society, and the civilization process is the field of study known as technology. (1980, p. xi)
It is important to recognize that this entire schema relied on the assumption that society would accept the premise of three bodies of knowledge (the humanities, the sciences, and the technologies) being integral to the development of general education programs (DeVore, 1968, p. 16).

\section{Technology Identified as the Future Direction within the Profession}

In 1972, the ACIATE sponsored an ad hoc "Committee for the Study of the Future." One goal of the Committee was to generate a yearbook dedicated to the topic of futurism and the future of industrial arts. This was achieved in 1976 with the publication of the 25th yearbook titled Future Alternatives for Industrial Arts. Chapter five, "Implications for Industrial Arts," was of direct interest to the profession. The authors, DeVore and Donald Lauda, cited eight implications the study of the future would have for industrial arts. The first declared, "if industrial arts is to contribute to the study of the future, then the most appropriate discipline base is the study of technology" (1976, p. 142). Other implications involved necessary changes in facilities, instructional strategies, teacher preparation, and a clear definition for the content and structure of "technology education."

That was a strong indication toward a desire to change the name of industrial arts. But it was not the first time such a suggestion was made. In 1966, William Warner said, "there is no question about our need for a new professional label because neither 'Industrial Arts' nor 'Industrial Education,' are descriptive or explicit enough to fill our needs in the decades ahead" (p. 8). Regarding the term "technology," Warner stated: "it is very palatable and certainly generic, but because of this, can be claimed by many others, so our use of it must be done with care" (1966, p. 8). This early consideration of a name change for the AIAA did not culminate in any action since a majority of leaders at that time were opposed to such a change.

As a graduate student at the University of Maryland, Kendall Starkweather established himself as a forward thinker. In 1975, he completed his doctoral dissertation titled $A$ Study of Potential Directions for Industrial Arts 
Toward the Year 2000 A.D. It was based on the views of 10 experts of futuristic studies within the industrial arts profession and concluded the following:

1. A new name should be created for the discipline appropriate for a profession seeking to interpret technology and industry in a post-industrial society.

2. Programs will move in the direction of applying technology to solve the major problems facing mankind.

3. Technology will begin to be studied from an international base.

4. New areas of content will begin to emerge (e.g., plastics, ceramics).

5. Traditional areas (e.g., wood, metal, drawing) will be grouped into broader areas of study such as materials and processes

6. Industrial arts will become more interdisciplinary and systems oriented.

7. Course content will have an emphasis on environmental considerations.

8. Post-industrial development will influence content with emphasis on technical knowledge, research, data retrieval, design, and technological change.

9. The affective domain and value systems will receive more attention. (Cited in Lauda, 1979, p. 237)

By virtue of employing a Delphi methodology, the conclusions from Starkweather's dissertation were effectively a compilation of the best existing ideas related to the development of a new approach for industrial arts. Each statement was well formed and helped to define the characteristics of the technology-based approach for instruction, serving as a forecast of things to come. Most of these conclusions became realities largely as the result of the strong convictions of Starkweather and the leaders who contributed to his study.

In 1979 and 1980, three separate meetings referred to as the Jackson's Mill Industrial Arts Curriculum Symposium provided the opportunity for 21 members from the vanguard of the profession to meet and deliberate on the direction of the industrial arts field. The significance of the Jackson's Mill Industrial Arts Curriculum Theory, the report from this symposium published in 1981, was the eventual consensus among differing points of view (Snyder \& Hales, 1981). For those who supported an industrybased view, it was difficult to give up "industry" as the key organizer even though they had identified technology as a major concern for the study of industry. The fact that those who favored that approach accepted technology as the motive underlying industrial arts education was significant. It represented a paradigm shift that, for many, required a great leap of faith.

In 1984, Starkweather (then Executive Director of AIAA) and the Association Board of Directors solicited a vote of the Association membership on the possibility of a name change. The vote required a two-thirds majority of the voting membership favoring a change of the name.

In April 1985, at the San Diego Conference, AIAA President William Dugger announced that organization would henceforth be known as the International Technology Education Association (ITEA). Also that year, Dugger directed a writing team from Virginia Polytechnic Institute and State University to rewrite standards to reflect the direction of technology education. The Standards for Technology Education provided a systematic arrangement of criteria to simplify the assessment of comprehensive technology education programs (Dugger, Bame \& Pinder, 1985). The primary goal of technology education, preparing students to be technologically literate, involved more than the mere understanding of what technology is and/or the acceptance of it. It involved many questions on the relevancy of the technology and its applications. Beyond the content, the learning process was also critical to the development of the student. "Thus the curricular role of technology education can and must be one that provides for an integrated, holistic approach to education in the 21st century" (Technology Education Advisory Council, 1988, p. 3).

\section{Integration of Disciplines}

During the 1990's, a number of approaches were devised for the delivery of technology education. Foster \& Wright recognized that many plans were developed "from an organizational standpoint" and gave examples such as "careerawareness" in elementary schools, "the modular 
approach" that became popular for middle or junior high, and "tech-prep" for high school programs. They stated, "technology education has also been viewed as constructive methodology for teaching important content from other school subjects" and identified approaches that had an "integrative theme" (1996, p. 15).

One of those (promoted by LaPorte \& Sanders in 1993) known as the Technology/Science/ Mathematics Integration Project was funded by the National Science Foundation (NSF) and designed to integrate disciplines at the middle school level. A later report by LaPorte \& Sanders concluded, "more than at anytime before in the history of education, the stage is now set for a closer working relationship among technology, science and mathematics" (1995, p. 209).

Dennis Herschbach (2009) also identified the trend toward integrating math \& science occurring around this time and that many science-related organizations were promoting science literacy. In 1990, the American Association for the Advancement of Science published Science for all Americans-and the third chapter was titled "The Nature of Technology." That chapter addressed ideas "sorted into three sections: the connection of science and technology, the principles of technology itself, and the connection of technology and society" (p. 25). Spurred by international studies that showed low achievement levels by American students, this report investigated how the nation could begin reforming its system of education in science, mathematics, and technology.

In 1996, the ITEA followed up with Technology for All Americans: A Rationale and Structure for the Study of Technology-a report based upon work funded through grants from NSF and NASA. This project stressed the need for technological literacy and that understanding technological systems "usually requires a knowledge from a variety of fields, especially science, mathematics, and technology" ( $p$. 19). The stated goal of the Technology for All Americans Project, led by William Dugger, was "to offer those who are interested in technology education a clear vision of what it means to be technologically literate, how this can be achieved at a national level, and why it is important for the nation (p. 49).
Prior to the turn of the century, significant discussion related to the coalescence of Science, Technology, Engineering and Math education occurred across many channels and within a wide range of related agencies and organizations, such as the National Council of Teachers of Mathematics and the American Society for Engineering Education. Although numerous groups were considering this amalgamation, Judith Ramaley is commonly credited with coining the acronym STEM (Koonce, Zhou, Anderson, Hening, \& Conley (2011). As assistant director of education and human resources at the National Science Foundation, she was unhappy with the acronym SMET in use at NSF since the 1990's. So, in 2001, she simply rearranged the letters and the emerging concept was branded (Christensen, Nov.13, 2011). Science, Technology, Engineering, and Math were now joined in the form with which we are now so familiar. However, as Mark Sanders pointed out, even though "some have suggested that STEM education implies interaction among the stakeholders. It doesn't." (2009, p. 21). Although a lot of funding has since been directed toward STEM education, and that doesn't mean all recipients are working together toward the same objectives.

David White pointed out that the "T and E" of STEM education "appears to be a stumbling block to producing meaningful STEM experiences to K-12 students"... because "many educators that are not in the fields Engineering and/or Technology are intimidated with (the associated) processes" (2014, p. 5). It is possible for one teacher to integrate concepts across all segments. Still, though a single teacher may have the ability, and desire, to teach across disciplines, they might be limited by the facilities, or tools and materials that are available to them. Optionally, working as a team, with teachers representing each discipline, toward common learning objectives can be an effective way to ensure that students are getting truly integrated STEM learning experiences.

\section{The Role of Technology in STEM}

STEM curricula's authors agree on the concept that it is beneficial to integrate the disciplines of science, technology, engineering, and mathematics. However, the integration of the disciplines must be substantial. The STEM initiative intends to avoid the traditional 
paradigm of separating subjects and, instead, blends them in a concrete, applied approach. The technology discipline has traditionally been recognized as an educational program with emphasis on the application and use of tools, materials, and techniques. Students "learn by doing" - using hands-on practices. Engineering involves design and planning for the application of math and science to build things.

Figure 1 identifies the role of each discipline in STEM that is based on the etymological origins of their titles. This organization of disciplines should not be perceived as a hierarchy. In the world around us, each discipline works in concordance with the others. For example, discoveries in math and science can inform engineering or, perhaps, generate new materials. In turn, developments in engineering and technology might create tools and techniques that shape materials to produce new artifacts, or devices, which can enable further discoveries. Also, between engineering and technology, the creation of "prototype" artifacts often reveals design flaws that need to be re-engineered. Once identified, these flaws can typically be explained by the principles of math and science.

Similarly, these disciplines can also work together harmoniously in education. An overemphasis on preparing "knowledge workers" (those who are proficient in math and science) may reduce the opportunity students have to work with real tools and materials to create technological artifacts. In contrast, those students focused exclusively on technology and developing skillful techniques often don't appreciate the mathematical and scientific principles that correspond to the work they do. STEM education can help technologyoriented students better understand this foundational knowledge. Engineering provides a bridge between the foundational knowledge and technological development through thoughtful planning and design. Technology and engineering can help make science and mathematics come to life through application. All the STEM disciplines are entwined like the threads in a steel cable.

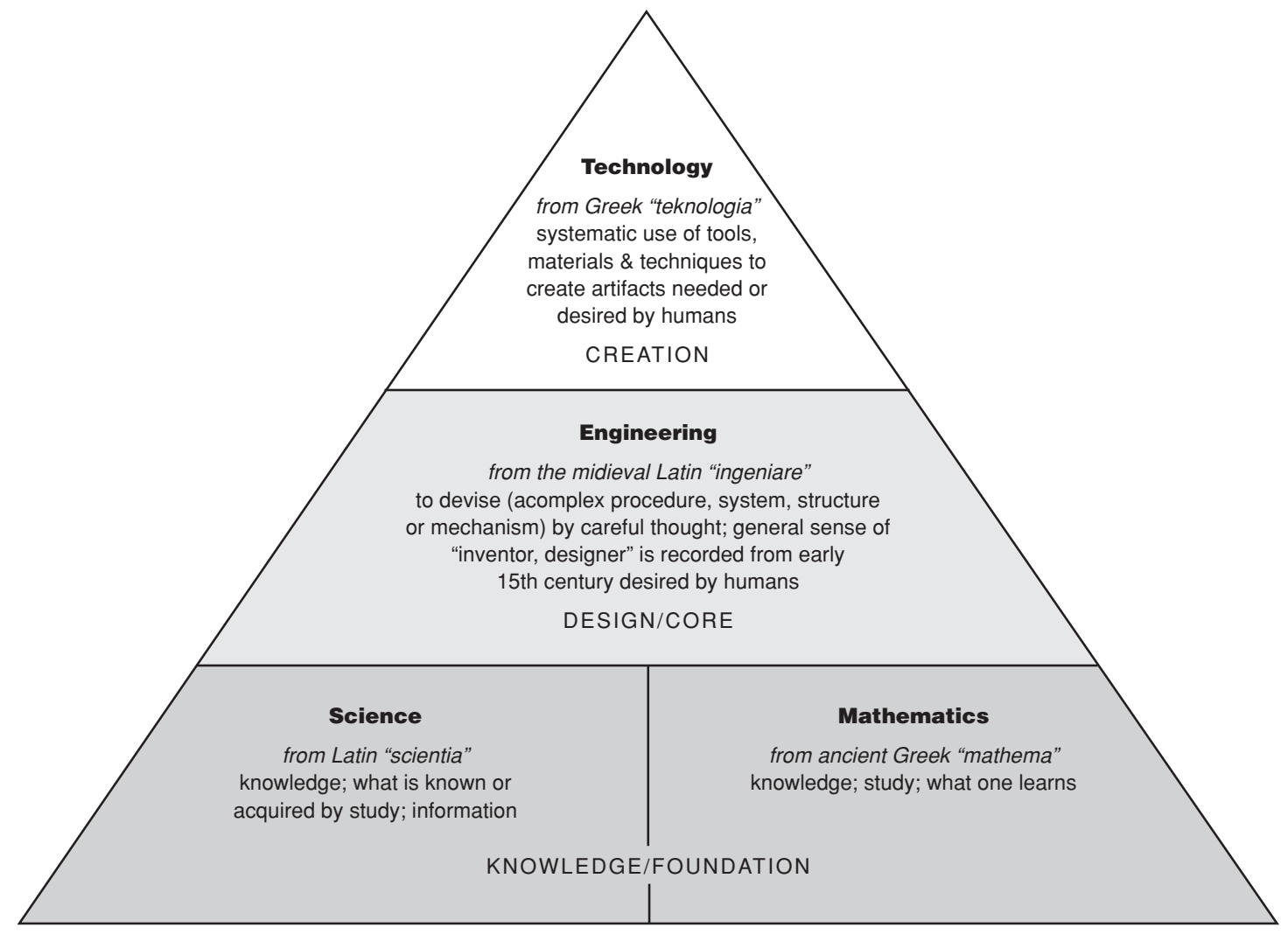

Figure 1. STEM disciplines organized based on etymological indications. This should not be perceived as a hierarchy. Each discipline works in concordance with the others. 
STEM education includes learning across all grade-levels and post-secondary programs. It is focused on developing scientific and technological literacy, teaching the engineering design process, as well as addressing innumeracy-the inability to utilize mathematical concepts and methods. Throughout the evolution of technology and engineering education, the discipline has applied hands-on, experiential learning methods to the design and creation of technological artifacts. Incorporating this methodology to solve problems that are inherently math and science oriented helps motivate learners, as well as increase their interest and abilities related to concepts they might not be drawn to otherwise.

The role technology and engineering plays in the broad spectrum of the STEM movement may not be straightforward for many STEM educators. Even through the past century, it took many people's perspectives and ideas to come to a consensus regarding the essence of the role of technology in education. Perhaps, through the review of this history, one can better understand the true nature of the field and come to appreciate the significance of integrating technology and engineering concepts into STEM education.

Dr. Mark Snyder is a Professor in the Department of Applied Engineering, Safety and Technology at Millersville University, Pennsylvania. He is a member of the Beta Chi Chapter of Epsilon Pi Tau. 
American Association for the Advancement of Science (1990). Science for all Americans. Oxford University Press.

American Industrial Arts Association (1948, June). The impact of technology. The Industrial Arts Teacher, p. 2.

Anderson, H., \& Olstadt, H. (1971). Why American industry? Man/Society/Technology, pp. 247-251.

Anderson, W. (1940, January). Editorial Comment: Industrial arts in general education. The Phi Delta Kappan, 22(5), pp. 233-234.

Bennett, C. (1917). The manual arts. Peoria, IL: The Manual Arts Press.

Bonser, F., \& Mossman, L. (1923). Industrial arts for elementary schools. New York, NY: Macmillan \& Company

Christenson, J. (2011, Nov.13). Ramaley coined STEM term now used nationwide. Winona Dailey News. www.winonadailynews.com/news/local/ramaley-coined-stem-term-now-used-nationwide/ article $457 \mathrm{afe} 3 \mathrm{e}-0 \mathrm{db} 3-11 \mathrm{e} 1$-abe $0-001 \mathrm{cc} 4 \mathrm{c} 03286 . \mathrm{html}$

Cochran, L. (1970). Innovative programs in industrial education. Bloomington, IL: McKnight \& McKnight Publishing Company.

Curtis, D. (1947, June). The new industrial arts curriculum. The Industrial Arts Teacher, pp. 1-3.

DeVore, P. (1964a). Technology: An intellectual discipline. Washington, DC: American Industrial Arts Association. (Bulletin Number 5)

DeVore, P. (1964b). Technology: A structure for industrial arts content. In New Directions for Industrial Arts: Addresses \& Proceedings of the 26th Annual Convention of the American Industrial Arts Association (pp. 78-80). Washington, DC: American Industrial Arts Association.

DeVore, P. (1968). Structure and content: Foundations for curriculum development. Washington, DC: American Industrial Arts Association.

DeVore, P. (1980). Technology: An introduction. Worcester, MA: Davis Publications, Inc.

DeVore, P., \& Lauda, D. (1976). Implications for industrial arts. In Smalley, L. H. (Ed.), Future alternatives for industrial arts: 25th yearbook of the American council on industrial arts teacher education. (pp. 137-162). Bloomington, IL: Mcknight Publishing Company.

Dewey, J. (1916). Democracy and education. New York, NY: The Macmillan Company.

Dugger, W., Bame, E., \& Pinder, C. (1985). Standards for technology education programs. South Holland, IL: Goodheart-Willcox Company, Inc.

Foster, P., \& Wright, M. (1996). Selected leaders' perceptions of approaches to technology education. Journal of Technology Education, 7 (2), pp. 13-27.

Herschbach, D. (2009) Technology education: Foundations and perspectives. Homewood, IL: American Technical Publishers, Inc.

Hickman, L. (1990). John Dewey's pragmatic technology. Indianapolis, IA: Indiana University Press.

Householder, D. (1979). Curriculum movements in the 1960's. In G. Martin, (Ed.) Industrial arts education: Retrospect prospect: 28th yearbook of the American council on industrial arts teacher education, (pp. 114-131). Bloomington, IL: McKnight Publishing Company.

International Technology Education Association (1996). Technology for all Americans: A rationale and structure for the study of technology. Reston, VA: ITEA. 
Koonce, D., Zhou, J., Anderson, C., Hening, D. \& Conley, V. (2011, June). What is STEM? Paper presented at the meeting of the American Society for Engineering Education, Vancouver, BC. www.asee.org/public/conferences/1/registration/view_session?session_id $=128$

Latimer, T. (1981). William E. Warner: Philosophy and influence on industrial arts. In D. R. Herschbach (Ed.) Industrial arts: A historical perspective. Reston, VA: American Industrial Arts Association.

LaPorte, J., \& Sanders, M. (1993). Integrating technology, science, \& mathematics in the middle school. The Technology Teacher, 52 (6), pp.17-21.

LaPorte, J., \& Sanders, M. (1995). Integrating technology, science, \& mathematics education.

In G. Eugene Martin (Ed.), Foundations of technology education, (pp. 179-219). 44th Yearbook of the Council on Technology Teacher Education.

Lauda, D. (1979). Industrial arts as a discipline for studying the future. In G. E. Martin, (Ed.) Industrial arts education: Retrospect prospect: 28th yearbook of the American council on industrial arts teacher education, (pp. 217-244). Bloomington, IL: McKnight Publishing Company.

Lemons, C. (1988). Technology education: The culmination of a seventy-nine year quest. In D.L. Householder, (Ed.), Industrial teacher education in transition: A Publication of the Papers Presented At the 75th Conference of the Mississippi Valley Industrial Teacher Education Conference (pp. 47-90). Mississippi Valley Industrial Teacher Education Conference.

Maley, D. (1973). The Maryland plan: the study of industry and technology in the junior high school. New York: Bruce.

Meyer, H. (1951, June). Industrial arts-What next? The Industrial Arts Teacher, pp. 15-17.

Meyer, H. (1959, November-December). Creed, deed and need. The Industrial Arts Teacher, pp. 16-18.

Olson, D. (1957). Technology and Industrial Arts. Columbus, OH: Epsilon Pi Tau.

Olson, D. (1963). Industrial Arts and Technology. Englewood Cliffs, NJ: Prentice-Hall, Inc.

Olson, D. (1971). Technology, environment, and industrial arts education. In Focus on technology in the classroom (pp. 10-17). Washington, DC: American Industrial Arts Association.

Olson, D. (1973). Technol-o-gee. Raleigh, NC: Office of Publications, North Carolina State University.

Osburn, B. (1955, December). Industrial Arts in Modern Education. The Industrial Arts Teacher, pp. 6-9.

Sanders, M (2009). STEM, STEM Education, STEMmania. The Technology Teacher, 68(4), pp.20-26.

Siepert, A. (1940, January). A philosophy. The Phi Delta Kappan, 22 (5), pp. 235-237.

Snyder, J. F., \& Hales, J.A. (1981). Jackson's mill industrial arts curriculum theory. Charleston, WV: West Virginia Dept. of Education.

Starkweather, K. (1975). A study of potential directions for industrial arts toward the year 2000 A.D. (Doctoral dissertation). MD: University of Maryland

Technology Education Advisory Council (1988). Technology: A national imperative. Reston, VA: International Technology Education Association.

Todd, R. (1991). The natures and challenges of technological literacy. In Dyrenfurth, M.\& Kozak, M. (Eds.) Technological literacy: Council on technology teacher education, (pp. 10-27).

Mission Hills, CA: Glencoe Publishing Company.

Warner, W. (1966). Industrial arts teacher education reflecting the technology in the decades ahead. Columbus, OH: Epsilon Pi Tau, Inc. 
56

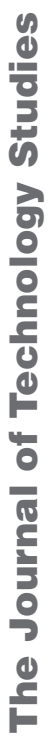

Warner, W., Gary, J., Gerbracht, C., Gilbert, H., Lisack, J., Kleintjes, P. \& Phillips, K. (1965). A curriculum to reflect technology. Columbus, $\mathrm{OH}$ : Epsilon Pi Tau. (Reprint)

White, D. (2014). What is STEM education and why is it important? Florida Association of Teacher Educators Journal, 1 (4), pp.1-9.

Whitesel, J. (1954, June). Purposes of the American council on industrial arts teacher education. The Industrial Arts Teacher, p. 9.

Wilber, G. (1948). Industrial arts in general education. Scranton, PA: International Textbook Company.

Williams, W. (1948, February). Industrial arts faces a new era. The Industrial Arts Teacher, pp. 1-3.

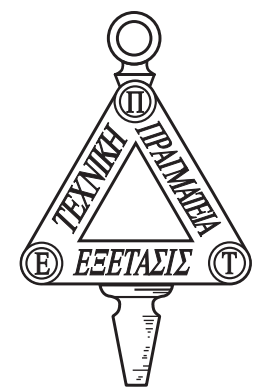




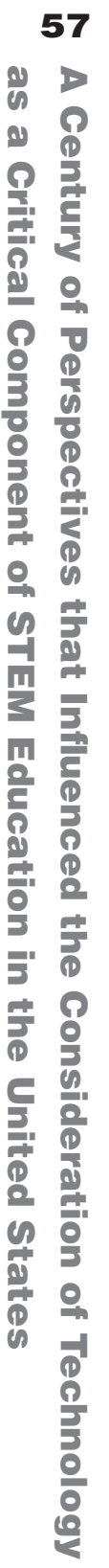




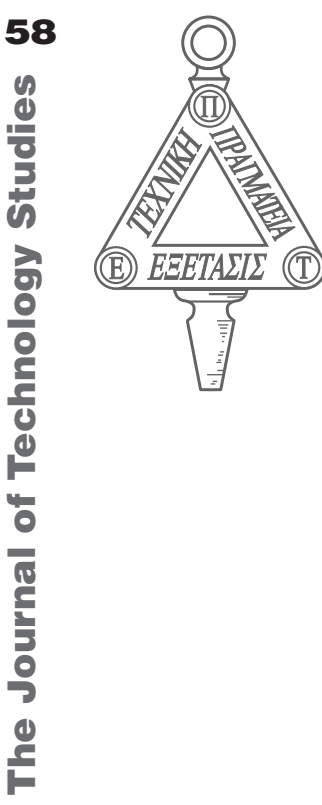

\section{Examining the Potential of Adaptive Comparative Judgment for Elementary STEM Design Assessment By Scott R. Bartholomew, Greg J. Strimel, Liwei Zhang, and Jessica Homan}

\begin{abstract}
STEM education practices and approaches have been emphasized in recent years at the elementary school level. The emphasis on STEM integration at the elementary level has stressed learning, motivation, and 21st-century skills as positive outcomes. Despite this emphasis, elementary level teacher assessment practices for open-ended STEM design challenges are not clearly established. Additionally, little is known about the teacher workload associated with various forms of assessment connected with these activities. Therefore, the researchers collected and examined data from four teachers and 100 elementary school students engaged in three STEM design problems. Teachers assessed student work using traditional approaches and a relatively new approach called adaptive comparative judgment (ACJ). The time teachers spent assessing student work using the two forms of assessment, the scores received through traditional assessment approaches, and the rank order of student work from the ACJ assessment were collected. The data analysis revealed key similarities and differences, in the time required for assessment and the outcome of traditional and ACJ assessment approaches.
\end{abstract}

Keywords: adaptive comparative judgment, elementary school STEM, design, assessment

\section{INTRODUCTION}

Efforts aimed at increasing science, technology, engineering, and mathematics (STEM) education at the elementary (grades K-6, ages 5-12) level have spread dramatically in recent years (Daugherty, Carter, \& Swagerty, 2014; Dejarnette, 2012; Murphy, 2011). Legislation, standards, curriculum, professional development, funding, and a variety of other resources have all been employed towards this end (Daugherty et al., 2014). Specifically, the development of the Next Generation Science Standards (NGSS Lead States, 2013), along with several initiatives geared toward STEM participation and younger students (i.e., Engineering is Elementary, Engineering by
Design, Project Lead the Way Launch, Teach Engineering, STEM: It's Elementary) have all led to an increased emphasis on STEM integration in elementary school classrooms. As elementary school teachers and administrators work to integrate STEM into their classroom, integration may often take shape in the form of problem-based, project-based, and designbased learning activities (Laboy-Rush, 2011), which engage students in hands-on activities with designing, prototyping, building, testing, and evaluating solutions to a posed problem. Advocates for implementing STEM activities, and the corresponding pedagogical approaches, posit that this integration will improve student motivation, achievement, and help students develop necessary 21 st-century skills and competencies for success in life (Daugherty et al., 2014; Laboy-Rush, 2011; National Academy of Engineering [NAE] \& National Research Council [NRC], 2014; NGSS Lead States, 2013).

However, in tandem with these curricular changes and emphases, teachers have often grappled with questions around the appropriate approaches to assess these open-ended activities (Bartholomew, 2017; Bartholomew, Nadelson, Goodridge, \& Reeve, 2017; Kimbell, 2007, 2012; Pollitt, 2012). This difficulty in assessment is not confined to elementary school classrooms; the open-ended nature of STEM problem-, project-, and design-based learning activities implies there is no single, correct answer for teachers to use in assessment (Bartholomew, 2017; Bartholomew \& Strimel, 2017; Pollitt, 2012). In conjunction with this difficulty, a variety of assessment approaches have been developed that employ various tools and techniques to try and improve these assessment situations; these include approaches such as rubrics, technology assessment platforms, and/or questionnaires (Bartholomew, 2017; Denson, Buelin, Lammi, \& D'Amico, 2015; Diefes-Dux, Moore, Zawojewski, Imbrie, \& Follman, 2004; Pollitt, 2004). 
One specific method for assessing open-ended problems, an approached called adaptive comparative judgment (ACJ), has proven especially reliable, valid, and effective with these open-ended problems at the middle school, high school, and higher education levels (Bartholomew, 2017; Bartholomew \& Yoshikawa, 2018; Pollitt, 2012; Seery, Canty, \& Phelan, 2012; Tarricone \& Newhouse, 2016). ACJ, as an approach to assessment, has been embodied in several web-based technology tools (e.g., CompareAssess), but it has not been previously tested with elementary school teachers in the United States (Bartholomew \& Yoshikawa, 2018). Further, ACJ — an approach developed with the express intent of a group of graders/ judges looking at student work (Pollitt, 2004) has not been tested with individual assessors completing the entire process (Bartholomew \& Yoshikawa, 2018). While we fully recognize that ACJ, as an approach, and CompareAssess, as a tool, were not intended to be used by individual judges, we also recognize that the educational paradigm and practices existing in many countries are centered on individual teachers assessing student work without the input of other assessors or judges (DigitalAssess, 2017).

Considering the increased emphasis on STEM education at the elementary school level, the challenges associated with the assessment of student work, the lack of research with ACJ at the elementary school level, and the uncertainty about the potential of an individual teacher using ACJ for assessment, this research sought to specifically investigate the teacher workload of individual elementary teachers while conducting assessments using both a traditional rubric approach and ACJ. This study specifically examined teacher experiences with the assessment of student work from 100 elementary school students (50 kindergarten [ages 5-7] and 50 fourth-grade [ages 8-10] students) using traditional rubric-centered approaches to assessment as well as ACJ. The data collected includes the score received through traditional rubric-based assessment and the rank order derived through ACJ assessment. Additionally, the time needed for teachers to complete each form of assessment for the student work and the teacher responses to a post-study questionnaire were both solicited to explore these implications and ideas.
PURPOSE OF THE STUDY

While the emphasis on STEM education practices, approaches, and techniques at the elementary school level has increased over recent years (Daugherty et al, 2014; Nadelson et al., 2013), less has been done to investigate different approaches to assessing open-ended design problems. ACJ, a new approach with high levels of reliability, appears to be a suitable approach for elementary school STEM settings, but little research has been done to test this potential and the associated classroom implications. Therefore, the purpose of this research was to examine the potential of using ACJ for assessing elementary school STEM design activities with individual teachers acting as judges.

\section{RESEARCH QUESTIONS}

Three specific research questions, which were used to guide this study and explore the overall potential and opportunities around $\mathrm{ACJ}$ in elementary school STEM assessment, were established:

$\mathrm{RQ}_{1}$ : What relationship exists, if any, between student achievement measures obtained through ACJ and rubric-based assessment approaches for elementary school STEM design activities?

$\mathrm{RQ}_{2}$ : What are the implications for teacher workload associated with ACJ and rubric-based assessment approaches to elementary school STEM design activities?

$\mathrm{RQ}_{3}$ : What are the practical implications of implementing ACJ assessment for elementary school STEM design activities by individual teachers?

\section{Elementary STEM Design Education}

The importance of STEM education, as early as elementary school, has been highlighted increasingly in recent years (Archer et al., 2012; Daugherty et al., 2014; DeJarnette, 2012; Kuenzi, 2008; Murphy, 2011). Kuenzi (2008) noted that STEM education, and the achievement of students in STEM subject areas, is critical in light of ensuring continued scientific and technological developments in years to come. Leading standards for STEM areas such as the Standards for Technological 
Literacy (ITEA/ITEEA, 2000/2004/2007) and the Next Generation Science Standards (NGSS, 2013) emphasize STEM concepts, principles, and literacy at the elementary level. DeJarnette (2012) posited that early exposure to STEM at the elementary level might lead to an increase in students' interest in STEM fields later in life. Furthermore, advancing STEM education may also provide students with opportunities to develop 21st-century skills, such as communication, problem solving, and systems thinking, while also increasing their understanding of important issues such health, energy efficiency, and environmental quality (Bybee, 2010).

\section{STEM Design Activities}

Classroom activities that incorporate STEM principles and concepts revolve around problem- and project-based learning scenarios where students often work in groups to design a solution to a problem (Laboy-Rush, 2011). Relatedly, the Standards for Technological Literacy suggest that elementary STEM education should provide students with diverse opportunities to address their natural curiosity and inventive thinking skills, and to develop their skills in designing, planning, making, and presenting solutions to technological problems (ITEEA, 2000/2004/2007). With the goal of STEM literacy, elementary teachers and educators can integrate problem-based learning opportunities which involve students in hands-on events where they design, make prototypes, test, evaluate, and document their solutions to real-life problems (Reeve, 2015). These types of learning situations have been proven effective in developing critical thinking, promoting student interest, and increasing opportunities for interactivity and innovation (DeJarnette, 2012).

\section{Elementary STEM Design Assessment}

Although there is an increased emphasis on STEM teacher training, knowledge of content, and pedagogy (Daugherty et al., 2014), the assessment of these open-ended STEM activities continues to be challenging for teachers (Bartholomew, 2017; Bartholomew \& Strimel, 2017). The large number of possible solutions to open-ended design problems and the elements of creativity and innovation can lead to difficulty in assessing student work using traditional approaches such as grading scales (Bartholomew, 2017; Kimbell, 2007, 2012; Pollitt, 2004, 2012). Even though rubrics, portfolios, and other assessment approaches have been recognized as potential options to assist teachers in assessing open-ended design activities (Kimbell, 2007, 2012), there are conflicting ideas and opinions regarding the best approach for assessing open-ended problems with validity, reliability, and efficiency (Pollitt, 2012). Further complicating the matter are teacher bias and subjectivity issues, which can influence assessment practices even when using rubrics and rubricbased approaches to assessment (Pollitt, 2004). Portfolios, along with student worksheets, are often used in conjunction with rubrics and criteria when evaluating design-based assignments; however, these approaches frequently require considerable time and effort for teachers to implement (Schilling \& Applegate, 2012). While technology tools are increasingly being leveraged to assess students' creativity and design-thinking skills (Denson et al., 2015), these tools can include similar problems via validity, reliability, and teacher biases (Pollitt, 2012).

\section{Adaptive Comparative Judgment}

$\mathrm{ACJ}$ is an assessment technique based on the principle of comparative judgment that was originally developed through the work of Thurstone (1927). Thurstone argued that human comparative judgments (judgments between two items) are more valid and reliable than subjective decisions based on some predetermined quality (Pollitt, 2004; Thurstone, 1927). Pollitt (2012) revisited Thurstone's work and piloted the use of comparative judgment (CJ) for the assessment of open-ended problems (Pollitt, 2004, 2012) In doing so, Pollitt utilized assessors without a rubric to tally a score for each student's project portfolio; rather, in a $\mathrm{CJ}$ approach assessors simply viewed pairs of student work and identified which item was "better" based on their own professional expertise. This judgment process was repeated with different pairings until a final rank order of student work was produced. A study by Pollitt and Murray (1993) that investigated the assessment of foreign language speaking was 
one of the first applications of CJ on modern assessment, and the results demonstrated a high level of reliability and validity for using CJ to assess student abilities. Pollitt's continued work with CJ eventually led to ACJ-an adaptive version of $\mathrm{CJ}$ that uses an algorithm to assist in lowering the number of judgments necessary to reach an appropriate reliability level (Pollitt, 2004, 2012). The ACJ process presents items for comparison that have similar win-loss records in order to increase the reliability and efficiency of the rank order production. As with $\mathrm{CJ}$, in ACJ a judgment is made holistically based on an assessor's professional expertise, experience with the subject area, and an identified "holistic statement," which frames the judgment (Pollitt, 2012). Once a "winner" is chosen out of each pairing, the system records the "win-loss" record for each item and facilitates the next comparison from the pool of items.

When employing ACJ techniques through CompareAssess, paired comparisons are completed until every item has been compared at least one time with another item - this is referred to as a "round" of judgment. The system updates the rank order of student work after each round so that the "winning" items rise and the "losing" items fall. The assessors (often referred to as "judges" in ACJ literature) continue to make judgments through multiple rounds to reach a desired level of reliability, which is calculated by the system after each round. Generally, the reliability of the final rank order increases as more rounds of judgments are completed (Pollitt, 2012); however, our experience suggests a point of diminishing returns where more judgments will only increase the reliability ever so slightly (experience has demonstrated that this happens after approximately 12 rounds of judgment). The final result of the ACJ process includes: (1) rank-order and parameter value statistics for all the items being compared, (2) Rasch-model misfit statistics for items and judges that can be used to identify any potentially significant areas of disagreement, and, if it is collected, (3) comments or justifications surrounding each decision made by the judges. The final rank order has been used in a variety of ways including, but not limited to the following: assigning grades, informing teacher pedagogy and student practice, as a formative tool for improvement, and as a fractional portion of total points received for a given assignment (Bartholomew, Strimel, \& Yoshikawa, 2019; Bartholomew \& Yoshikawa, 2018; Jones \& Wheadon, 2015; McMahon \& Jones, 2015).

The web-based ACJ portal used in this research, CompareAssess (DigitalAssess, 2017), is marketed out of England and has repeatedly demonstrated the ability to reach a high reliability level $(r>9)$ within approximately 12 rounds of judgments (Bartholomew \& Yoshikawa, 2018). ACJ, and CompareAssess specifically, have been studied and demonstrated reliable, valid, and effective results in both formative and summative assessment approaches at middle schools, high schools, and higher education levels (Bartholomew et al., 2017; Bartholomew \& Yoshikawa, 2018; Hartell \& Skogh, 2015; Kimbell, 2012; Pollitt, 2004; Seery et al., 2012; Strimel, Bartholomew, Jackson, Grubbs, \& Bates, 2017). However, ACJ as a tool for elementary teachers to assess open-ended design activities has not been tested (Bartholomew \& Yoshikawa, 2018). Additionally, ACJ as an approach and CompareAssess as a tool, for an individual teacher to use in assessment, have not been tested (Bartholomew \& Yoshikawa, 2018) because an individual teacher approach runs counter to the original intent of the approach that relies on, and uses, multiple judges, Rasch modeling, and the adapted algorithm from Thurstone (1927) to calculate the reliability of the emerging rank order of items. Despite this seemingly contradictory approach to ACJ assessment we believe it is important, and useful, to understand the implications of an individual teacher employing this tool for assessment in their classroom as an individual teacher approach most closely mirrors many of the current teacher practices in assessment. Therefore, this study purposefully sought to investigate the potential of ACJ for elementary school STEM design assessment use and the possibility of an individual teacher leveraging ACJ for their own assessment of student work.

\section{METHOD}

This study took place in a small suburban school district located in the Midwestern United States. This district is composed of a mostly Caucasian (85.6\%) middle-class population and serves approximately 10,000 students with a small free/ reduced lunch student population $(22 \%)$. 
Teachers.

Following the receipt of IRB approval, four teachers (two fourth grade teachers and two Kindergarten teachers) from one elementary school in this district were recruited for participation in this study based on their interest in ACJ and their STEM integration efforts in their classrooms. Each of the teachers was recommended by the school instructional excellence coach and had similar years of experience, licensure qualifications, and interest in STEM integration. All of the teachers were Caucasian, had taught for more than five years, and had little previous experience with STEM integration. Three of the teachers were female and none of the teachers had prior experience with ACJ assessment techniques. All teachers were trained prior to the study on the STEM activities and CompareAssess. Throughout the study, a member of the research team was present during each class to ensure fidelity of implementation (in both the classroom activities and ACJ use). The teachers led their students through three open-ended STEM design activities which involved students working in groups to employ an elementary school level design process and resolve a posed problem from a classroom text (see Table 1).

\section{Activities.}

A total of 100 students, from the four participating classrooms, were recruited for participation in the study, which took place during three in-class time blocks (between 60 to 90 minutes each) spanning three weeks. These activities represented the first time students were involved with STEM activities during this school year. The students, in each grade level, were presented with a problem from a book currently being read in the class (e.g., Pink and Say by Patricia Polacco for the fourth grade students), and then they were asked how they might solve the problem (see Table 1). Students worked in groups of 2-3 (uniquely-formed for each design problem by the classroom teachers) to identify the criteria and constraints around the problem (from the book), explored pertinent questions, brainstormed ideas, and examined possible solutions. The students filled out one design worksheet (developed collaboratively by the teachers involved in this project) per group while working on the problem (see Figure 1).

Students were provided with building supplies to use for creating a mock-up of their solution to the presented problem

Table 1. Student Problems and Supporting Text by Grade

\begin{tabular}{|c|c|c|}
\hline Grade & Problem & Mentor Text \\
\hline K & $\begin{array}{l}1 \text { - Design and build a box that does not allow frogs } \\
\text { but allows bugs access in/out }\end{array}$ & My Bug Boy by Pat Blanchard \\
\hline K & $\begin{array}{l}2 \text { - Design and build something to help the dragonfly } \\
\text { catch prey }\end{array}$ & Dragonflies by Margaret Hall \\
\hline K & $\begin{array}{l}3 \text { - Design and build something to help the toad come } \\
\text { out into the sunlight without getting too hot }\end{array}$ & Toads by Alyse Sweeney \\
\hline 4 & 1 - Design and build something to help Pink carry Say & Pink and Say by Patricia Polacco \\
\hline 4 & $\begin{array}{l}2 \text { - Design and build something to conceal and carry } \\
\text { a secret message for the army }\end{array}$ & $\begin{array}{l}\text { Great women of the Civil War } \\
\text { by Molly Kolpin }\end{array}$ \\
\hline 4 & 3 - Design and build something to help carry soldiers & $\begin{array}{l}\text { The Terrible, Awful Civil War } \\
\text { by Kay Mechiserdech }\end{array}$ \\
\hline
\end{tabular}




\begin{tabular}{|c|c|}
\hline \multicolumn{2}{|c|}{ Lesson 1: 4th Grade STEM Thinking Sheet } \\
\hline $\begin{array}{l}\text { Criteria: } \\
\text { - Design must lift Say off the ground } \\
\text { - Design should be no taller or wider than } \\
12 \text { inches }\end{array}$ & $\begin{array}{l}\text { Constraints: } \\
\text { - Limited to materials provided } \\
\text { - } 1 \text { - Dixie Cup } \\
\text { - } 2 \text { feet - String } \\
\text { - } 16 \text { - popsicle sticks } \\
\text { - } 1 \text { - 9' x } 11 \text { " sheet of paper } \\
\text { - } 2 \text { - normal length straws } \\
\text { - Masking Tape } \\
\text { - Limited time for creation }\end{array}$ \\
\hline $\begin{array}{l}\text { Ask: } \\
\text { How can we help Pink carry Say? }\end{array}$ & Explore: \\
\hline Model: & Evaluate: \\
\hline Explain: & Other ideas: \\
\hline
\end{tabular}

\begin{tabular}{|c|c|c|c|c|}
\hline \multicolumn{5}{|c|}{ STEM Thinking Assessment Rubric } \\
\hline & Emerging & Approaching & $\begin{array}{c}\text { Meets } \\
\text { Expectations }\end{array}$ & $\begin{array}{c}\text { Exceeds } \\
\text { Expectations }\end{array}$ \\
\hline Collaboration & $\begin{array}{l}\text { Group has no } \\
\text { product } \\
\text { - No evidence of } \\
\text { collaboration }\end{array}$ & $\begin{array}{l}\text { Group has multiple } \\
\text { products } \\
\text { - No evidence of } \\
\text { collaboration }\end{array}$ & $\begin{array}{l}\text { Group has no } \\
\text { product } \\
\text { - Evidence of } \\
\text { collaboration }\end{array}$ & $\begin{array}{l}\text { Group has one } \\
\text { product } \\
\text { - Evidence of } \\
\text { collaboration } \\
\text { with designated } \\
\text { roles }\end{array}$ \\
\hline $\begin{array}{l}\text { Process of } \\
\text { thinking }\end{array}$ & $\begin{array}{l}\text { No evidence } \\
\text { of thinking on } \\
\text { design process } \\
\text { page }\end{array}$ & $\begin{array}{l}\text { Attempts evidence } \\
\text { of thinking on } \\
\text { design process } \\
\text { page } \\
\text { - May not make } \\
\text { sense }\end{array}$ & $\begin{array}{l}\text { Clear evidence of } \\
\text { thinking on design } \\
\text { process page } \\
\text { about the text, } \\
\text { brainstorming, } \\
\text { and sketch of the } \\
\text { model }\end{array}$ & $\begin{array}{l}\text { Clear evidence of } \\
\text { thinking of the } \\
\text { design process } \\
\text { page with depiction } \\
\text { of connections } \\
\text { from brainstorming } \\
\text { tomode (arrows, } \\
\text { lines) }\end{array}$ \\
\hline Product Creation & $\begin{array}{l}\text { Limited evidence } \\
\text { of criteria and } \\
\text { constraints. } \\
\text { Prototype } \\
\text { does not fix } \\
\text { the problem }\end{array}$ & $\begin{array}{l}\text { Some evidence } \\
\text { of criteria and } \\
\text { constraints and } \\
\text { prototype solves a } \\
\text { problem } \\
\text { - Solved a } \\
\text { problem, but not } \\
\text { directly } \\
\text { connected } \\
\text { to the text }\end{array}$ & $\begin{array}{l}\text { Evidence of } \\
\text { adherence to } \\
\text { criteria and } \\
\text { constraints and } \\
\text { model solves the } \\
\text { problem from the } \\
\text { text }\end{array}$ & $\begin{array}{l}\text { Evidence of } \\
\text { adherence to } \\
\text { criteria and } \\
\text { constraints and } \\
\text { model solves the } \\
\text { problem from the } \\
\text { text. Students } \\
\text { include a written } \\
\text { description of the } \\
\text { produce }\end{array}$ \\
\hline
\end{tabular}

Figure 1: Student Worksheet and Rubric for the STEM Design Activities (4th grade, Problem 1) 

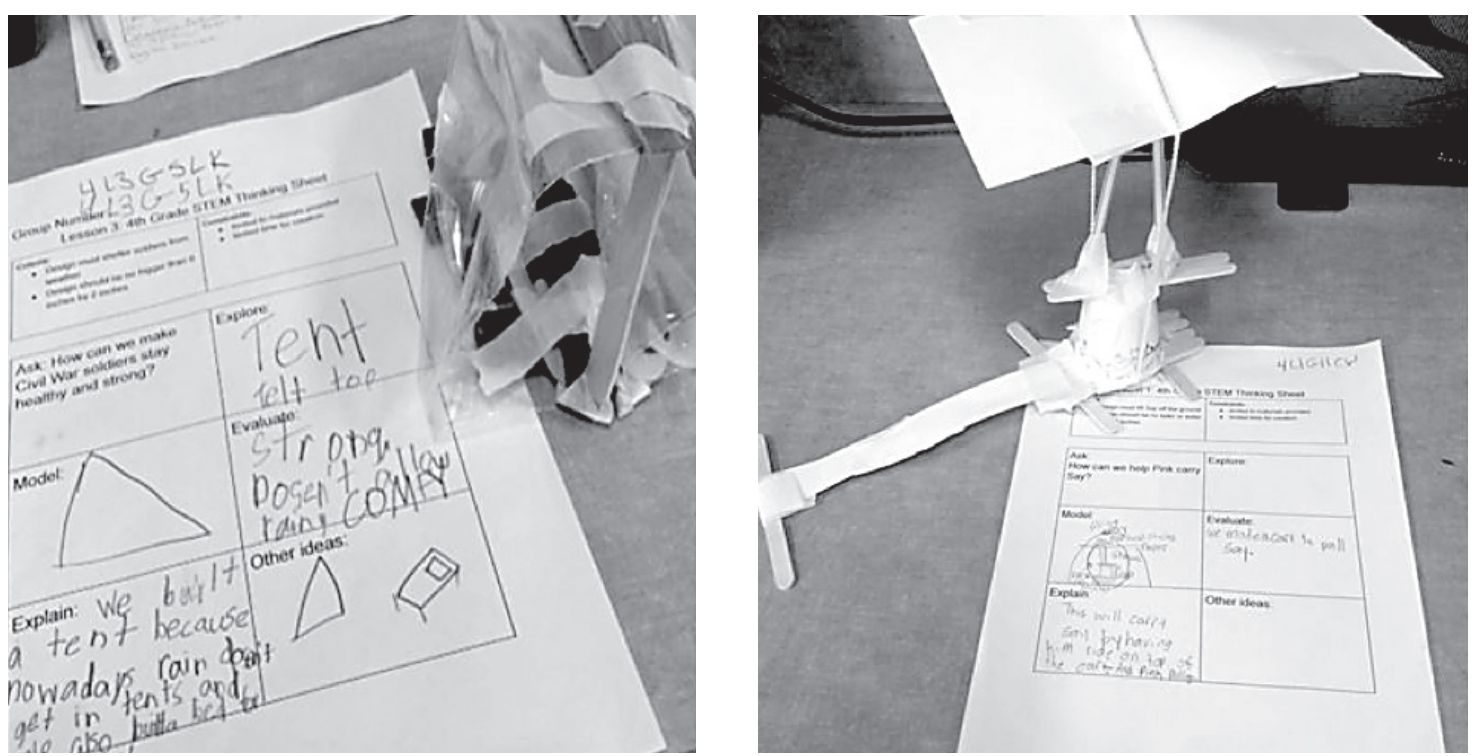

Figure 2. Student Worksheet and Mock-up Examples (Left: 4th grade, problem 3; Right: 4th grade problem 1)

(see Figure 2). While working on the problem, students were allowed to move freely about the classroom, solicit help from neighbors or the teacher, and obtain additional supplies, if needed, with permission from the teacher. An example of the student group mock-ups and finished worksheets are shown in Figure 2.

Following each activity the student groups submitted their worksheets and mock-ups for assessment. Each student mock-up was collected and a picture of the mock-up, and the accompanying worksheet, was taken for assessment. In alignment with the research protocol, no student names were collectedrather a unique group identifier was placed on the student worksheets and used to link student work, scores, and teacher assessment practices.

\section{Assessment.}

After pictures of the student work were collected and uploaded to CompareAssess, the teachers were instructed to assess their students' projects twice - using both rubric-based and ACJ assessment approaches for each submission. The assessment was completed for each portfolio and prototype that represented the work for one student group. Restrictions around the viewing of student work maintained that each piece of work was only assessed by the students' teacher. However, efforts to minimize the possible influence of two specific lurking variables (e.g., maturation and history) resulted in the researchers designating a specific assessment sequence for teachers around $\mathrm{ACJ}$ and traditional rubric methods for assessment (see Figure 3).

\begin{tabular}{|c|c|c|c|c|c|c|}
\hline & \multicolumn{2}{|c|}{ Problem 1 } & \multicolumn{2}{c|}{ Problem 2 } & \multicolumn{2}{c|}{ Problem 3 } \\
\hline $\begin{array}{c}\text { Kindergarten } \\
\text { Teacher 1 }\end{array}$ & $\begin{array}{c}\text { Traditional } \\
\text { Assessment }\end{array}$ & $\begin{array}{c}\text { Adaptive } \\
\text { Comparative } \\
\text { Judgment }\end{array}$ & $\begin{array}{c}\text { Adaptive } \\
\text { Comparative } \\
\text { Judgment }\end{array}$ & $\begin{array}{c}\text { Traditional } \\
\text { Assessment }\end{array}$ & $\begin{array}{c}\text { Traditional } \\
\text { Assessment }\end{array}$ & $\begin{array}{c}\text { Adaptive } \\
\text { Comparative } \\
\text { Judgment }\end{array}$ \\
\hline $\begin{array}{c}\text { Kindergarten } \\
\text { Teacher 1 }\end{array}$ & $\begin{array}{c}\text { Adaptive } \\
\text { Comparative } \\
\text { Judgment }\end{array}$ & $\begin{array}{c}\text { Traditional } \\
\text { Assessment }\end{array}$ & $\begin{array}{c}\text { Traditional } \\
\text { Assessment }\end{array}$ & $\begin{array}{c}\text { Adaptive } \\
\text { Comparative } \\
\text { Judgment }\end{array}$ & $\begin{array}{c}\text { Adaptive } \\
\text { Comparative } \\
\text { Judgment }\end{array}$ & $\begin{array}{c}\text { Traditional } \\
\text { Assessment }\end{array}$ \\
\hline $\begin{array}{c}\text { 4th Grade } \\
\text { Teacher 1 }\end{array}$ & $\begin{array}{c}\text { Traditional } \\
\text { Assessment }\end{array}$ & $\begin{array}{c}\text { Adaptive } \\
\text { Comparative } \\
\text { Judgment }\end{array}$ & $\begin{array}{c}\text { Adaptive } \\
\text { Comparative } \\
\text { Judgment }\end{array}$ & $\begin{array}{c}\text { Traditional } \\
\text { Assessment }\end{array}$ & $\begin{array}{c}\text { Traditional } \\
\text { Assessment }\end{array}$ & $\begin{array}{c}\text { Adaptive } \\
\text { Comparative } \\
\text { Judgment }\end{array}$ \\
\hline $\begin{array}{c}\text { 4th Grade } \\
\text { Teacher 1 }\end{array}$ & $\begin{array}{c}\text { Adaptive } \\
\text { Comparative } \\
\text { Judgment }\end{array}$ & $\begin{array}{c}\text { Traditional } \\
\text { Assessment }\end{array}$ & $\begin{array}{c}\text { Traditional } \\
\text { Assessment }\end{array}$ & $\begin{array}{c}\text { Adaptive } \\
\text { Comparative } \\
\text { Judgment }\end{array}$ & $\begin{array}{c}\text { Adaptive } \\
\text { Comparative } \\
\text { Judgment }\end{array}$ & $\begin{array}{c}\text { Traditional } \\
\text { Assessment }\end{array}$ \\
\hline
\end{tabular}

FIGURE 3. Assessment Approach Sequence for Teachers 
Teachers followed the specified approach (Figure 3), completing both the traditional assessment, using the rubric in Figure 2, and an additional web-based ACJ assessment through the CompareAssess portal. The ACJ portal facilitated the assessment by prompting teachers to login and then select a project for assessment (e.g., Project 1-3) after which teachers were then shown two images, each containing both the student's worksheet and mock-up, and asked to make a comparative judgment as to which was better. Teachers were instructed to make the decision between the two items holistically during ACJ assessment while also bearing specifically in mind the rubric and assignment description (see Kimbell [2007] and Pollitt [2012] for a thorough explanation and rationale behind the holistic nature of ACJ assessment). Teacher assessment times were collected automatically through CompareAssess and electronically through a web-based timer for the rubric-based approach.
Data Collection.

Data was collected to investigate the

overarching research question around the utility of ACJ, as an assessment tool, for STEM design activities - as performed by an individual teacher (see Figure 4). In order to compare the workload of the teachers for each of the assessment approaches, the time teachers spent assessing the student work, in each of the two approaches, was collected. Additionally, the results from the ACJ sessions were gathered and the teacher perceptions of ACJ, both as an assessment tool overall and specifically as a possible option for individual classroom teacher use, were collected through a poststudy questionnaire. These responses were specifically gathered and analyzed to better understand the teacher experiences with, and perceptions of, ACJ for individual assessment and classroom use.

\begin{tabular}{|c|c|c|c|c|}
\hline \multicolumn{5}{|c|}{ Traditional Scoring Rubric } \\
\hline & 1. Emerging & 2. Approaching & $\begin{array}{l}\text { 3. Meets } \\
\text { expectations }\end{array}$ & $\begin{array}{l}\text { 4. Exceeds } \\
\text { expectations }\end{array}$ \\
\hline Collaboration & $\begin{array}{l}\text { Group has no } \\
\text { product and } \\
\text { no evidence of } \\
\text { collaboration }\end{array}$ & $\begin{array}{l}\text { Group has } \\
\text { multiple } \\
\text { products } \\
\text { but no evidence } \\
\text { of collaboration }\end{array}$ & $\begin{array}{c}\text { Group has one } \\
\text { product } \\
\text { and there is } \\
\text { evidence of } \\
\text { collaboration }\end{array}$ & $\begin{array}{l}\text { Group has one } \\
\text { product } \\
\text { and evidence of } \\
\text { collaboration with } \\
\text { designated roles }\end{array}$ \\
\hline $\begin{array}{l}\text { Process of } \\
\text { thinking }\end{array}$ & $\begin{array}{c}\text { No evidence of } \\
\text { of thinking on } \\
\text { design process } \\
\text { page }\end{array}$ & $\begin{array}{l}\text { Attempts } \\
\text { evidence of } \\
\text { thinking on } \\
\text { design process } \\
\text { page but may } \\
\text { not make sense }\end{array}$ & $\begin{array}{c}\text { Clear evidence } \\
\text { of thinking } \\
\text { on design } \\
\text { process page } \\
\text { through text, } \\
\text { brainstorming, } \\
\text { and sketch of } \\
\text { model }\end{array}$ & $\begin{array}{l}\text { Clear evidence of } \\
\text { thinking on design } \\
\text { process page } \\
\text { with depiction of } \\
\text { connections from } \\
\text { brainstorming } \\
\text { to model (e.g., } \\
\text { arrows, lines) }\end{array}$ \\
\hline $\begin{array}{l}\text { Product } \\
\text { Creation }\end{array}$ & $\begin{array}{c}\text { Limited } \\
\text { evidence of } \\
\text { criteria and } \\
\text { constraints. } \\
\text { Prototypes } \\
\text { does not fix the } \\
\text { problem }\end{array}$ & $\begin{array}{l}\text { Some evidence } \\
\text { of criteria and } \\
\text { constraints and } \\
\text { prototype solves } \\
\text { a problem } \\
\text { but not directly } \\
\text { connected to } \\
\text { text }\end{array}$ & $\begin{array}{c}\text { Evidence of } \\
\text { criteria and } \\
\text { contraints and } \\
\text { model solves } \\
\text { problem from } \\
\text { text }\end{array}$ & $\begin{array}{c}\text { Evidence of } \\
\text { criteria and } \\
\text { constraints and } \\
\text { model solves the } \\
\text { problem from the } \\
\text { text. Students } \\
\text { include a written } \\
\text { description of the } \\
\text { product }\end{array}$ \\
\hline
\end{tabular}
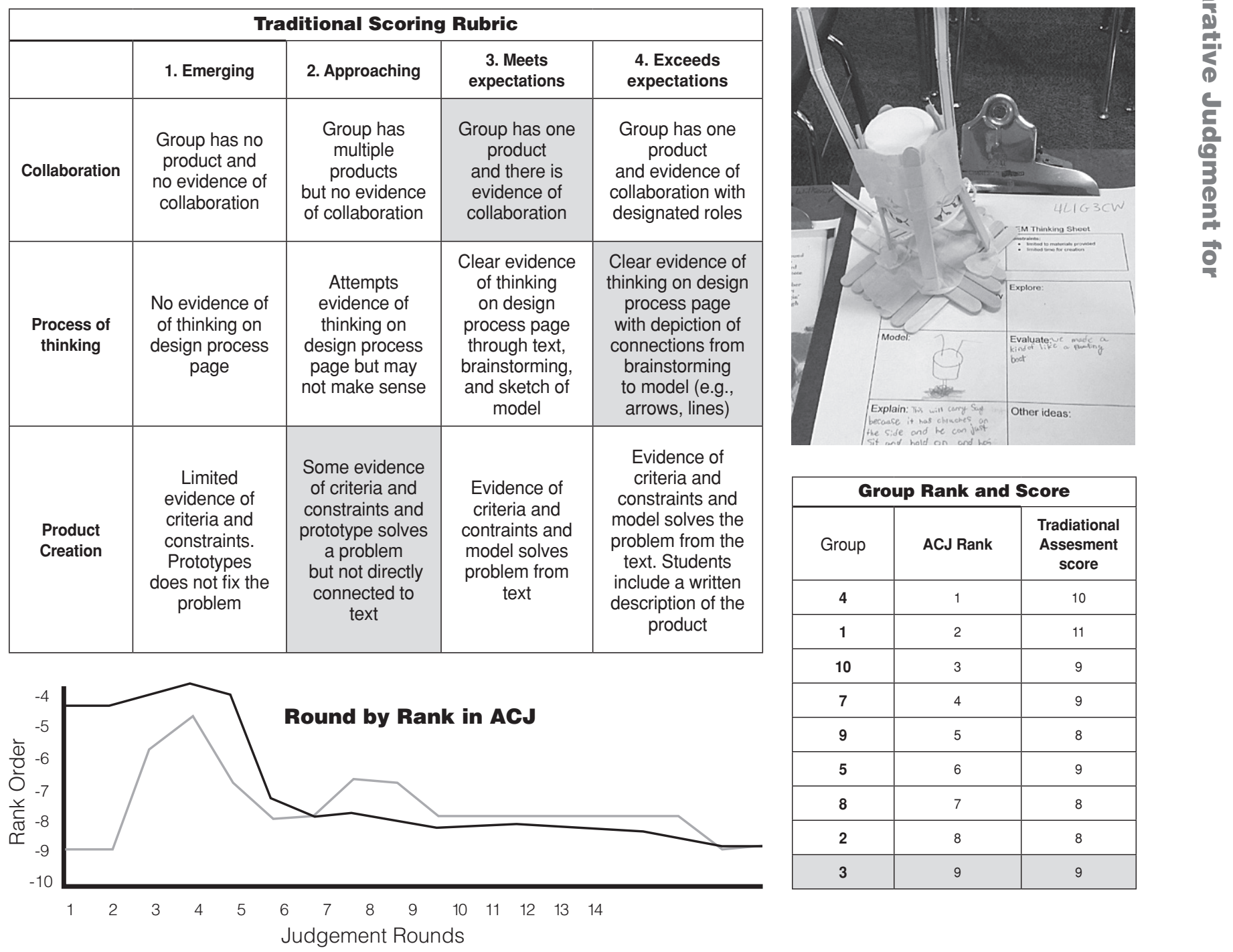

FIGURE 4. Assessment Data for Teacher 4, Group 3, Project 1 
These data were collected in an effort to explore the teacher workload, their perceptions of using ACJ for assessment, and the similarities and differences between the two different approaches to grading. All data were collected, conditioned, and analyzed using SPSS statistical software (Version 23). The data collection and the accompanying analysis for each research question are presented here.

\section{FINDINGS}

The findings from this study will be presented here in conjunction with each of the specific research questions that framed this work.

$\mathrm{RQ}_{1}$ : What relationship exists, if any, between student achie vement measures obtained through ACJ and rubric-based assessment approaches for elementary school STEM design activities?

The first research question investigated the potential relationship between ACJ and traditional assessment approaches for the elementary school STEM design activities. The teacher assessment scores and ranksobtained through rubric-based approaches and CompareAssess - were collected, and a Spearman correlation test was conducted for each problem by the teacher (see Table 2).

First, it should be noted that a negative correlation was expected as a lower rank corresponds with a higher-quality item - thus a negative correlation demonstrates alignment between the two approaches while a positive correlation would suggest dissonance. Second, it should be noted that the traditional rubric was created with the cooperating teachers and the teacher marks are based on their knowledge, understanding, and expectations for the associated grade level. Therefore, while it stands to reason that fourth grade students could be expected to outperform Kindergarten students on a given activity based on their maturity level and experience, each rubric used by teachers was designed with student's age, abilities, and backgrounds in mind.

Interestingly, two of the teachers $(1,4)$ were significantly aligned in their ACJ judgments and their traditional assessment for the first two problems, but they were not significantly aligned in problem 3 . Teacher 3's assessment practices were significantly correlated with the ACJ rank for the second assignment but were not significantly correlated for the other two problems. Finally, teacher 2 never demonstrated a significant correlation between the ACJ-ranks received and the score received by students through traditional assessment. A closer investigation of Teacher 2 revealed that almost every group in Teacher 2's classroom received the same grade for each problem through traditional assessment; for example, on problem 2 every group received a score of " 6 " except for one group, which was awarded a "5." Thus, these correlations were likely not significant as there was very little variation in score received through traditional assessment while the ACJ ranking demonstrated a spread from 1-7.

Table 2. Correlation between ACJ rank and Rubric Grade Received for Each Assignment

\begin{tabular}{llcl}
\hline Teacher & \multicolumn{3}{c}{$\begin{array}{c}\text { Problem } \\
\text { r, sig. (2-tailed) }\end{array}$} \\
\hline & \multicolumn{3}{c}{2} \\
\cline { 2 - 4 } $\begin{array}{l}\text { Teacher 1 } \\
\text { (Kindergarten, } \mathrm{n}=7)\end{array}$ & $-.94^{*}, .00$ & $-.79^{*}, .02$ & $-.52, .19$ \\
$\begin{array}{l}\text { Teacher 2 } \\
\text { (Kindergarten, } \mathrm{n}=7)\end{array}$ & $-.68, .10$ & $-.58, .13$ & $-.67, .07$ \\
$\begin{array}{l}\text { Teacher 3 } \\
\text { (Fourth Grade, } \mathrm{n}=7)\end{array}$ & $-.12, .80$ & $-.88^{*}, .02$ & $-.52, .30$ \\
$\begin{array}{l}\text { Teacher 4 } \\
\text { (Fourth Grade, } \mathrm{n}=9)\end{array}$ & $-.67^{*}, .05$ & $-.80^{*}, .01$ & $-.47, .20$ \\
\hline
\end{tabular}

*Correlation is significant at the 0.05 level (2-tailed) 
$\mathrm{RQ}_{2}$ : What are the implications for teacher workload associated with ACJ and rubric-based assessment approaches to an elementary school STEM design activity?

The second research question emphasized the similarities and differences in the workload required for teachers to use each assessment approach (rubric-based vs. ACJ)—as measured through the overall time taken for each form of assessment. The total time used for traditional assessment and ACJ was recorded and a onesample $t$-test was conducted to compare the differences in the total time taken by teachers using traditional assessment approaches and ACJ assessment approaches. There was a significant difference in the total time taken for teachers to conduct the assessment of each project through traditional $(M=389$ seconds, $S D=152.14)$ and ACJ assessment approaches $(M=715$ seconds, $S D=323.52)$ approaches, $t(11)=-2.98, p=.01$.

Closer analysis of the data revealed two significant outliers (more than triple the time taken in any other assessment) in the time taken by Teacher 4 to complete the ACJ assessment for projects 1 and 3 . These outliers, which may have resulted from a variety of factors (e.g., the teacher stepped away from the computer while the ACJ session was open and the extended time was recorded), were removed and the one-sample $t$-test was conducted again to further investigate this relationship. The one-sample $t$-test, conducted with the outliers removed, once again demonstrated a significant difference in the time taken for teachers to conduct the assessment through traditional ( $M$ $=412$ seconds, $S D=153.15)$ and $\mathrm{ACJ}(M=588$ seconds, $S D=131.38)$ approaches, $t(9)=-3.95$, $p=.006$. These results indicate that $\mathrm{ACJ}$, as an assessment approach, took significantly longer for the teachers in this study than the traditional assessment approaches.

In order to investigate the potentially significant influence of teacher, grade-level, or assignment on the total time for each assessment approach, we used a three-way main effect model with nesting. Following a check to ensure the required assumptions were met, the analysis was conducted and revealed that there was no significant influence on the time taken in either assessment approach from teacher, grade-level, or assignment.
To further investigate the quantitative findings

from this research, the teachers were asked, as part of the post-study questionnaire, how the use of ACJ for assessment compared with traditional approaches to assessment in terms of teacher workload. Overall, the teachers were undecided about whether ACJ took more, less, or the same amount of time as traditional methods of assessment; of the four teachers surveyed, half (2) responded that ACJ took less time than traditional forms of assessment, one teacher marked that it took same amount of time, and one teacher marked that ACJ took more time. When the teachers were asked for further clarification they responded with comments that suggested that ACJ was more time-intensive than traditional approaches. A few qualitative comments from the teachers include:

" $[A C J]$ took more time than I originally thought it would"

"I wish ACJ was a bit more efficient. I felt like there were more steps than were necessary while assessing projects"

"At first [ACJ] seemed to take a long time.

It seemed like it got faster as I did the evaluations more"

"Getting [the ACJ done] took a considerable amount of time. I think the traditional rubric was slightly easier and teachers would need to understand the benefits of comparing projects in order to see its value"

$\mathrm{RQ}_{3}$ : What are the practical implications of implementing ACJ assessment for elementary school STEM design activities by individual teachers?

The third research question investigated the potential possibility of an individual classroom teacher using ACJ for assessment of student work in order to address the lack of research done in this area (Bartholomew \& Yoshikawa, 2018; M. Wingfield, personal communication, May 17, 2017). This was important as the majority of classroom assessment, in the current educational culture in the United States, involves a teacher assessing student work individually and then assigning grades. The data collected around this question comes from two sources: poststudy questionnaires completed by the teachers and the round-by-round exploratory analysis of rank-order for the ACJ sessions completed by the teachers. 
The post-study questionnaire sought to specifically elicit teacher perceptions of ACJ, as an approach, and CompareAssess, as a tool, for an individual teacher to use in assessment, as compared with traditional rubric-based approaches to assessment. Recognizing the small sample size $(N=4)$, we position the teacher responses as informative and stimulating in terms of guiding future research around ACJ. The findings from the post-study questionnaire, classified by theme, are presented next:

\section{Ease of Use}

Overall the teachers believed that ACJ was easier to use for assessment than rubric-based forms of assessment with $75 \%$ ( 3 out of 4 ) teachers noting that ACJ was easier to use than a rubric for assessment, whereas one teacher marked that it was the same, in terms of difficulty. When asked about the ease of use several teachers commented:

It's easy to compare two images side by side, I can zoom in, I see the same project more than once, compared to other items, I can add comments.

I liked that ACJ made it easy to see projects side by side in a comparison. It made it easy to see the differences in the projects, and assess the projects accordingly. I liked the speed with which I could assess projects with ACJ...it was faster than going through the rubric.

\section{Confidence in Results.}

All of the surveyed teachers responded that they were "confident in the results obtained from ACJ" when surveyed. Every teacher identified the same confidence level in the results obtained from ACJ as that from traditional assessment approaches. Related, all teachers marked that the rank orders from ACJ were "similar in usefulness" to traditional assessment results. Teachers suggested using the results as a learning tool for students (i.e., using the top ranked item as an example for discussion) or as a portion of the student's final grade from an assignment. When asked about their confidence one teacher remarked:

The same project continued to pop up as the best one so I was confident in my decision.
Similarly, when asked about the usefulness of ACJ and possible future uses two teachers noted the potential for future use of ACJ in their classrooms:

[ACJ] is quick to use and has lots of use for what we do in 4th grade.

I would like to try this with writing.

\section{Implications of Individual Teacher Use}

While previous work with ACJ has revolved around groups of judges completing the judgments, this study emphasized the exploration of the potential for using ACJ with one teacher. In order to do this, we sought to investigate the implications of this use and explore the number of judgment rounds necessary for an individual teacher to use ACJ effectively in the classroom and obtain a useful rank order. In previous work with ACJ, and CompareAssess, the resulting reliability level of the rank order has been a tool for identifying a "solid" rank (Pollitt, 2012), however, with only one individual performing the ACJ assessments in each session the reliability level was no longer a useful measurement around which to determine the stopping point for judgments (M. Wingfield, personal communication, May 17, 2017).

Fully recognizing limitations in our approach; namely, not relying on/trusting the computed reliability with the ACJ-based statistics, and not using the approach (ACJ) or the interface (CompareAssess) as intended (i.e., with a group of judges) - we informed the teachers to continue with ACJ judgments until they had completed at least eight rounds of judgment for each of the assignments. This was done intentionally to facilitate both random and adaptive pairings - the first five rounds of judgment displayed random pairings while the later rounds included the "adaptive" component with similarly judged items displayed in pairs. The rank orders of student work for each round were compared; round by round, to identify how the compared items moved between rounds based on the judgments made by teachers. Additionally, the eventual top-ranking item (from round 8) was tracked in an effort to explore how this item's rank fluctuated through the rounds of judgment. Figure 5 presents the findings from this exploratory exercise with the rank order at the conclusion of round 8 identified in gray and the top-ranking item identified with black. 
Teacher 1, Project 1

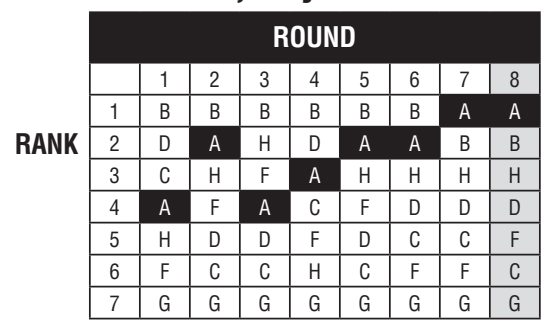

Teacher 1, Project 2

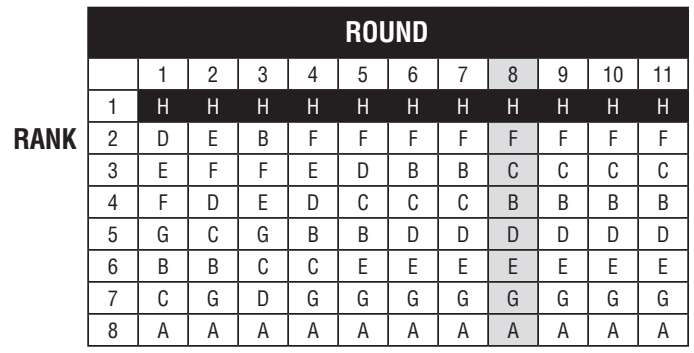

Teacher 1, Project 3

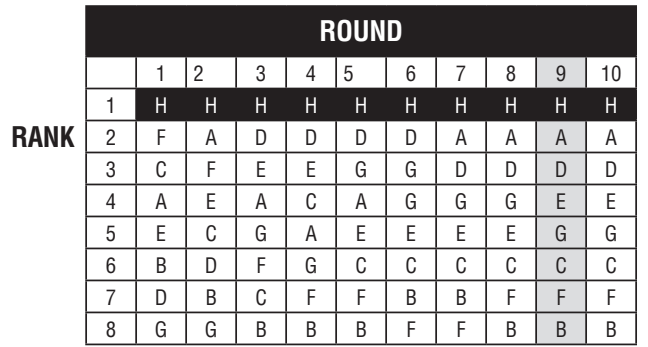

Teacher 2, Project 1

\begin{tabular}{|c|c|c|c|c|c|c|c|c|c|}
\hline & & & & & I & & & & \\
\hline & & 1 & 2 & 3 & 4 & 5 & 6 & 7 & 8 \\
\hline & 1 & C & $E$ & $E$ & B & B & B & B & B \\
\hline RANK & 2 & B & B & B & $\mathrm{F}$ & C & $E$ & $E$ & $E$ \\
\hline & 3 & $E$ & $\mathrm{~F}$ & C & $C$ & $E$ & $F$ & $F$ & $F$ \\
\hline & 4 & A & C & $F$ & $E$ & $F$ & C & C & C \\
\hline & 5 & $F$ & $A$ & $G$ & $A$ & $A$ & A & $A$ & $A$ \\
\hline & 6 & $\mathrm{D}$ & $G$ & $A$ & $G$ & $\mathrm{D}$ & $G$ & $G$ & $G$ \\
\hline & 7 & $G$ & $D$ & $D$ & $D$ & $G$ & $D$ & $D$ & \\
\hline
\end{tabular}

Teacher 2, Project 2

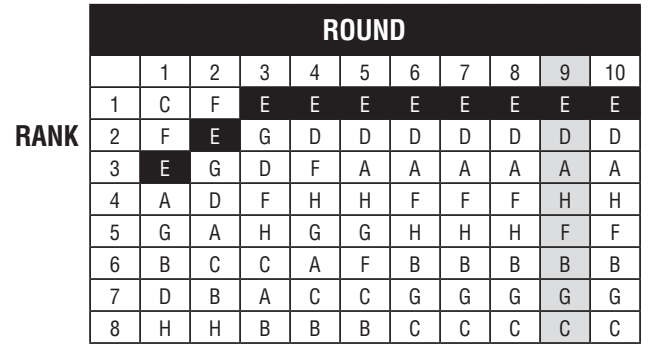

Teacher 2, Project 3

\begin{tabular}{c|c|c|c|c|c|c|c|c|c|c|c|}
\multicolumn{10}{c|}{} & \multicolumn{10}{c|}{ ROUND } \\
\hline & RANK & 2 & 3 & 4 & 5 & 6 & 7 & 8 & 9 & 10 \\
\cline { 2 - 12 } & 1 & B & E & E & E & E & E & E & E & E & E \\
\cline { 2 - 11 } & 2 & J & J & J & A & B & A & A & B & B & B \\
\hline & 3 & E & F & A & B & J & B & B & A & A & A \\
\hline 4 & F & G & F & D & A & J & J & J & D & F \\
\hline 5 & D & D & B & F & K & F & F & F & F & D \\
\hline 6 & A & A & K & J & F & D & D & D & J & K \\
\hline 7 & C & B & D & H & D & K & K & K & K & J \\
\hline 8 & G & H & G & C & C & C & C & C & C & C \\
\hline 9 & K & K & C & G & G & H & H & H & H & H \\
\hline 10 & H & C & H & K & H & G & G & G & G & G \\
\hline
\end{tabular}

Teacher 3, Project 1

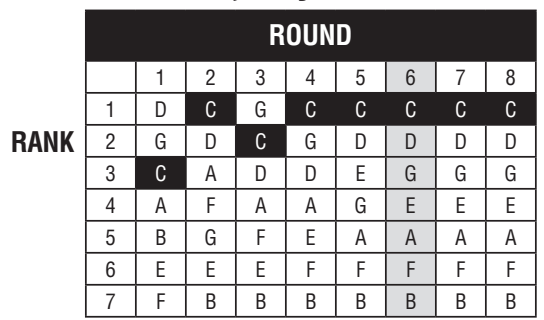

Teacher 3, Project 2

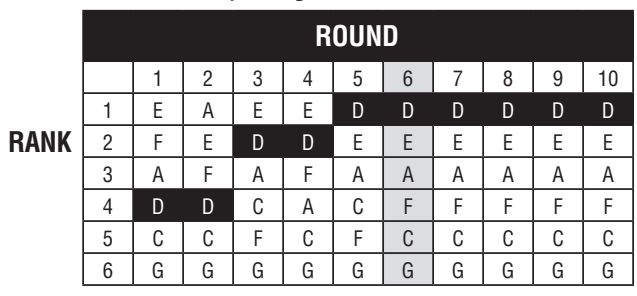

Teacher 3, Project 3

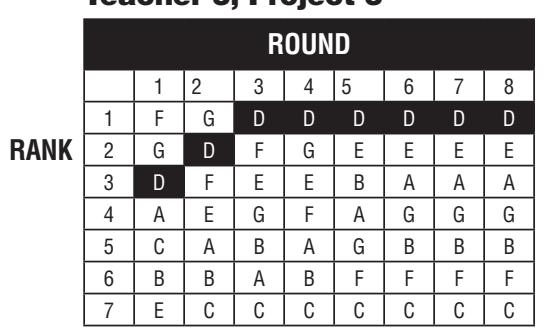

Teacher 4, Project 1

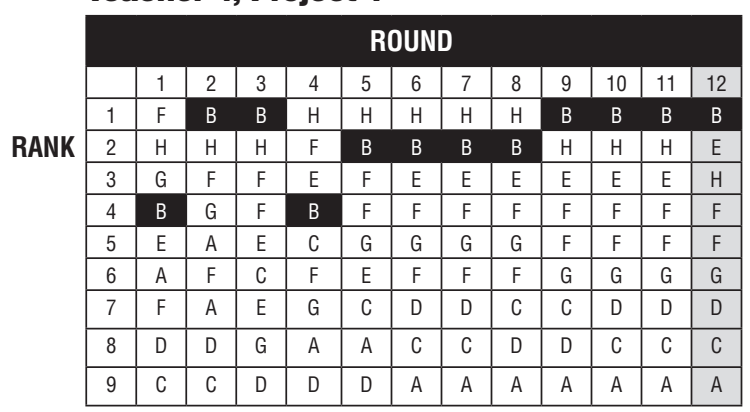

Teacher 4, Project 2

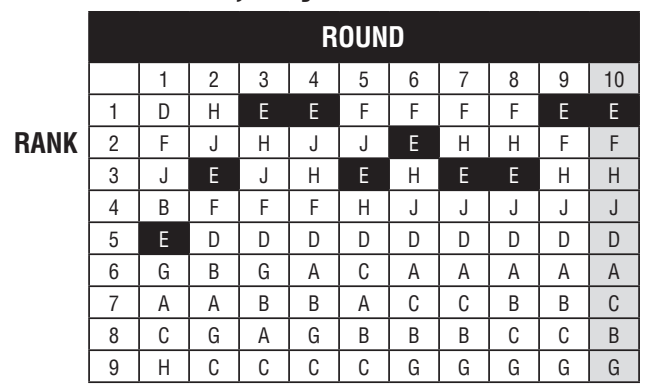

Teacher 4, Project 3

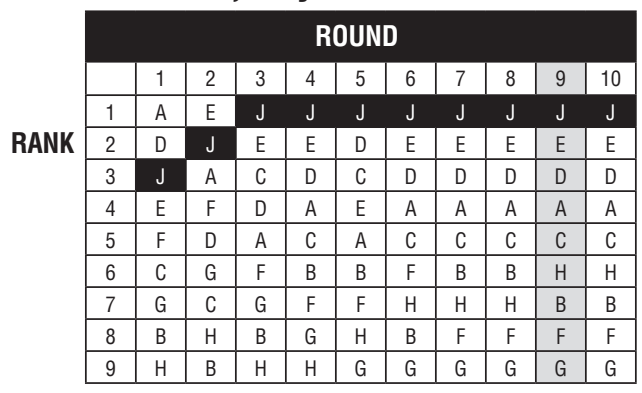

FIGURE 5. Round by Round Rank of Student Work for Each Teacher and Project Assignment 
The analysis showed that, when completed individually, the number of rounds required to reach a "stable" rank order may be, at least partially, contingent on the judging style of each teacher/judge. Holistically, our analysis suggested that somewhere between six and ten rounds of judgment the rank order of items began to stabilize when ACJ was completed by an individual judge. For some teachers (Teacher 3) six to eight rounds of judgment appeared to consistently produce a more "stable" rank order, whereas for other teachers (Teacher 4) ten rounds of judgment was still not enough for the rankings of student work to demonstrate consistency. We fully recognize that a variety of factors influenced these rank orders and the preliminary indications including, but not limited to, the number of pieces of student work, the type of work being assessed, the teachers involved in this study and their training, experiences, grading practices, background, and exposure to ACJ. Further, it should be noted that these findings - which are exploratory in nature - were contingent on the ACJ-platform (CompareAssess), the order items were presented to judges, and the way items were paired. Additionally, while these findings are confined to the judges in this study, the student work, and the ACJ tool used for this research, the analyses, findings, and implications are important and provocative in terms of future implications and research around $\mathrm{ACJ}$ - especially if classroom teachers continue to complete assessment for student work individually.

\section{DISCUSSION AND CONCLUSION}

Similar to previous research with high school (Pollitt \& Crisp, 2004; Newhouse, 2011; Steedle \& Ferrara, 2016), middle school (Bartholomew, Reeve, Veon, Goodridge, Stewardson, Lee, \& Nadelson, 2017; Bartholomew, et al., 2017), and post-secondary students (Seery, Canty, \& Phelan, 2012; Strimel et al., 2017), the correlation between the ACJ ranking and the students' scores obtained through traditional assessment approaches at the elementary school level was significant for select teachers during certain problems. However, for other problems these same teachers, and the other teachers involved, did not demonstrate significant correlations between their traditional assessment practices and the rank order of student work. This suggests that alignment of ACJ results with traditional forms of assessment may not be universal and may be a function of a variety of factors such as grade level, problem scenario, number of judges, and teacher assessment strategies and practices. Additionally, it should be considered that although ACJ provides a rank order of the included items, it does not speak to the overall, or specific, quality of the items (e.g., the topranked item may still not be very "good" in terms of functionality of teachers' expectations, or the lowest ranked items may be considered acceptable work according to the assignment criteria). It is possible that neither approach to assessment was truly a valid measure of student achievement or learning. It is also possible that only one of the assessment approaches is valid, whereas the other approach is not. We also wish to draw attention to the fact that no reliability or validity data was available for the teacher-created rubrics - these are important considerations, which may influence areas for future research and exploration.

Our findings, while limited in nature by the small sample of teachers, the problem context, and the research design, highlighted significant differences in assessment approaches between teachers. Although the provided rubric guided teachers to use their expectations of students in assessment, it was apparent from the results that these expectations were sometimes very different for different teachers. Also, while some teachers traditional assessment scores varied significantly, other teachers had little to no variation in the scores students were given through traditional assessment; a difference that was especially highlighted in comparison with ACJ because ACJ systematically established differences between each student through the ranking process. It was evident, from our findings and observations, that some of the teachers included in this study routinely had very little deviation in the scores assigned to students with many, if not all, students receiving full marks for simply completing an assignment. We also wish to point out that, keeping in line with commonly practiced approaches, no reliability measures were attempted in relation to the traditional scoring approaches utilized by the teachers. The teachers included in this study used rubrics with reliability testing only in "high-stakes" test scenarios (i.e., state- and nationally-administered tests). 
A look at the teacher comments and the collected time records revealed that ACJ took significantly longer than traditional forms of assessment. The findings from this study, uniquely situated with an individual teacher using ACJ, align with previous research (Pollitt, 2012) around groups of judges using ACJ. The significant difference in time was consistent for all teachers in this study and teacher comments on the post-study questionnaire supported this sentiment. Despite the increased time required to implement $\mathrm{ACJ}$, teachers in this study were positive toward its potential for integration into their classrooms and believed ACJ was easier in terms of making judgments than making criteria score decisions using traditional forms of assessment. Teachers expressed confidence in the results obtained through ACJ and the majority of the suggestions for improvement were focused on the interface of the software platform rather than the actual approach.

While ACJ may take more time than traditional forms of assessment, several benefits of ACJ, which have also been identified elsewhere, were identified by teachers in this study including: the comparability of the results obtained through ACJ and traditional assessment practices (Strimel et al., 2017), the ease of implementation in classrooms (Bartholomew, 2017), a holistic emphasis in assessment (Kimbell, 2007), and the prospects of using ACJ for student learning (Bartholomew et al., 2017). While the teachers in this study recognized that ACJ took more time than traditional assessment, several pointed out that the built-in feedback and comparison function of CompareAssess was an added benefit that may actually work to expedite the process of assessment in certain settings. Therefore, while our findings indicate that traditional assessment approaches were more time efficient, there may be several other important factors (i.e., the time required to provide feedback to students), which were not taken into consideration.

Based on our findings we contend that ACJ is most feasible used as directed - with multiple judges. Although this runs counter to commonly practiced educational assessment tactics in K-12 classrooms, this method appears to not only be the most valid and reliable but also to be the most effective and efficient. We recommend that future research into the possibilities and implications of individual teacher use be conducted to investigate possible widespread implementation of ACJ by individual teachers and other potential models which

may increase the validity, reliability, utility, and efficiency of its integration. For example, comparing student work with items on a known scale/rank could potentially be useful in terms of facilitating judgments by an individual teacher while still collecting reliability and validity measures.

Our findings revealed that the number of judgment rounds required to reach a "stable" rank order was different for each teacher/judge. This is sensible given the variety of difference in teacher perceptions, backgrounds, and the factors involved in assessment of student work (Alkharusi, 2011; Crossman, 2004; Dietrich, 2010; Rice, 2010). From our research, we identified a range of 6-10 rounds of judgment as a potential basis for future research, practice, and implementation of ACJ by an individual.

Despite the differences in the number of rounds required for a stable rank to appear, the teachers hinted at a potential increased efficiency at identifying the top-ranking item over the course of the research (spanning three design projects) suggesting that, with time, teachers may become more efficient at producing a stable rank order and identifying the relative quality of student work through ACJ. Future research could focus on identifying the number of required rounds for a stable rank to appear and the potential for teachers to increase in judgment efficiency over time. Additionally, the possibility of using ACJ to assist individuals and teams of teachers in reducing inherent teacher biases (Bartholomew, 2017) and implementing different approaches to assessment, merits further investigation, research, and discussion.

Scott R. Bartholomew, Ph.D., is an assistant professor of Engineering/Technology Teacher Education at Purdue University, West Lafayette, Indiana.

Greg J. Strimel, Ph.D., is an assistant professor of technology leadership and innovation at Purdue University, West Lafayette, Indiana.

Liwei Zhang is a masters student and graduate research assistant in the Engineering Technology Teacher Education program at Purdue University.

Jessica Homan is a library media specialist at Noble Crossing Elementary. Jessica is a Project Lead the Way lead teacher, technology lead teacher, and inquiry lead teacher for Noblesville Schools, Indiana. 
Alkharusi, H. (2011). Teachers' classroom assessment skills: Influence of gender, subject area, grade level, teaching experience and in-service assessment training. Journal of Turkish Science Education, 8(2), 39-48.

Archer, L., DeWitt, J., Osborne, J., Dillon, J., Willis, B., \& Wong, B. (2012). Science aspirations and family habitus: How families shape children's engagement and identification with science. American Educational Research Journal, 49(5), 881-908.

Bartholomew, S. R. (2017). Assessing open-ended design problems. Technology \& Engineering Teacher, 76(6), 13-17.

Bartholomew, S. R., Nadelson, L. S., Goodridge, W. H., \& Reeve, E. M. (2018). Adaptive comparative judgment as a tool for assessing open-ended design problems and model eliciting activities. Educational Assessment, 23(2), 85-101.

Bartholomew, S. R., Reeve, E., Veon, R., Goodridge, W., Stewardson, G., Lee, V., Nadelson, L. (2017). Mobile devices, self-directed learning, and achievement in Technology and Engineering Education classrooms during a STEM activity. Journal of Technology Education, 29(1), 2-24.

Bartholomew, S. R., \& Strimel, G. J. (2017, March). The problem with assessing open-ended problems, Techniques. 44-49.

Bartholomew, S. R., Strimel, G. J., \& Yoshikawa, E. (2019). Using adaptive comparative judgment for student formative feedback and learning during a middle school open-ended design challenge. International Journal of Technology \& Design Education, 29(2), 363-385, https://doi.org/10.1007/s10798-018-9442-7

Bartholomew, S. R., \& Yoshikawa, E. (2018). A systematic review of research around Adaptive Comparative Judgment (ACJ) in K-16 education. 2018 CTETE Monograph Series, https://doi.org/10.21061/ctete-rms.v1.c.1

Bybee, R. W. (2010). Advancing STEM education: A 2020 vision. Technology and Engineering Teacher, 70(1), 30-35.

Crossman, J. (2004). Factors influencing the assessment perceptions of training teachers. International Education Journal, 5(4), 582-590

Daugherty, M. K., Carter, V., \& Swagerty, L. (2014). Elementary STEM education: The future for technology and engineering education? Journal of STEM Teacher Education, 49(1), 44-55.

DeJarnette, N. K. (2012). America's children: Providing early exposure to STEM (science, technology, engineering and math) initiatives. Education, 133(1), 77-84.

Denson, C. D., Buelin, J. K., Lammi, M. D., \& D’Amico, S. (2015). Developing instrumentation for assessing creativity in engineering design. Journal of Technology Education, 27(1), 23-40.

Diefes-Dux, H. A., Moore, T., Zawojewski, J., Imbrie, P. K., \& Follman, D. (2004). A framework for posing open-ended engineering problems: Model-eliciting activities. Paper presented at the IEEE Frontiers in Education 2004 Annual Conference.

Dietrich, C. (2010). Decision making: Factors that influence decision making, heuristics used, and decision outcomes. Student Pulse, 2(2), pp. 1-3.

DigitalAssess. (2017). What we do. Retrieved on October 20, 2017 from: http://digitalassess.com/ what-we-do/\#compareassess

Epstein, D., \& Miller, R. (2011). Elementary school teachers and the crisis in STEM education. The Education Digest, 77(1), 4-10. 
Hartell, E., \& Skogh, I. B. (2015). Criteria for success: A study of primary technology teachers' assessment of digital portfolios. Australasian Journal of Technology Education, 2(1), 2-17.

International Technology and Engineering Educators Association (ITEA/ITEEA). (2000/2002/2007). Standards for technological literacy: Content for the study of technology. Reston, VA: Author.

Jones, I., \& Wheadon, C. (2015). Peer assessment using comparative and absolute judgement. Studies in Educational Evaluation, 47, 93-101

Kimbell, R. (2007). E-assessment in project e-scape. Design \& Technology Education: An International Journal, 12(2), 66-76.

Kimbell, R. (2012). The origins and underpinning principles of e-scape. International Journal of Technology \& Design Education, 22, 123-134.

Kuenzi, J. J. (2008). Science, technology, engineering, and mathematics (STEM) education: Background, federal policy, and legislative action. Congressional Research Service Reports. Retrieved from http://digitalcommons.unl.edu/ crsdocs/35.

Laboy-Rush, D. (2011). Integrated STEM education through project-based learning. Retrieved from https://pdfs.semanticscholar.org/a51b/9bab3eb593b36098bf93da0d34caae927228.pdf

McMahon, S., \& Jones, I. (2015). A comparative judgement approach to teacher assessment. Assessment in Education: Principles, Policy \& Practice, 22(3), 368-389.

Murphy, T. (2011, August 29). STEM education-It's elementary. US News and World Report. Retrieved from http://www.usnews.com/news/articles/ 2011/08/29/stem-education--its-elementary.

Nadelson, L. S., Callahan, J., Pyke, P., Hay, A., Dance, M., \& Pfiester, J. (2013). Teacher STEM perception and preparation: Inquiry-based STEM professional development for elementary teachers. The Journal of Educational Research, 106(2), 157-168.

National Academy of Engineering (NAE) \& National Research Council (NRC). (2014). STEM integration in K-12 education: Status, prospects, and an agenda for research. Washington, DC: National Academies Press.

Newhouse, P. (2011). Comparative pairs marking supports authentic assessment of practical performance within constructivist learning environments. In Applications of Rasch measurement in learning environments research (pp. 141-180). SensePublishers.

NGSS Lead States. (2013). Next generation science standards: For states, by states. Washington, DC: The National Academies Press.

Pollitt, A. (2012). The method of adaptive comparative judgment. Assessment in Education: Principles, Policy \& Practice, 19(3), 281-300.

Pollitt, A. (2004). Let's Stop Marking Exams. Retrieved from http://www.cambridge assessment.org. uk/images/109719-let-s-stop-marking-exams.pdf

Pollitt, A., \& Crisp, V. (2004). Could comparative judgements of script quality replace traditional marking and improve the validity of exam questions? Retrieved from www.leeds.ac.uk/educol/ documents/00003731.htm

Pollitt, A, \& Murray, N. J. (1993). What raters really pay attention to. Language Testing Research Colloquium, Cambridge. Republished in Milanovic, M. \& Saville, N. (Eds.), Studies in Language Testing 3: Performance Testing, Cognition and Assessment, Cambridge University Press, Cambridge.

Reeve, E. M. (2015). STEM thinking! Technology and Engineering Teacher, 75(4), 8-16.

Rice, J. K. (2010). The impact of teacher experience: Examining the evidence and policy implications. Brief, 11. Washington, DC: Center for Analysis of Longitudinal Data in Education Research. 
Schilling, K., \& Applegate, R. (2012). Best methods for evaluating educational impact:

A comparison of the efficacy of commonly used measures of library instruction. Journal of the Medical Library Association, 100(4), 258-269.

Seery, N., Canty, D., \& Phelan, P. (2012). The validity and value of peer assessment using adaptive comparative judgement in design driven practical education. International Journal of Technology and Design Education, 22(2), 205-226.

Steedle, J. T., \& Ferrara, S. (2016). Evaluating comparative judgment as an approach to essay scoring. Applied Measurement in Education, 29(3), 211-223.

Strimel, G. J., Bartholomew, S. R., Jackson, A., Grubbs, M., \& Bates, D. G. M. (2017).

Evaluating freshman engineering design projects using adaptive comparative judgment.

Paper presented at the American Society of Engineering Education 124th Annual Conference \& Exposition, Columbus, $\mathrm{OH}$.

Tarricone, P., \& Newhouse, C. P. (2016). Using comparative judgement and online technologies in the assessment and measurement of creative performance and capability. International Journal of Educational Technology in Higher Education, 13(1), 16-27.

Thurstone, L. L. (1927). A law of comparative judgment. Psychological Review, 34, 273-286.

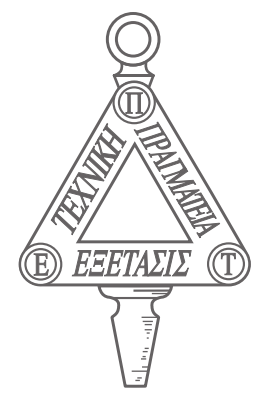




\title{
The 2017 Paul T. Hiser Exemplary Publication Award Recipients
}

\author{
Jeremy Ernst, Aaron Clark, and Sharon Bowers \\ "Cyber-supported Professional Learning Experiences that Build Technology and \\ Engineering Educators' Practice"
}

The Board of Editors of The Journal of Technology Studies and the Epsilon Pi Tau Board of Directors are pleased toannounce the recipient of the Paul T. Hiser Exemplary Publication Award for Volume XLIII, 2017.

The Board of Directors established this award for deserving scholars. In recognition for his exemplary service to the profession and to the honorary as a Trustee and Director, the award bears Dr. Hiser's name. It is given to the author or authors of articles judged to be the best of those published each year in this journal.

\section{Selection Process}

Each member of the Editorial Board recommends the manuscript that he or she considers the best of those reviewed during the year. The board nominates articles based on their evaluation against specific criteria. A majority vote of the editors is required for the award to be made. The honor society's Board of Directors renders final approval of the process and the award.

\section{Criteria}

1. The subject matter of the manuscript must be clearly in the domain of one or more of the professions in technology.

2. The article should be exemplary in one or more of the following ways:

- Ground-breaking philosophical thought.

- Historical consequence in that it contains significant lessons for the present and the future.

- Innovative research methodology and design.

- Trends or issues that currently influence the field or are likely to affect it.

- Unique yet probable solutions to current or future problems.

A \$300 award recognizes the recipient(s) for the year and is presented during an Epsilon Pi Tau program at an annual professional association conference. 


\section{GUIDELINES FOR \\ The Journal of Technology Studies \\ A refereed publication of Epsilon $\mathscr{Q}_{i} \mathcal{T}_{\mathfrak{a} u}$ the International Honor Society for Professions in Technology.}

The Journal of Technology Studies (JOTS) is the peer-reviewed journal of Epsilon Pi Tau, an international honor society for technology professions. One printed volume per year is mailed to all active members of the society as well as to subscribing academic and general libraries around the globe. All issues (beginning with 1995 to the current year), both print and those published in electronic format, are available online at scholar.lib.vt.edu/ejournals/ JOTS.

The journal is indexed in Current Index to Journals of Education, the International Bibliography of the Social Sciences, and by VOCED, the UNESCO/NCVER research database for technical and vocational education and training maintained by NCVER in Adelaide, Australia (www.voced.edu.au).

\section{SUBJECT FOCUS}

JOTS welcomes original manuscripts from scholars worldwide, focused on the depth and breadth of technology as practiced and understood past, present, and future. Epsilon Pi Tau, as perhaps the most comprehensive honor society among technology professions, seeks to provide up-to-date and insightful information to its increasingly diverse membership as well as the broader public. Authors need not be members of the society in order to submit manuscripts for consideration. Contributions from academe, government, and the private sector are equally welcome.

An overview of the breadth of topics of potential interest to our readers can be gained from the 17 subclasses within the "Technology" category in the Library of Congress classification scheme (http:// www.loc.gov/catdir/cpso/lcco/lcco_t.pdf). Authors are strongly urged to peruse this list as they consider developing articles for journal consideration. In addition, JOTS is interested in manuscripts that provide:
- brief biographical portraits of leaders in technology that highlight the individuals' contributions made in distinct fields of technology or its wider appreciation within society,

- thoughtful reflections about technology practice,

- insights about personal transitions in technology from formal education to the work environment or vice versa,

- anthropology, economics, history, philosophy, and sociology of technology,

- technology within society and its relationship to other disciplines,

- technology policy at local, national, and international levels,

- comparative studies of technology development, implementation, and/or education,

- industrial research and development,or

- new and emerging technologies and technology's role in shaping the future. 


\section{GUIDELINES FOR The Jounnal of Technology Studies (Continued)}

The immense diversity of technology, along with its applications and import, requires that authors communicate clearly, concisely, and only semi-technically to readers from a diverse set of backgrounds. Authors may assume some technical background on the part of the reader but not in-depth knowledge of the particular technology that is the focus of the article. Highly technical articles on any field of technology are not within the purview of the journal. Articles whose focus has been extensively explored in prior issues of the Journal are of potential interest only if they (a) open up entirely new vistas on the topic, (b) provide significant new information or data that overturn or modify prior conceptions; or (c) engage substantially one or more previously published articles in a debate that is likely to interest and inform readers. Syntheses of developments within a given field of technology are welcome as are metanalyses of research regarding a particular technology, its applications, or the process of technical education and/ or skill acquisition. Research studies should employ methodological procedures appropriate to the problem being addressed and must evince suitable design, execution, analysis, and conclusions. Surveys, for example, that exhibit any or all of the following characteristics are of no interest to the journal: (a) insufficient awareness of prior research on this topic, (b) insufficient sample size, (c) improper survey design, (d) inappropriate survey administration, (e) high mortality, (f) inadequate statistical analysis, and/or (g) conclusions not supported by either the data or the research design employed. The JOTS is neutral in regards to qualitative, quantitative, or mixed method approaches to research but insists on research of high quality.

\section{GUIDELINES FOR SUBMISSION}

Articles must conform to the current edition of the Publication Manual of the American Psychological Association. All articles must be original, represent work of the named authors, not be under consideration elsewhere, and not be published elsewhere in English or any other language. Electronic submissions in either rich-text format or Microsoft Word formats are required. E-mail submissions should be sent to the editor at jots@bgsu.edu.

Manuscripts should be no more than 25 double- spaced and unjustified pages, including references. Abstracts are required and should be no longer than 250 words. Also required is a list of keywords from your paper in your abstract. To do this, indent as you would if you were starting a new paragraph, type keywords: (italicized), and then list your keywords. Listing keywords will help researchers find your work in databases.

Typescript should be 12 point Times New Roman or a close approximation. Only manuscripts in English that conform to American usage will be accepted. Figures, tables, photographs, and artwork must be of good quality and conform to the Publication Manual of the American Psychological Association, specifically complying with the rules of Style ${ }^{\circledR}$ for form, citation style, and copyright. The Journal of Technology Studies seeks to maintain the highest standards of academic integrity and asks all contributors to apply proper due diligence in manuscript preparation. 


\section{GUIDELINES FOR \\ The Journal of Technology Studies \\ (Continued)}

\section{REVIEW PROCESS}

Articles deemed worthy for consideration by the editor undergo anonymous peer review by members of the JOTS editorial board. Authors who submit an article that does not merit review by the editorial board are informed within approximately three weeks of receipt of the article so they may explore other publishing venues. A rejection may be based solely on the content focus of the article and not its intrinsic merit, particularly where the topic has been extensively explored in prior JOTS articles. Articles that exhibit extensive problems in expression, grammar, spelling, and/or APA format are summarily rejected. Authors of articles that have been peer-reviewed are informed within three months from the date of submission. Anonymous comments of reviewers are provided to authors who are invited to submit a revised article for either publication or a second round of review. The editor does not automatically provide reviewer comments to authors whose articles have been rejected via the peer review process. However, such feedback may be provided if the editor determines that the feedback might prove helpful to authors as they pursue other publishing opportunities.

\author{
PUBLICATION \\ Accepted articles are published in the on- \\ line version of the journal (http://scholar.lib. \\ vt.edu/ejournals/JOTS/) as the manuscript \\ exits the layout and proofing process. \\ Currently, JOTS articles also appear in \\ a print issue at the beginning of the next \\ calendar year. Authors co-retain rights to \\ the published article along with Epsilon Pi \\ Tau. When requested, the editor will supply \\ information about an accepted article that \\ has not yet appeared on-line or in print for \\ faculty undergoing tenure review.
}


Notes

울

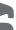

응

0

(1)

ํㅜㅇ

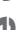

E 